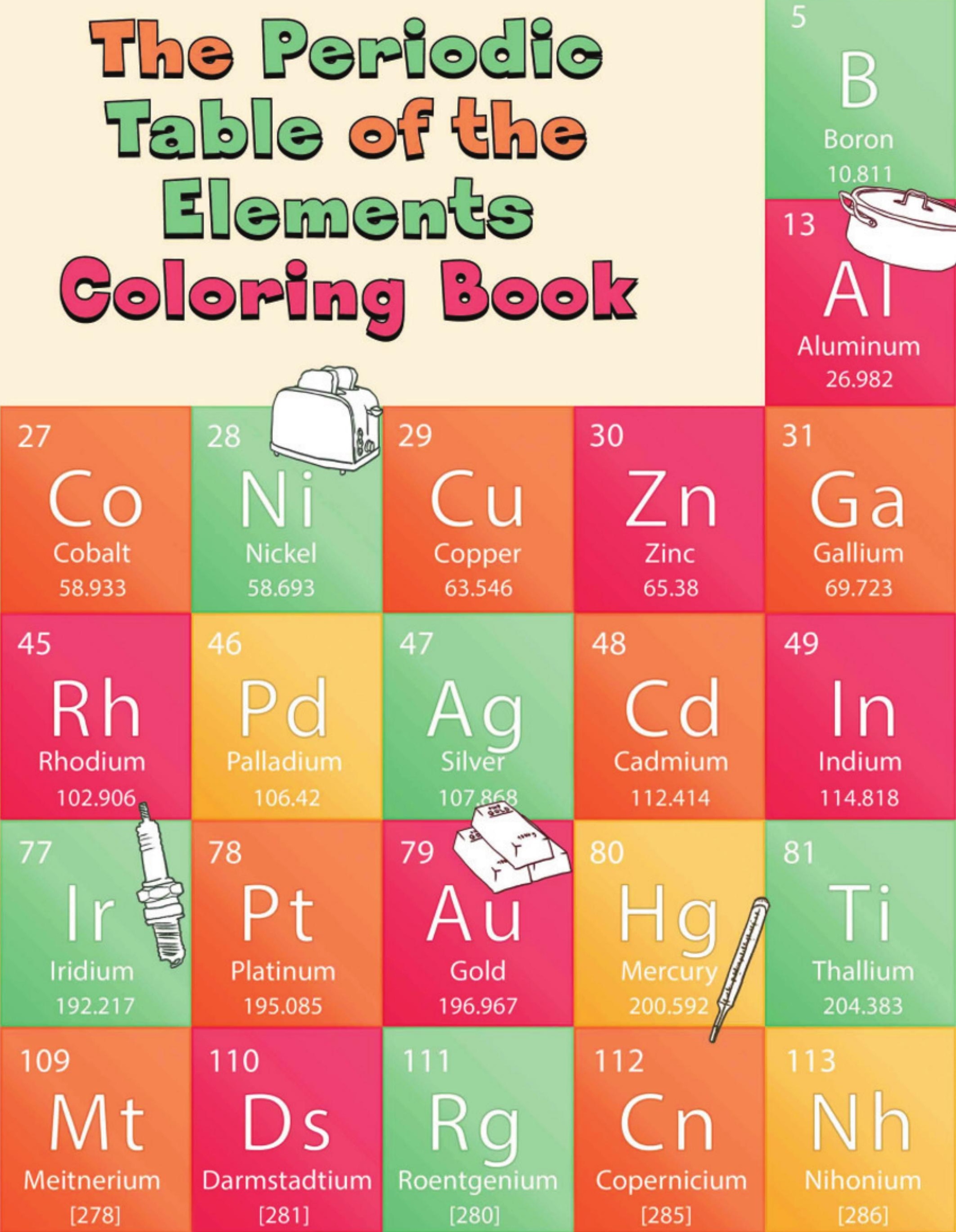




\section{Periodic Table of the Elements Coloring Book}

Project managing and chemistry overseen by Yann Brouillette (Faculty, Chemistry, Dawson College).

Element representations and cover by Dawson College Illustration \& Design students ( $2^{\text {nd }}$ year)*

overseen by Meinert Hansen (Faculty, Illustration \& Design, Dawson College).

At the forefront of Active Learning strategies in the STEAM disciplines, the Chemistry Department and Illustration \& Design Department from Dawson College initiated a collaborative project to create a palpable introduction to the building blocks of matter for kindergarten children. Together, they created a Periodic Table Coloring Book illustrating the known elements of Mendeleev's table. In an internationally accessible format, each page displays only the atomic number and symbol of an element, in addition to a few black \& white outlines representing an example of its real-world application.

The chemical elements are the building blocks of matter, the LEGO ${ }^{\circ}$ blocks of the world. And since kids from ages 4 to 99 enjoy assembling $\mathrm{LEGO}^{\circledR}$ blocks, this colouring book is not just "for children"; all can enjoy and learn from it.

Put together, the elements create a magnificently organized system of knowledge, classifying physical \& chemical properties in groups and trends which in turn help us to navigate the entropy of the material world through an understanding of its chemical composition. But the Periodic Table remains a complex system to grasp in its entirety, and the process of learning about all the possible elements can be difficult for anyone, young and old alike, who is new to chemistry. The colouring book thus provides a simple, ordered way of entering into this field of study while also making the experience fun, motivating the learner to explore further.

Just as Dimitri Mendeleev bravely left gaps in the systematic arrangement of elements that later became the modern periodic table, gaps where he thought undiscovered elements at the time would be located, some pages of this coloring book have no illustration, mirroring the idea that, so far, no applications have been found for these particular elements. The gaps are a form of invitation to the generations to come to find meaningful applications for the most recently isolated and/or synthesized elements.

Science is an evolving field, and this book will be old-fashioned one day. But until then, enjoy coloring the world.

\footnotetext{
*Artists (Dawson College Illustration \& Design students):

Theo Elton Andreville, Antoine David Arnould, Antonia Aspros, Dalia Ataev, Skylar Aung-Thwin, Tobias Avison, Sahar Bakhtiari, Angela Chiarelli, Malika Chim, Natalia Czaharyn, Audrey Desaulniers, Sophie Després, Nicole Evstakhov, Andrea Fabris Pascual, Benjamin Fisher, Marie Joëlle Fournier, Rose Fulford, Marie-Maxime Giguère, Kaya Gonzalez, Vanessa lerfino, Lydian Kirkwood, Megan Lalonde, Sarah Lemieux, Joanna-M Marianakis-Belec, Valentina Martorana, Rebecca McFarlane, Sakeenah Montanaro, Emma Murphy-Furze, Julie Nguyen, Lauren Pagotto, Xuan Huong Phan, Pavlina Petrova Rahneva, Ngoc Tri Tu, Derek Ung, Jafer Wong.
}

Cover by: Dalia Ataev 


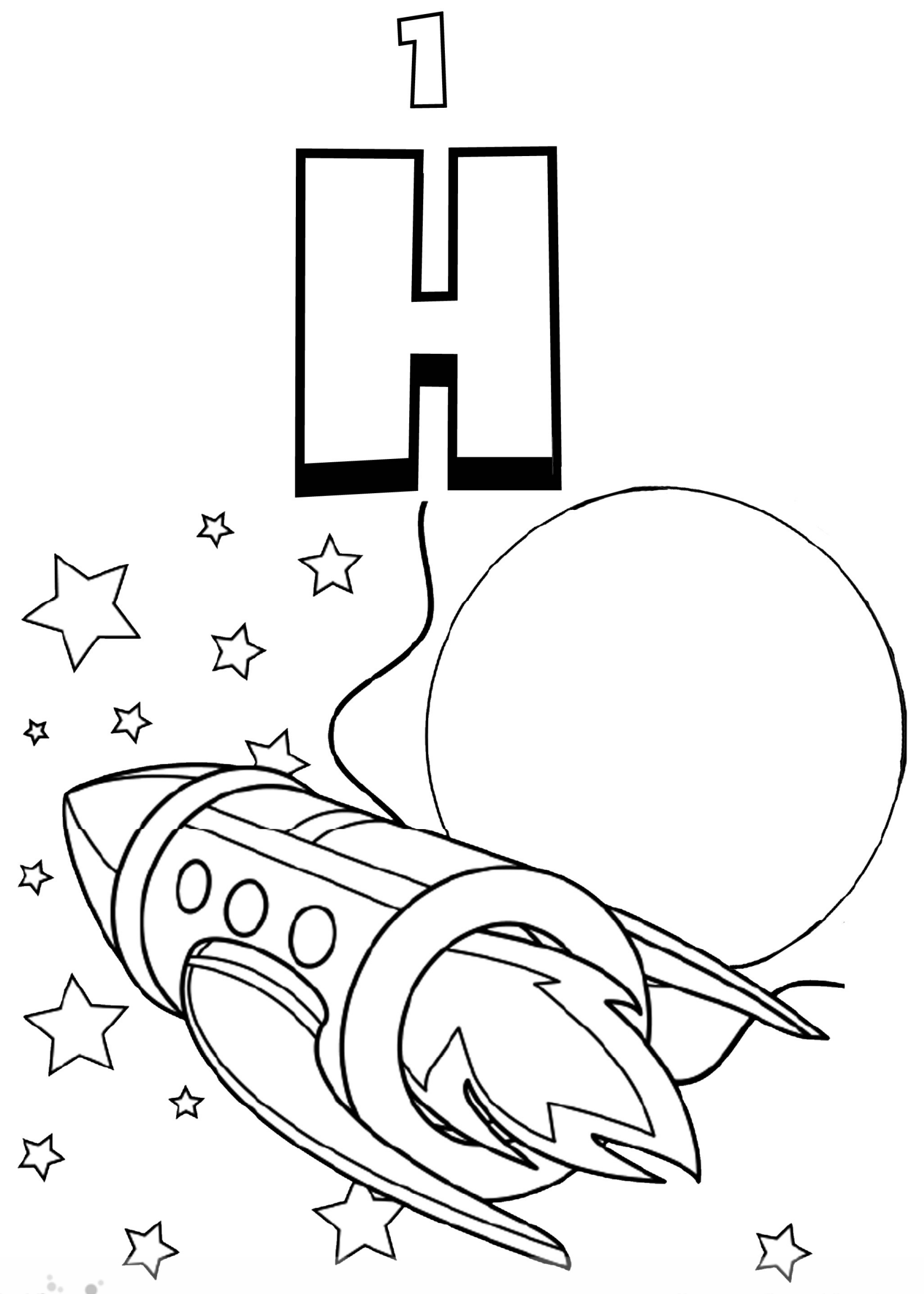




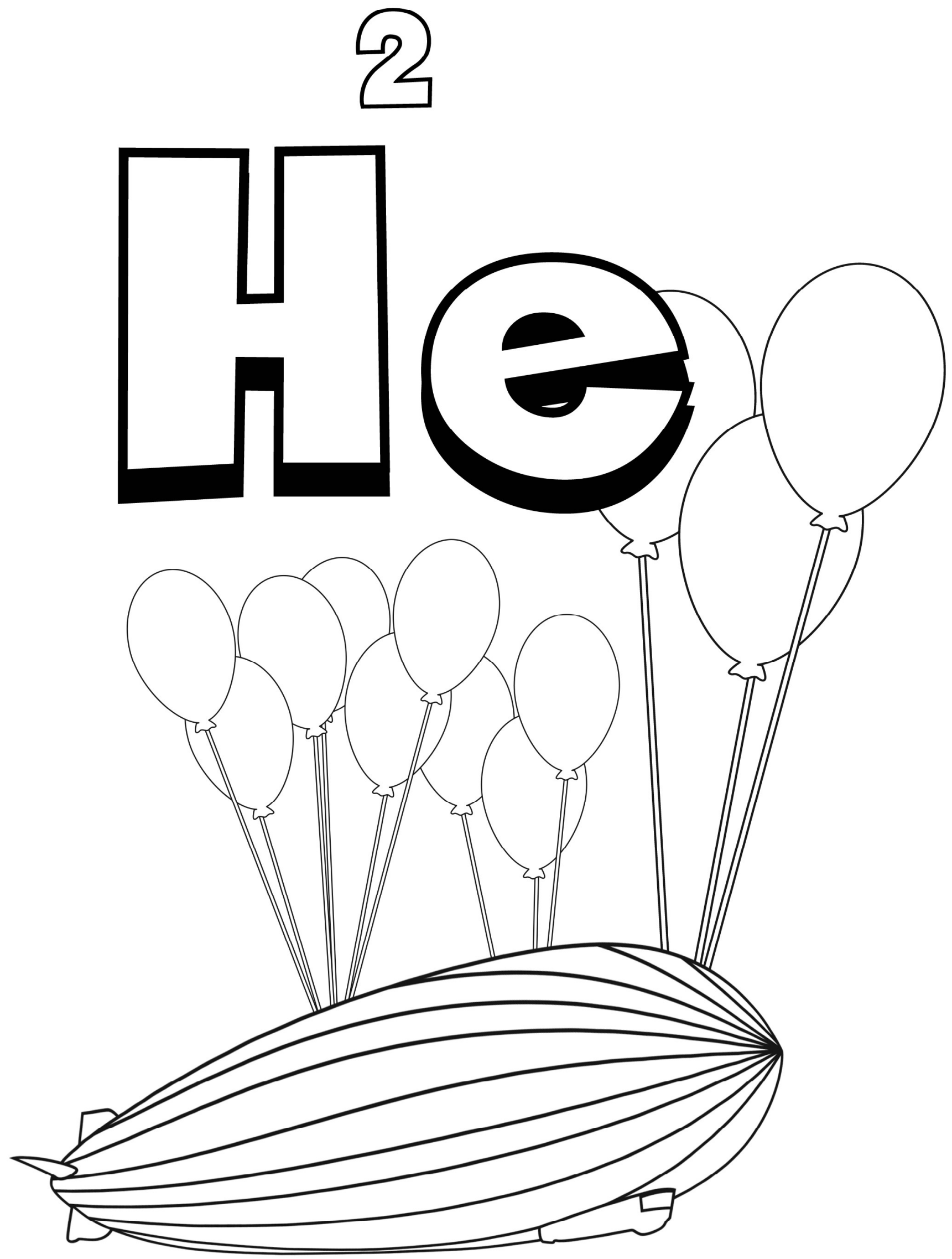


@
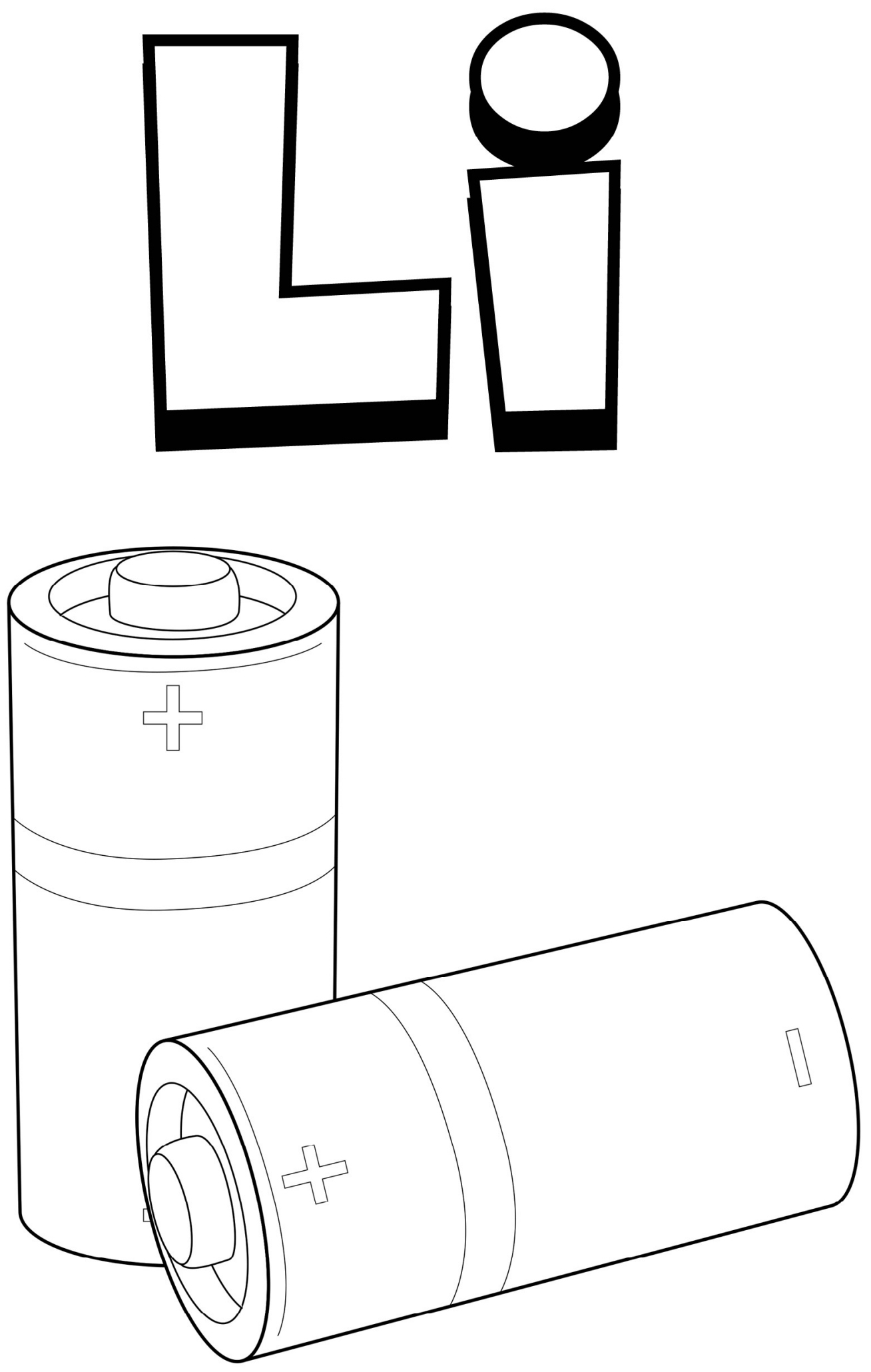
4
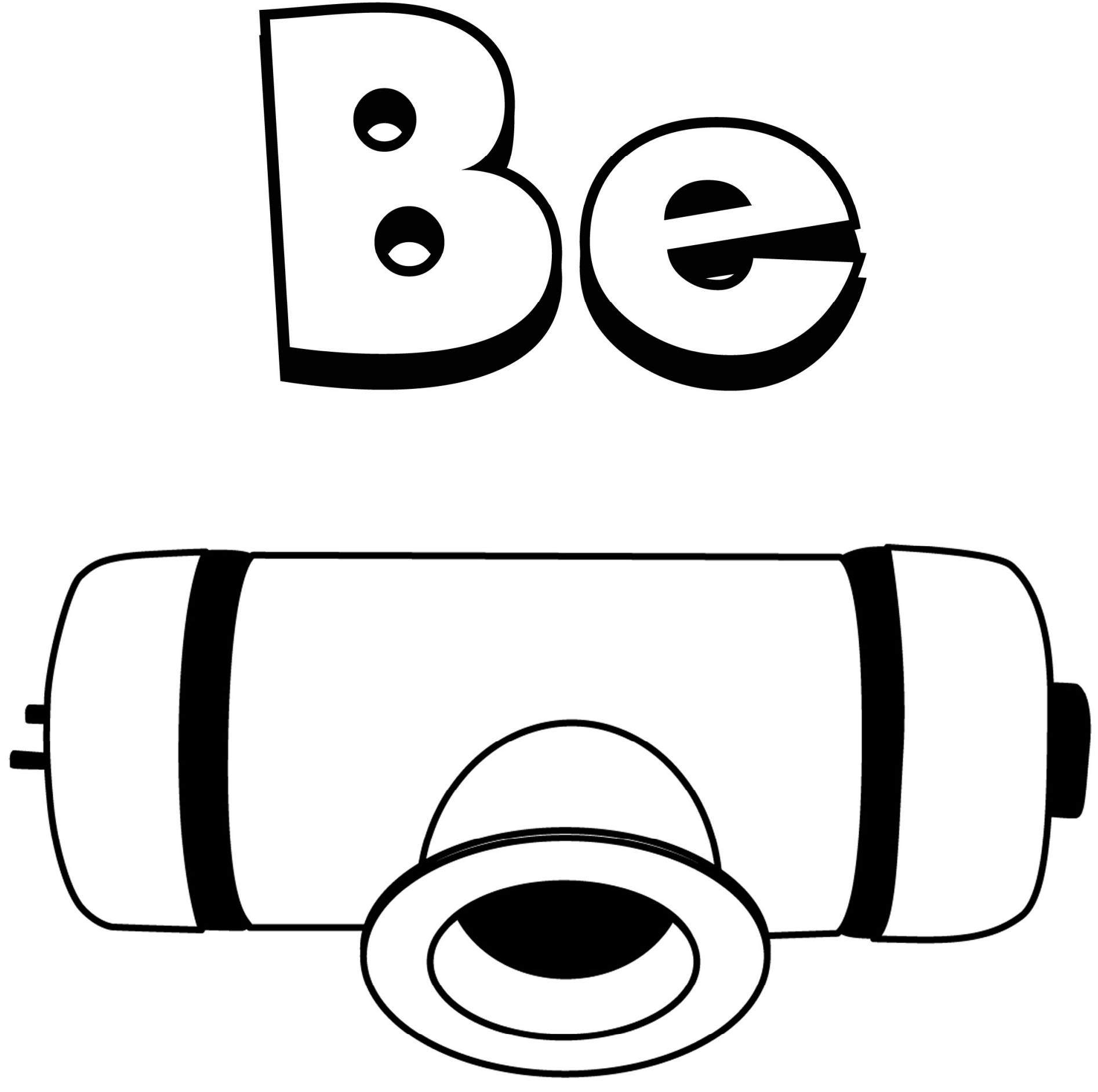


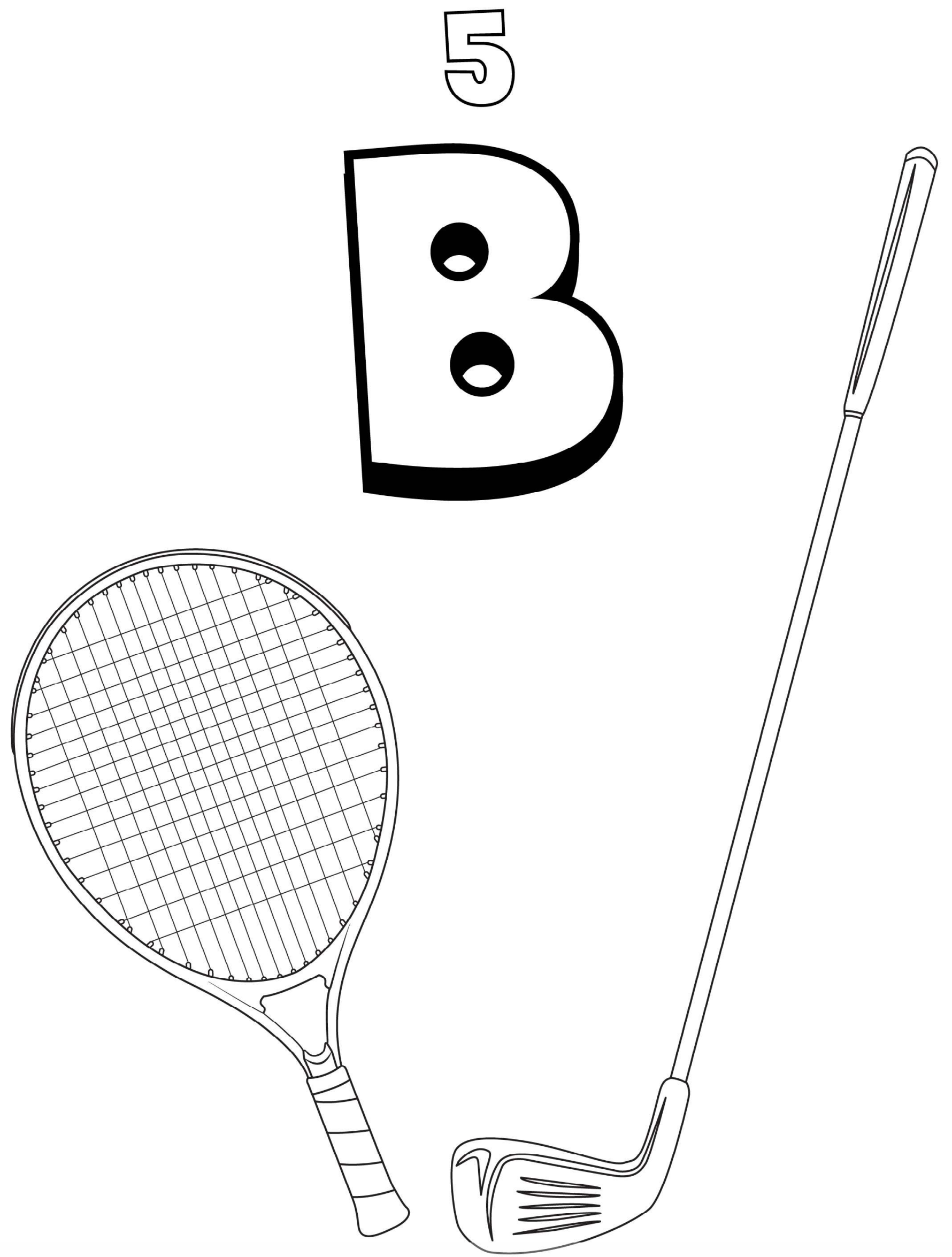



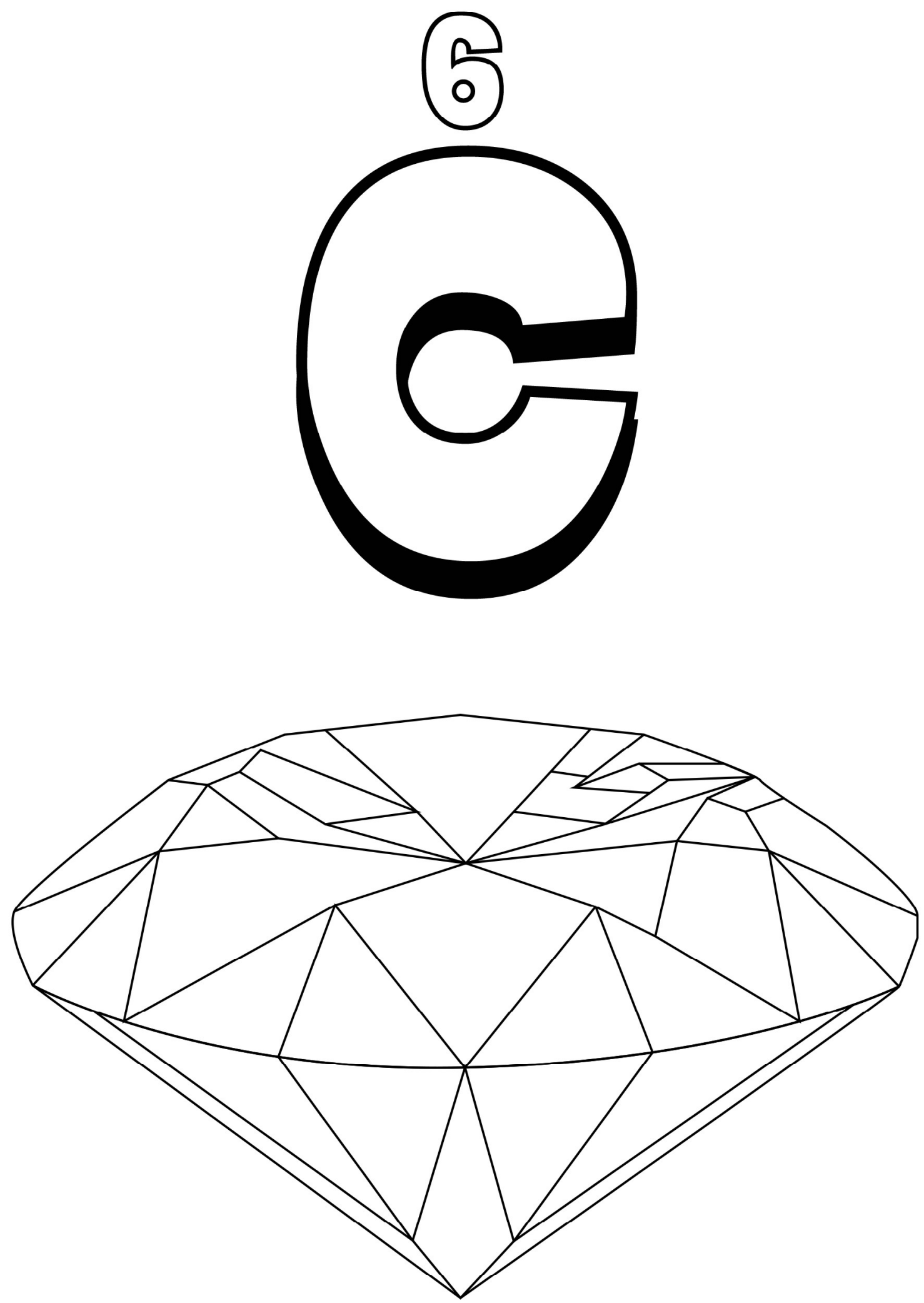


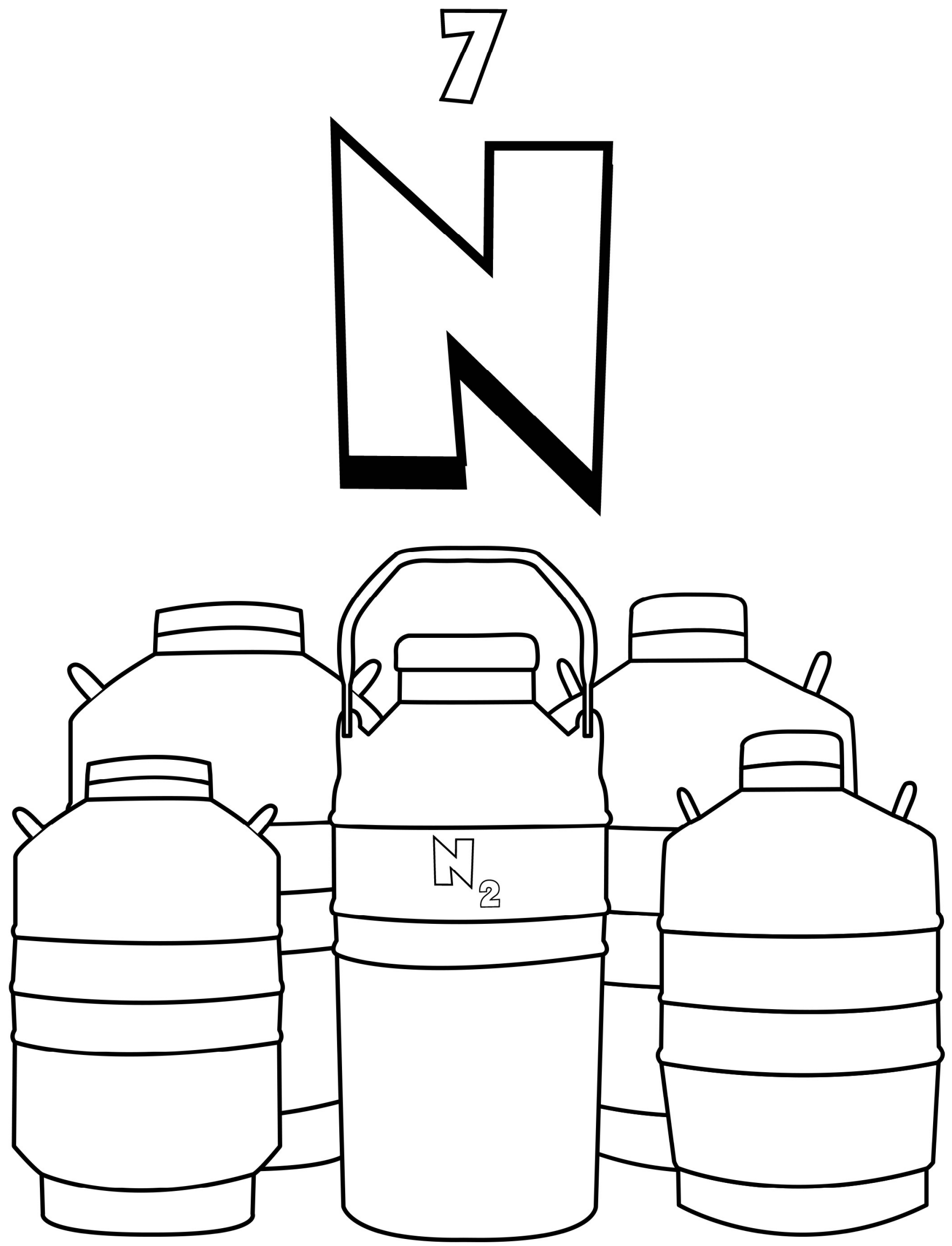




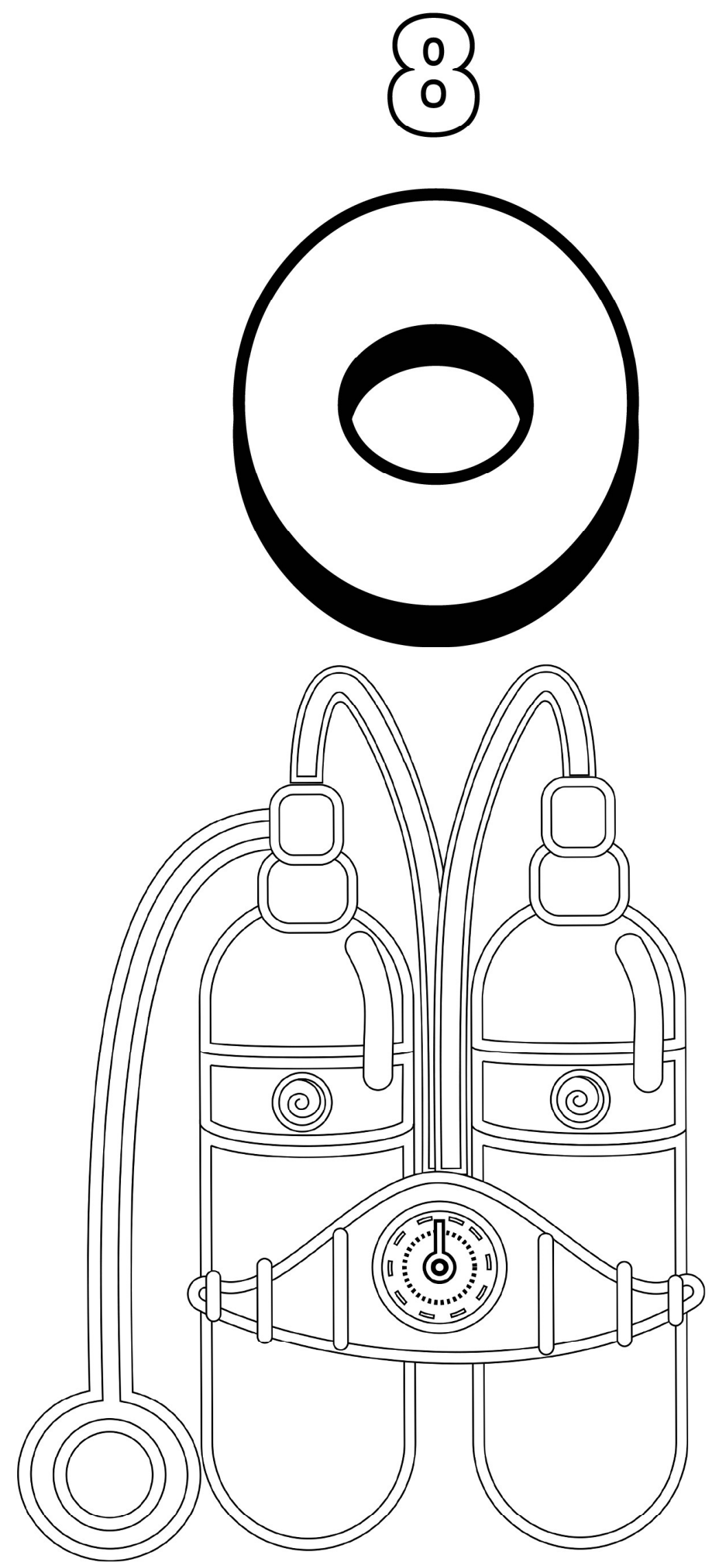




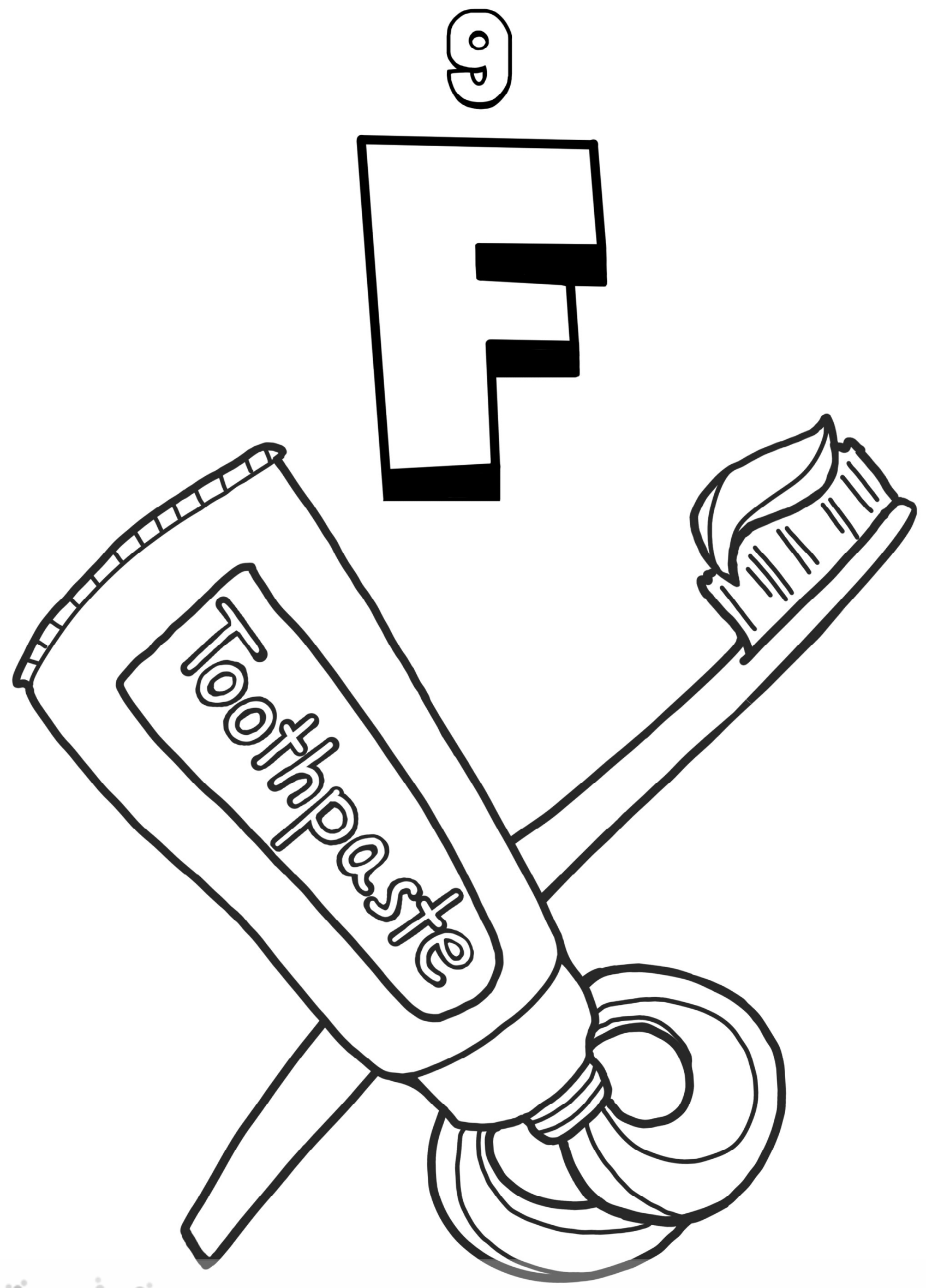




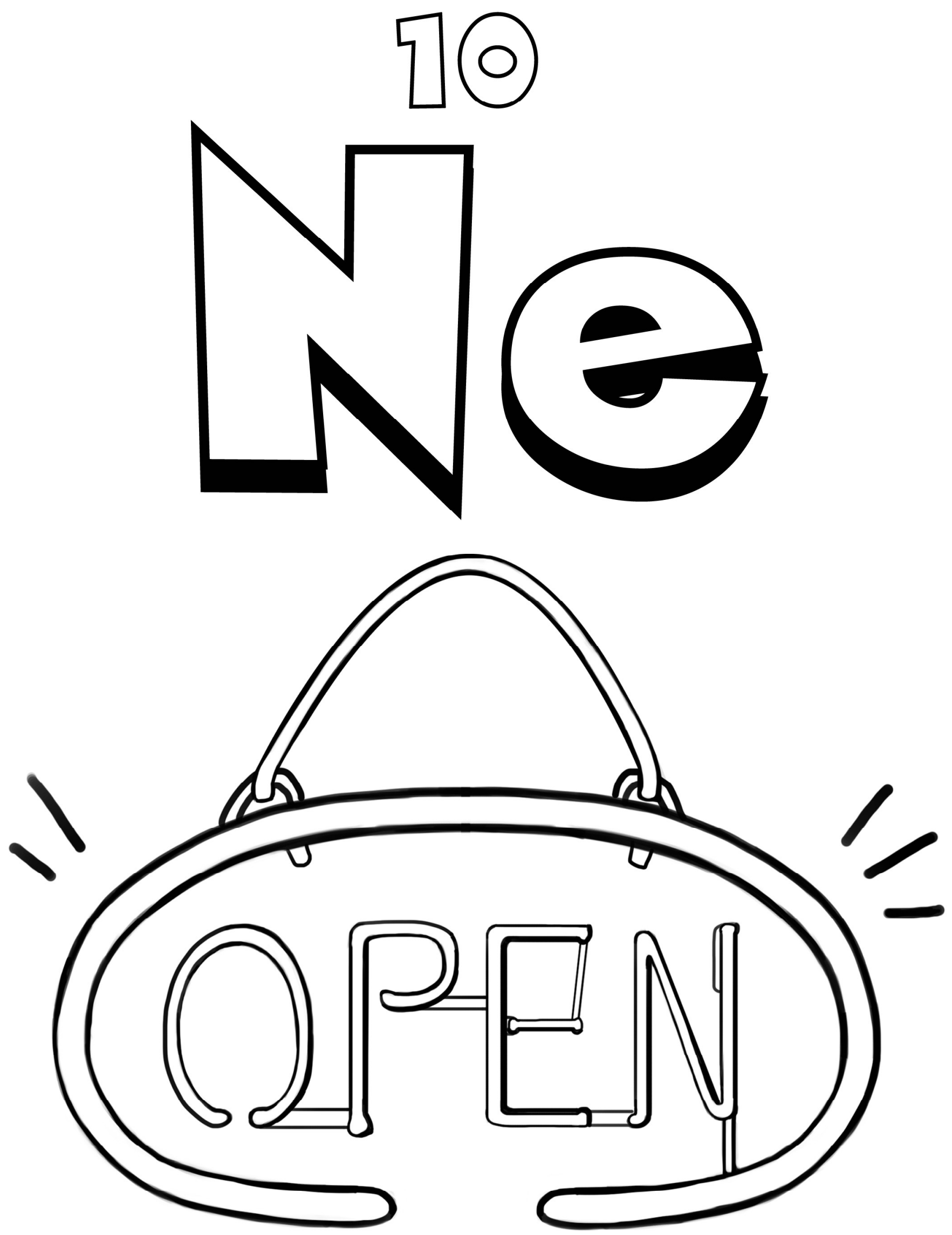




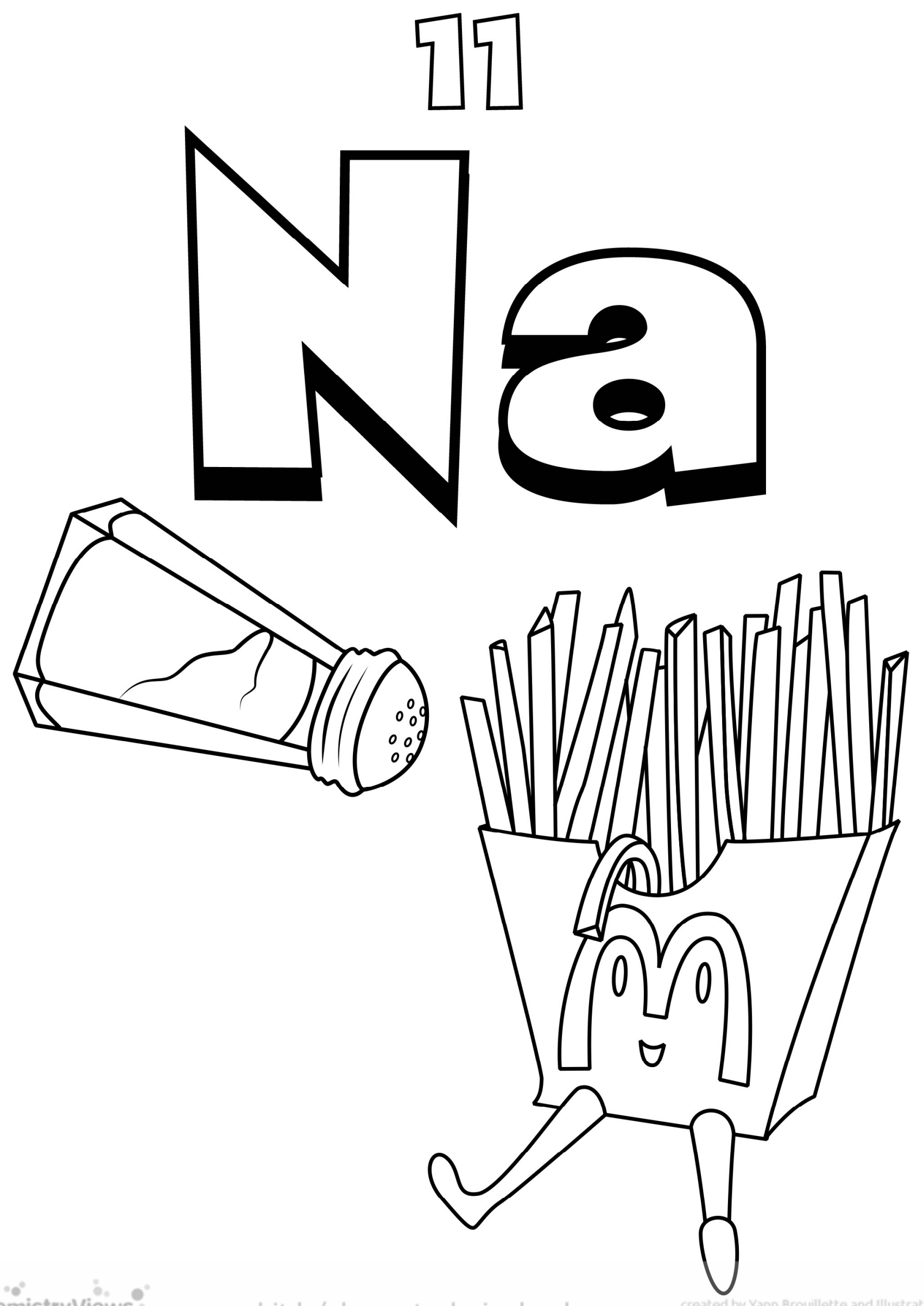




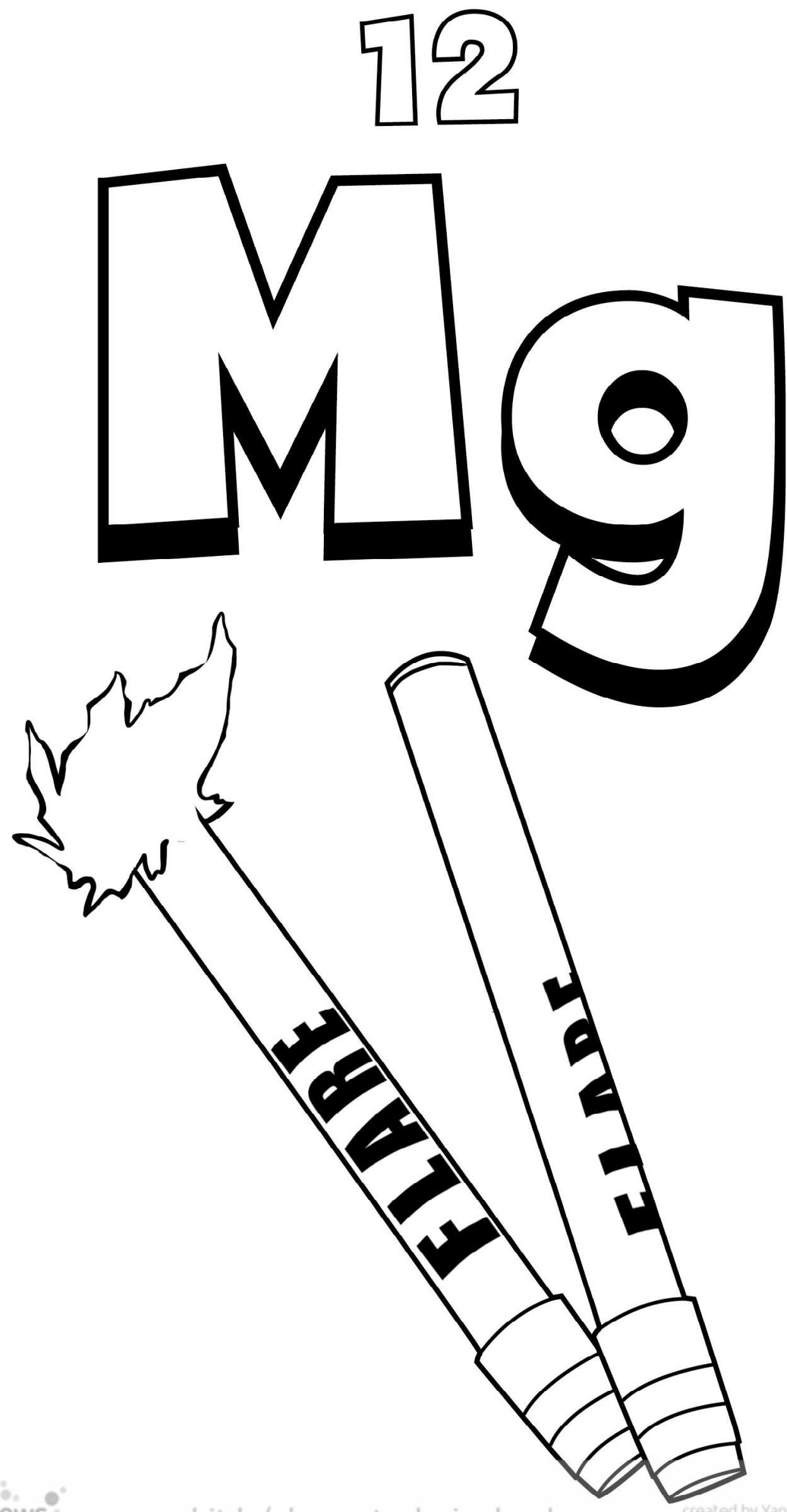



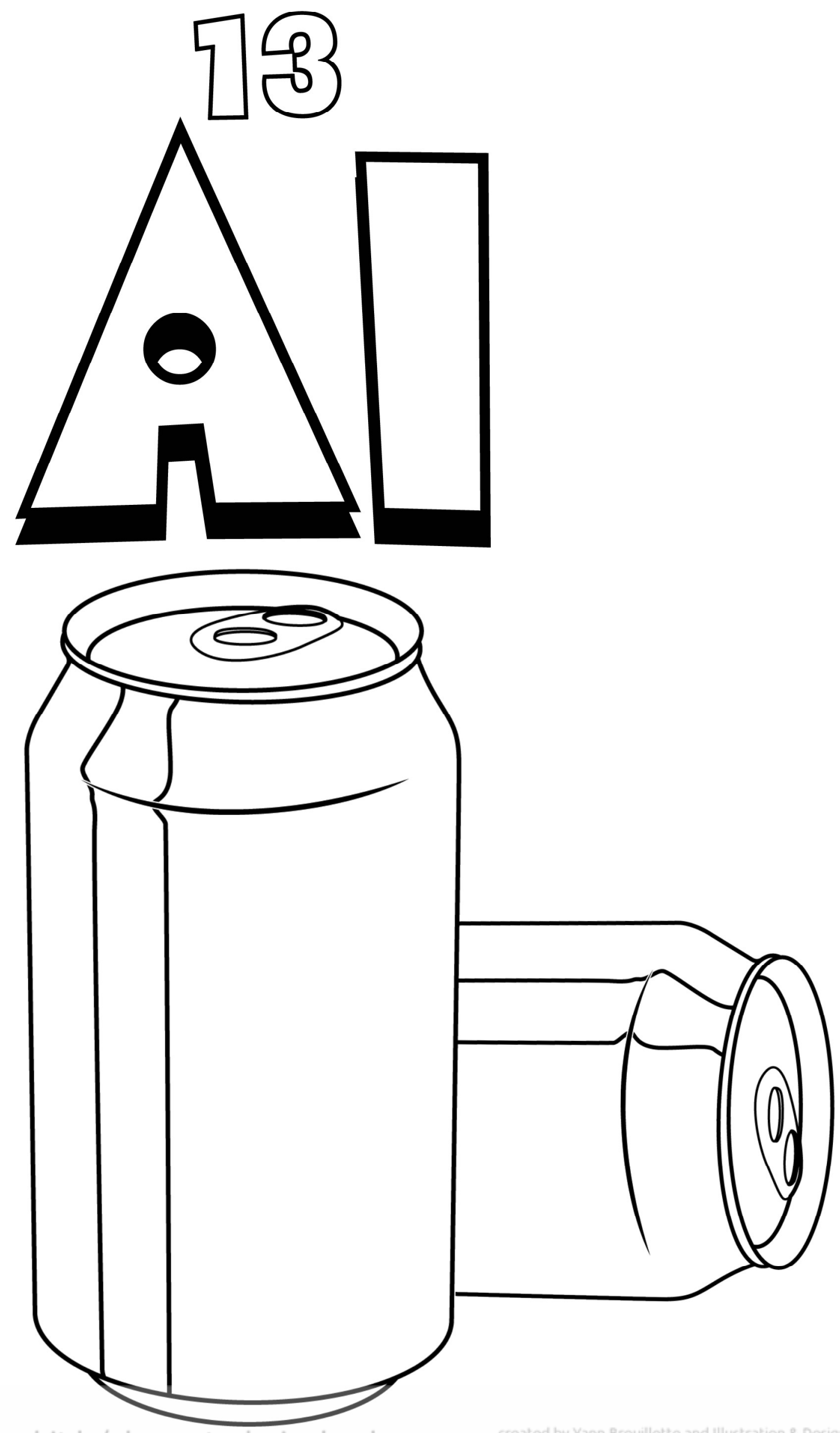


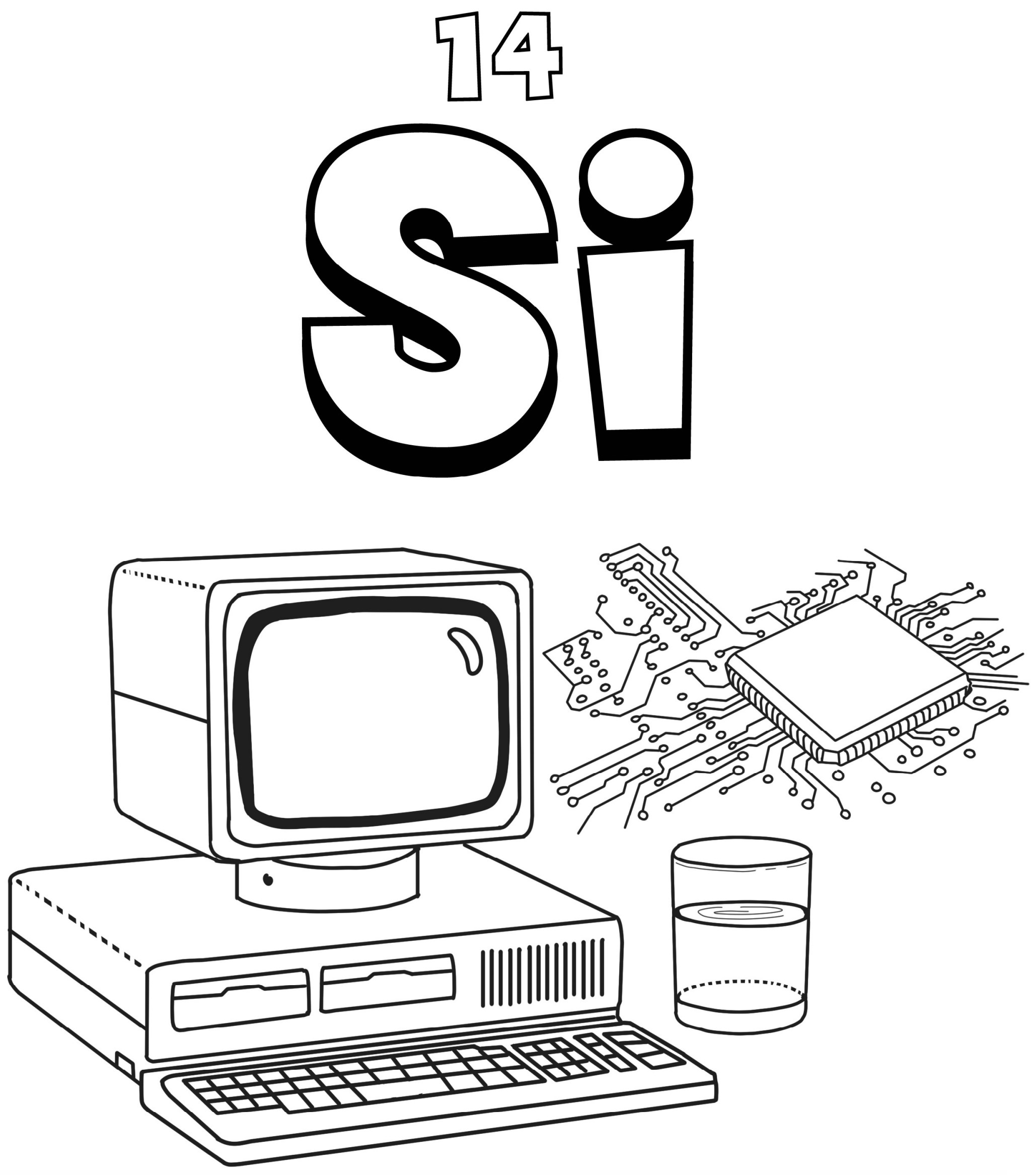




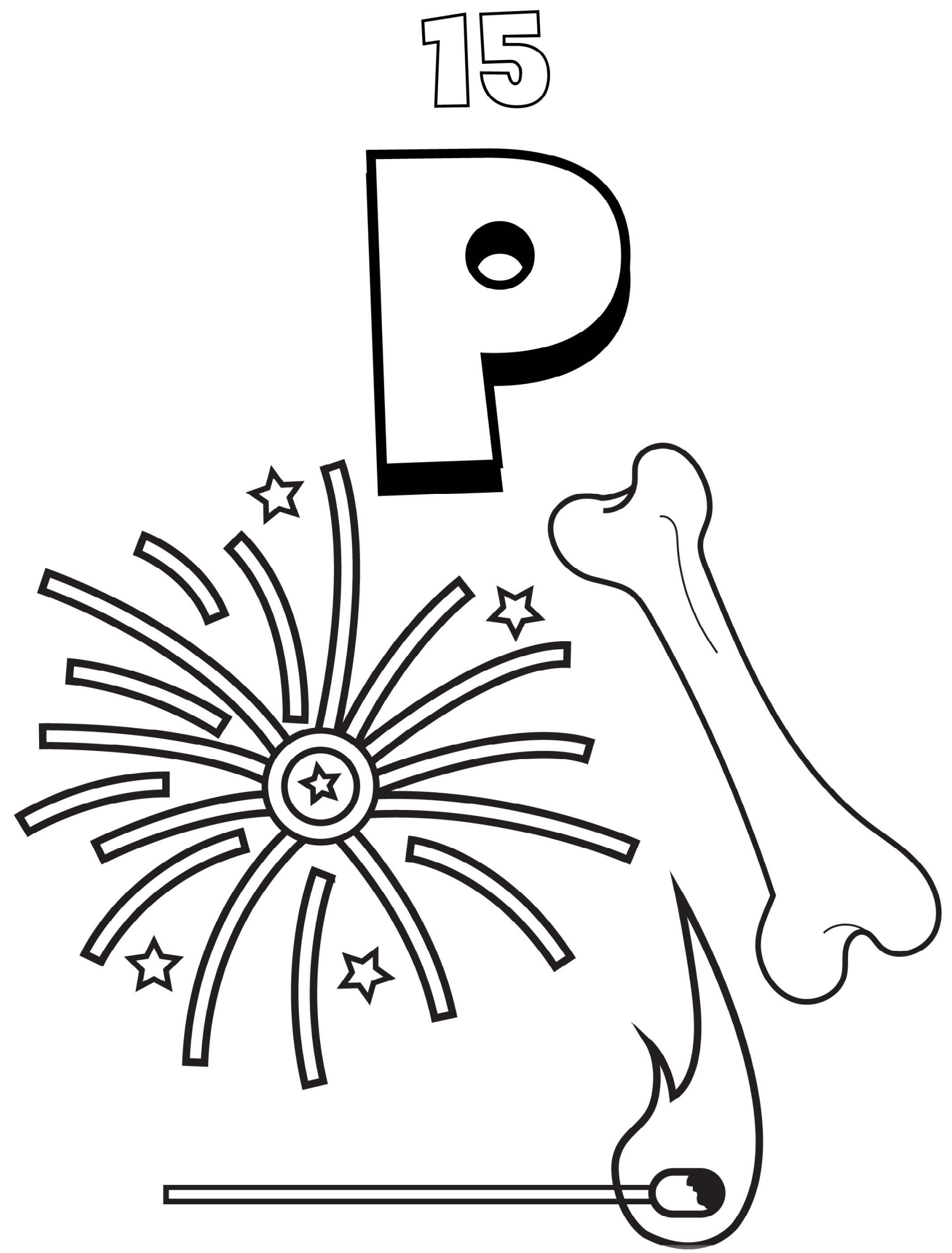




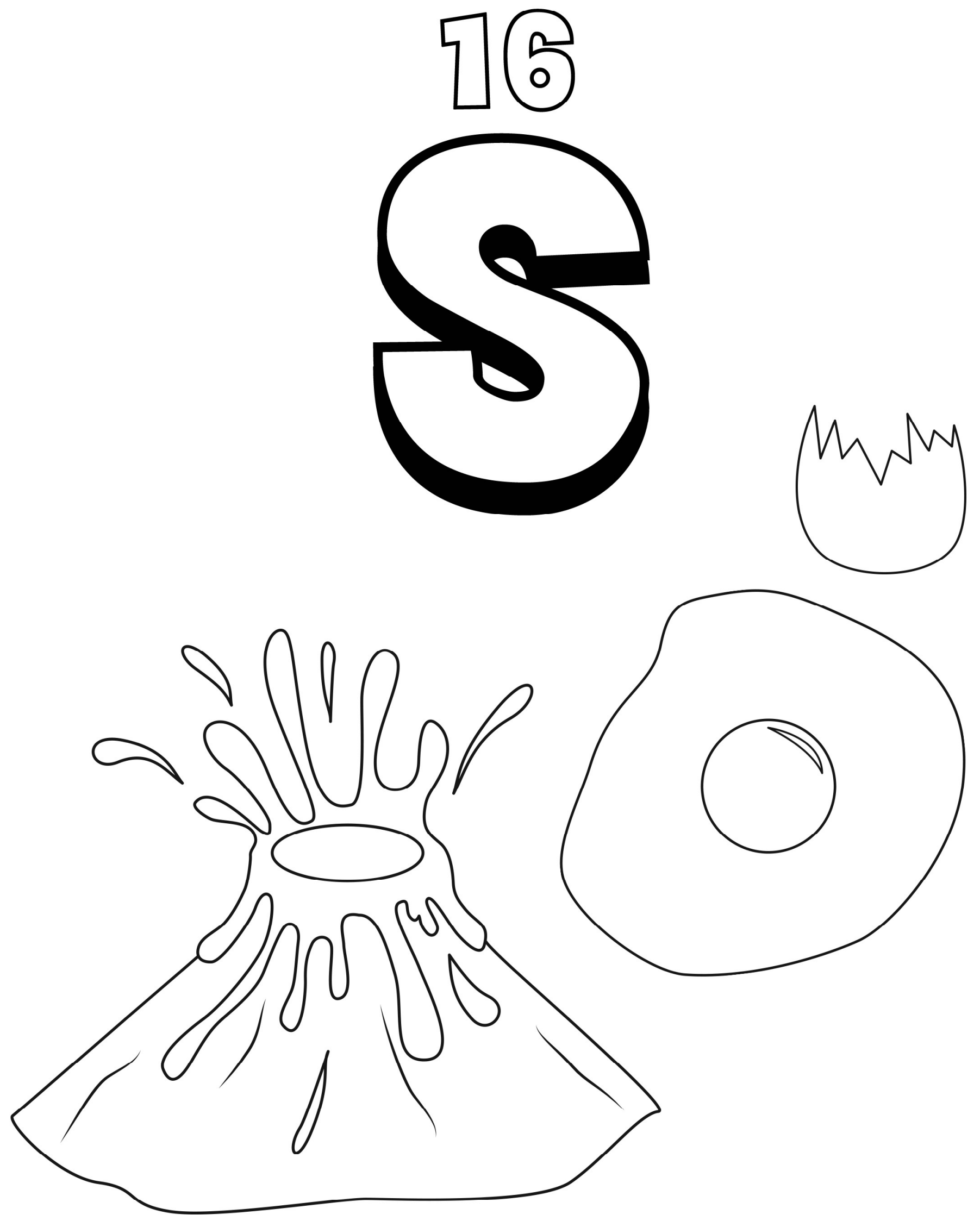




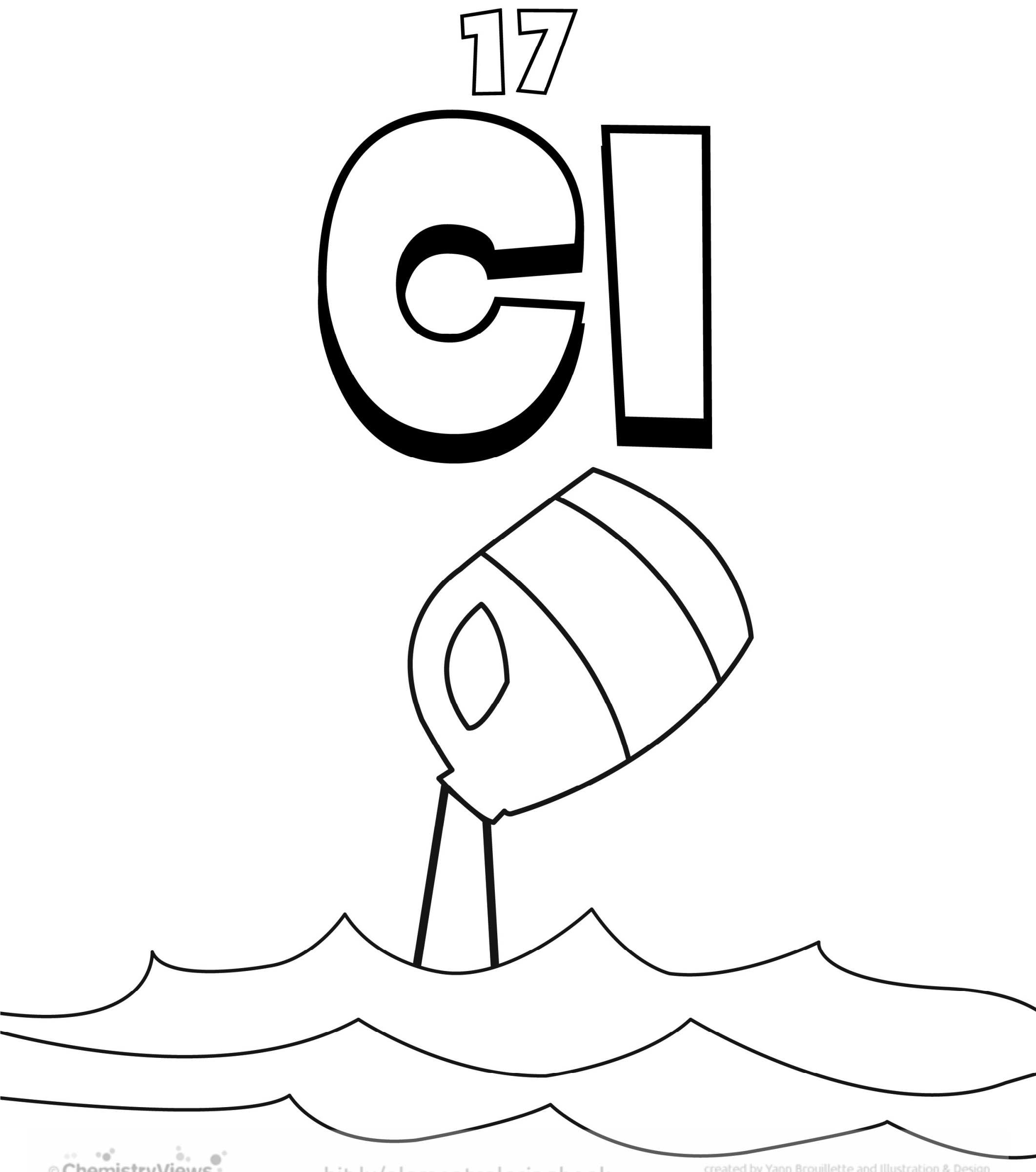




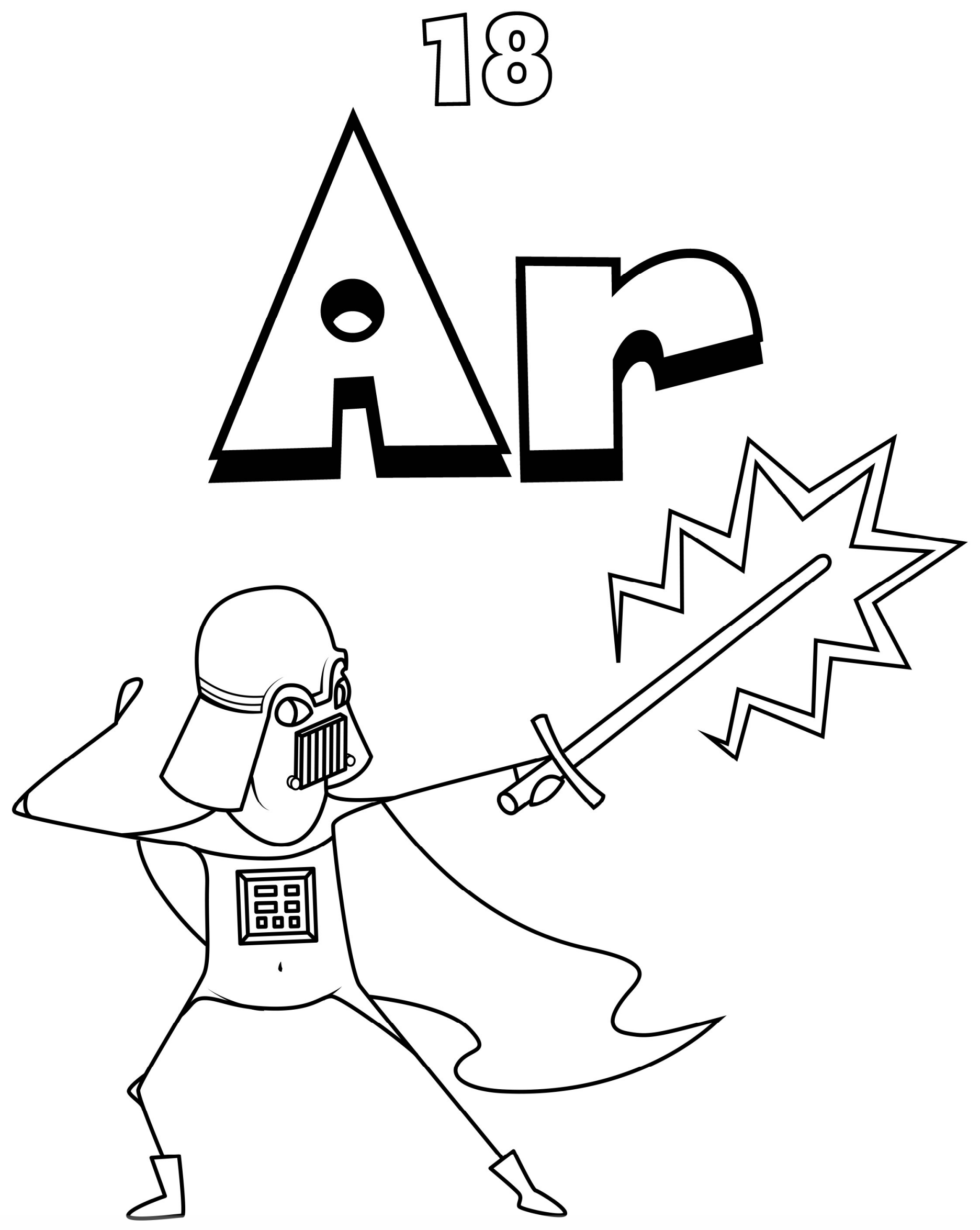


00

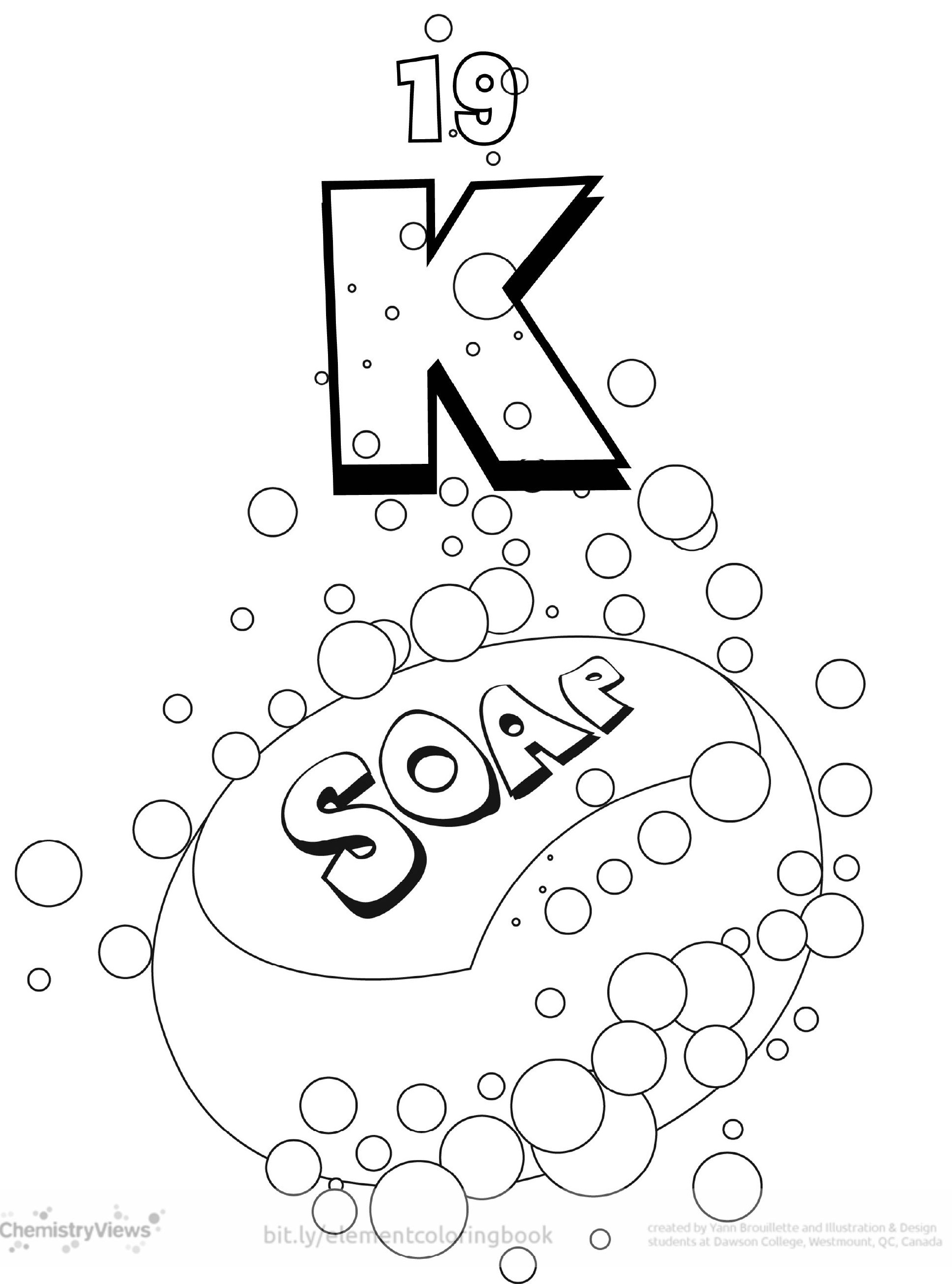




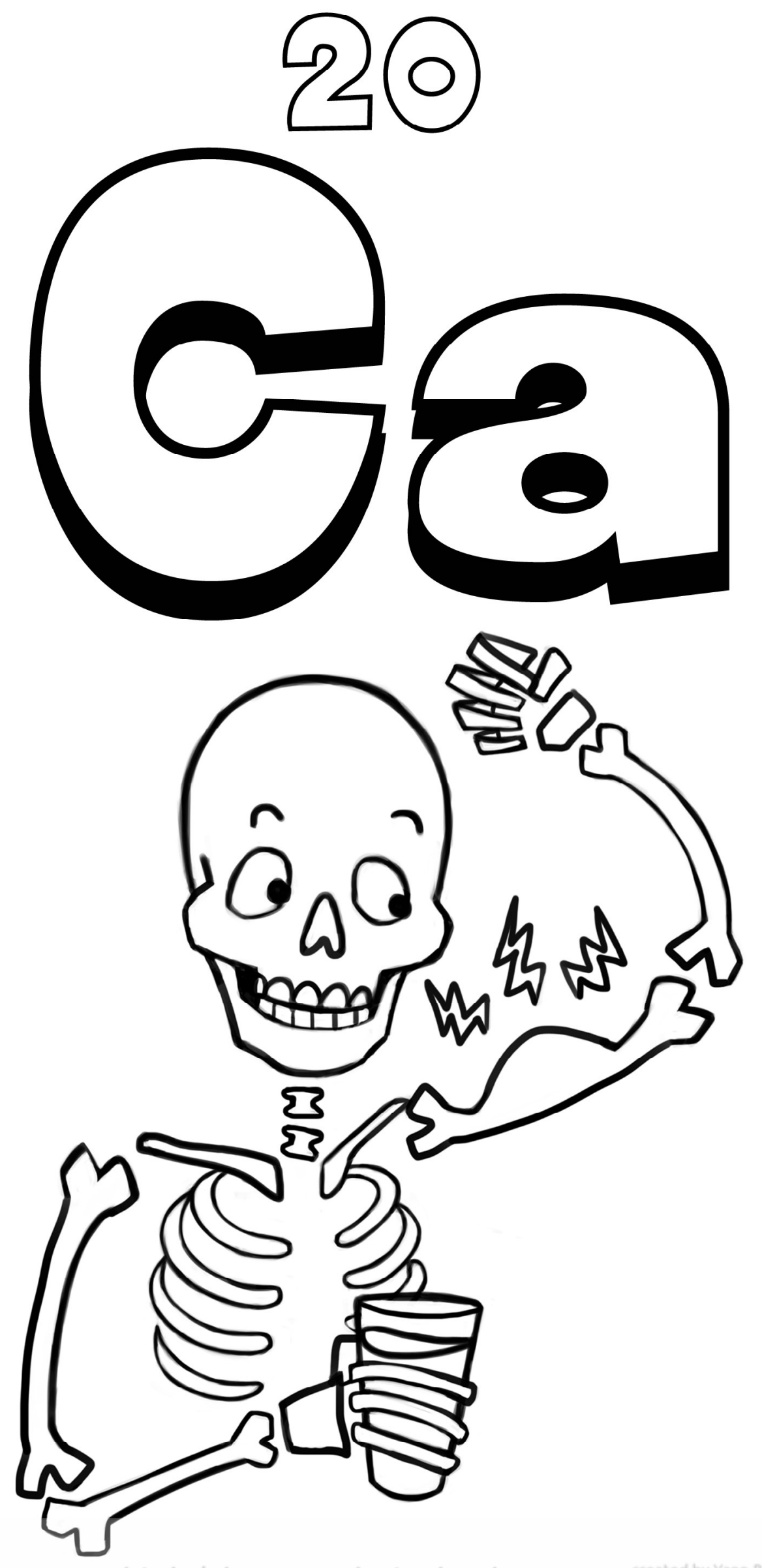




\section{2)}
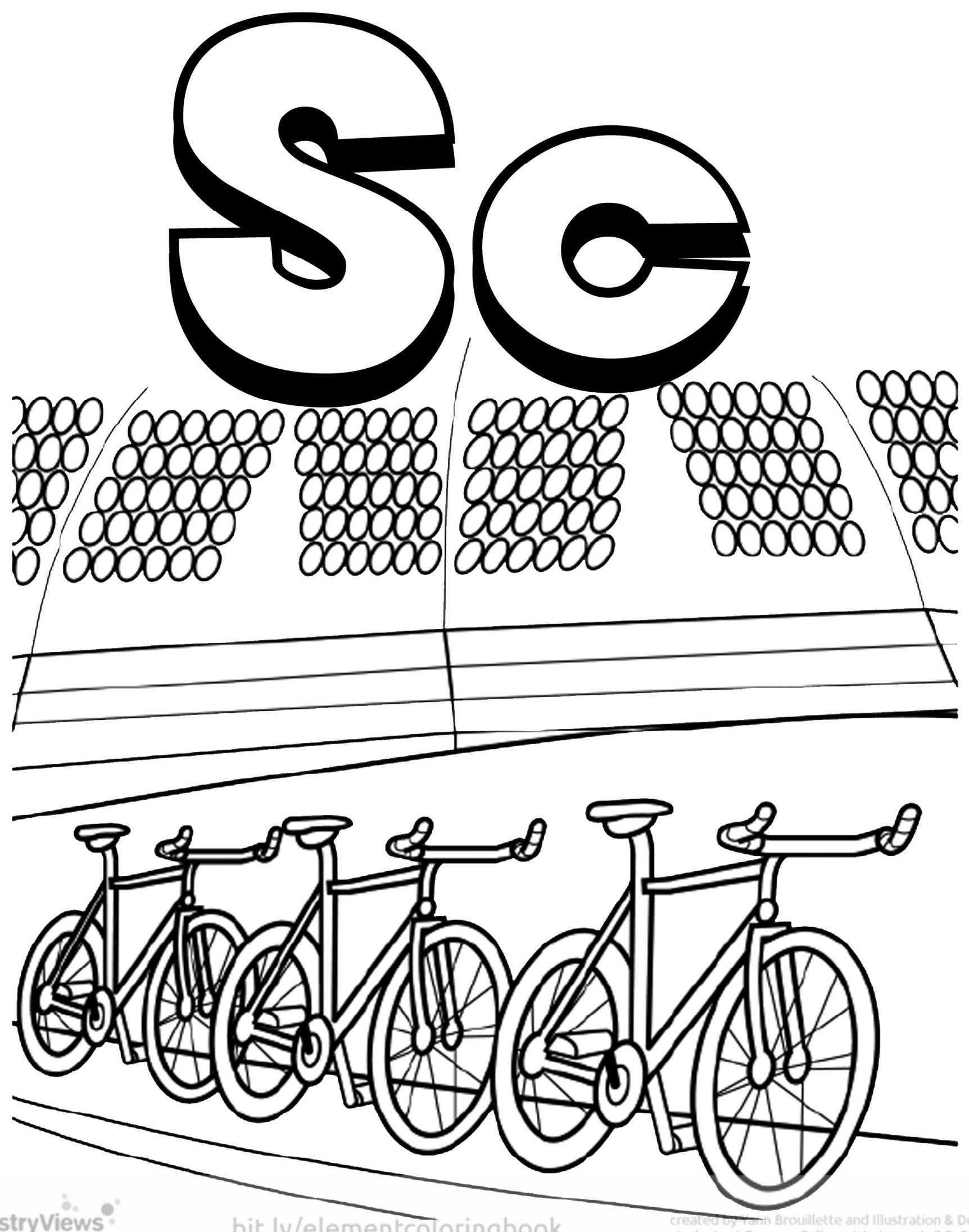


$$
22
$$

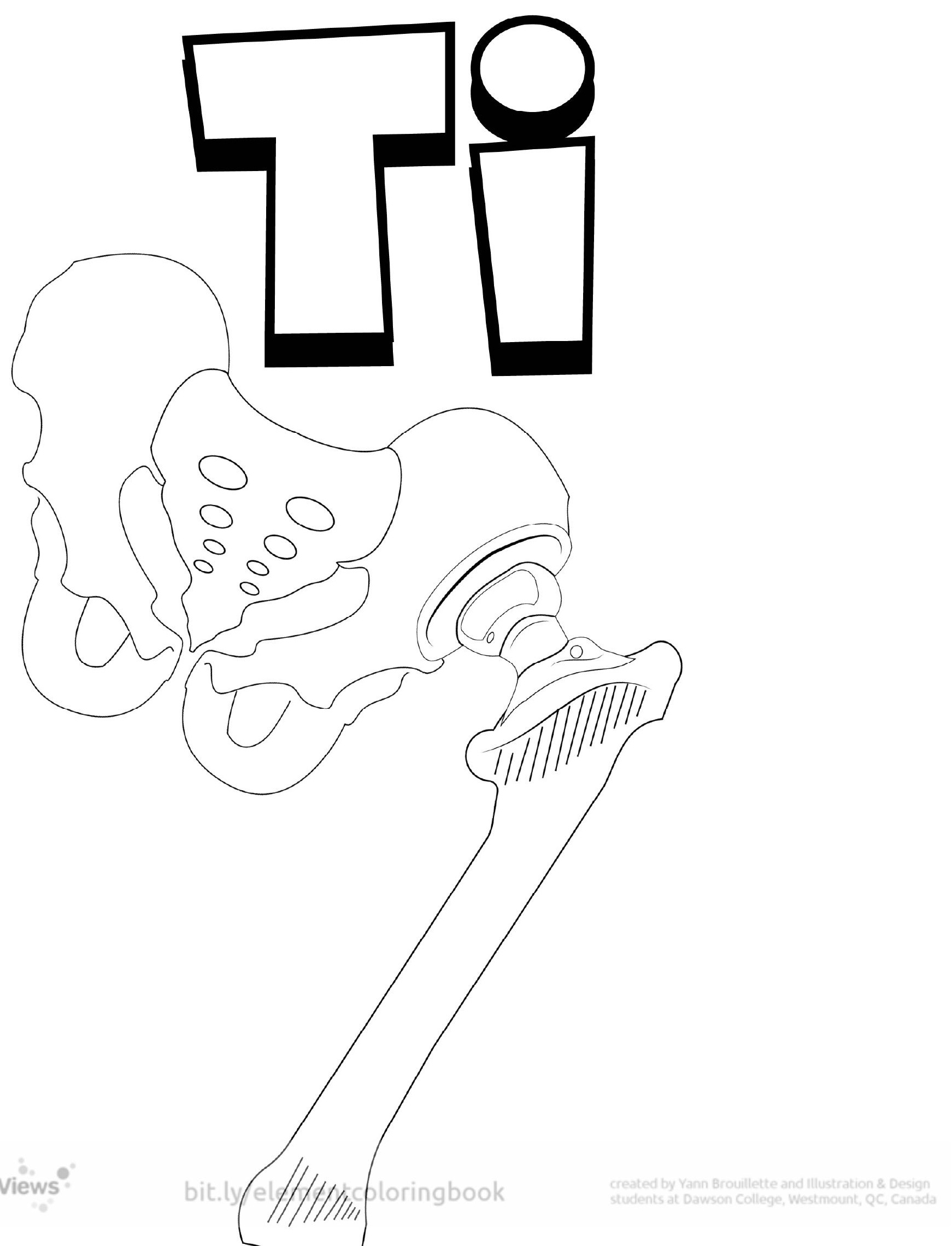




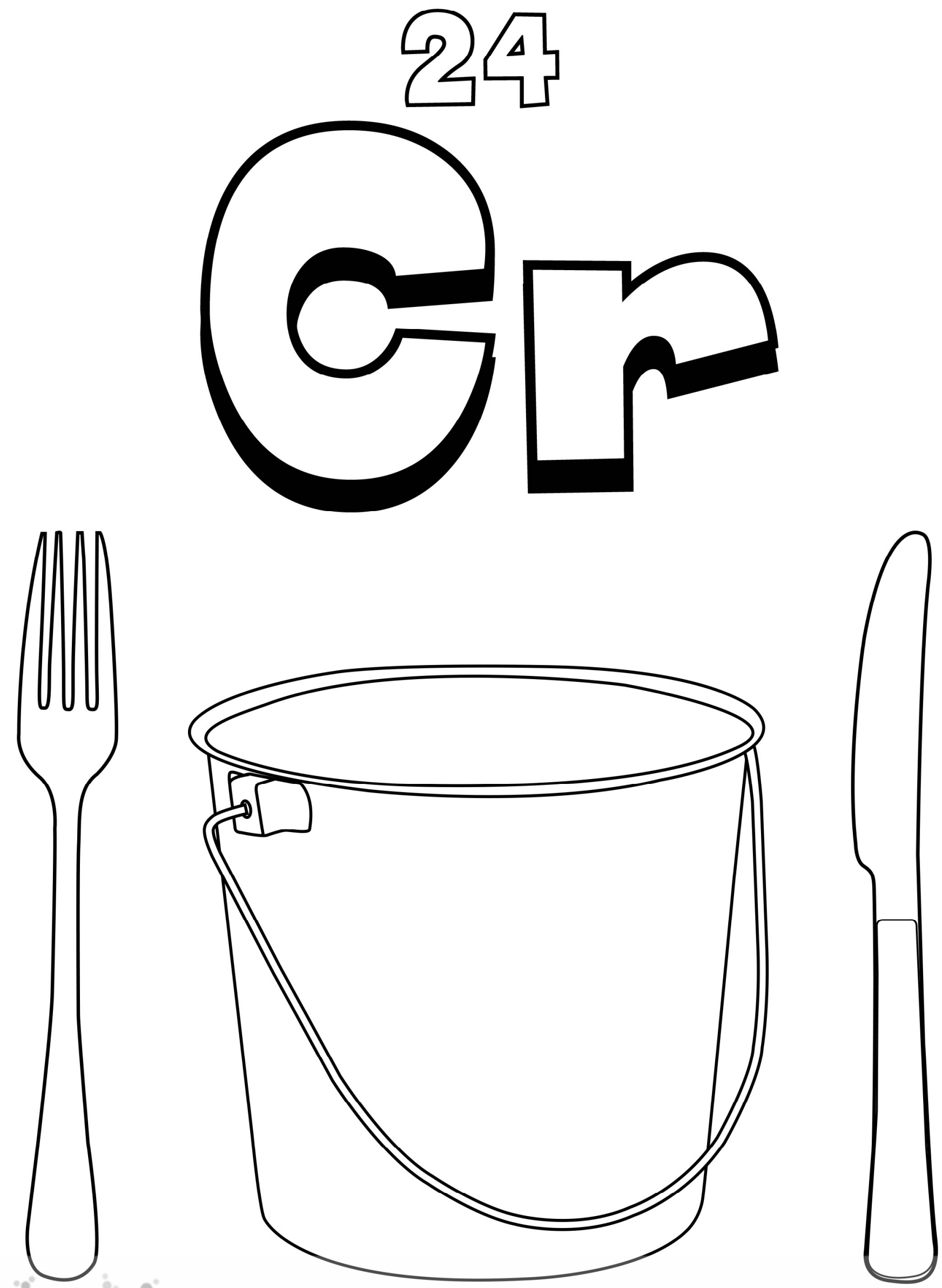


\section{5}
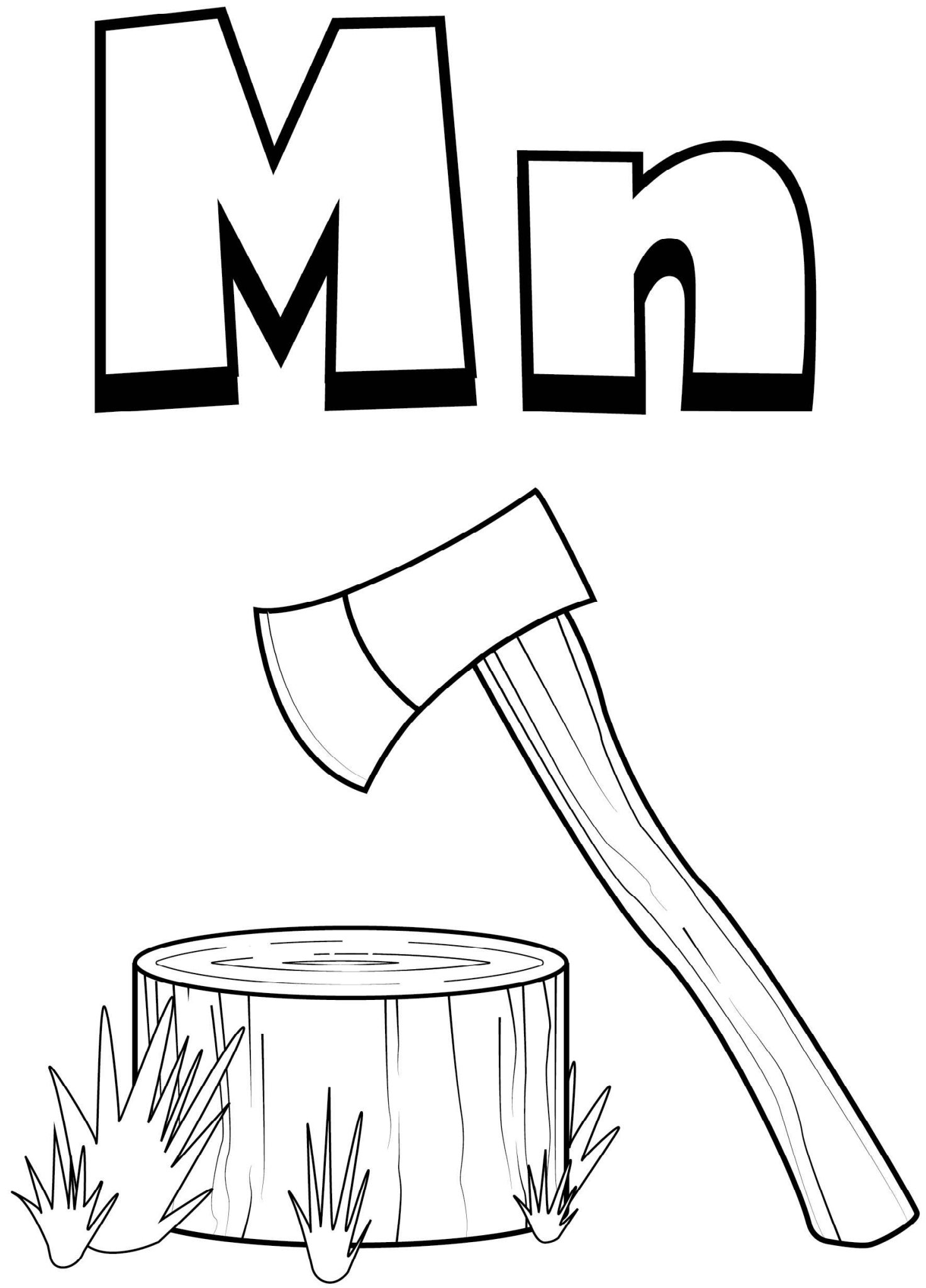


\section{0}
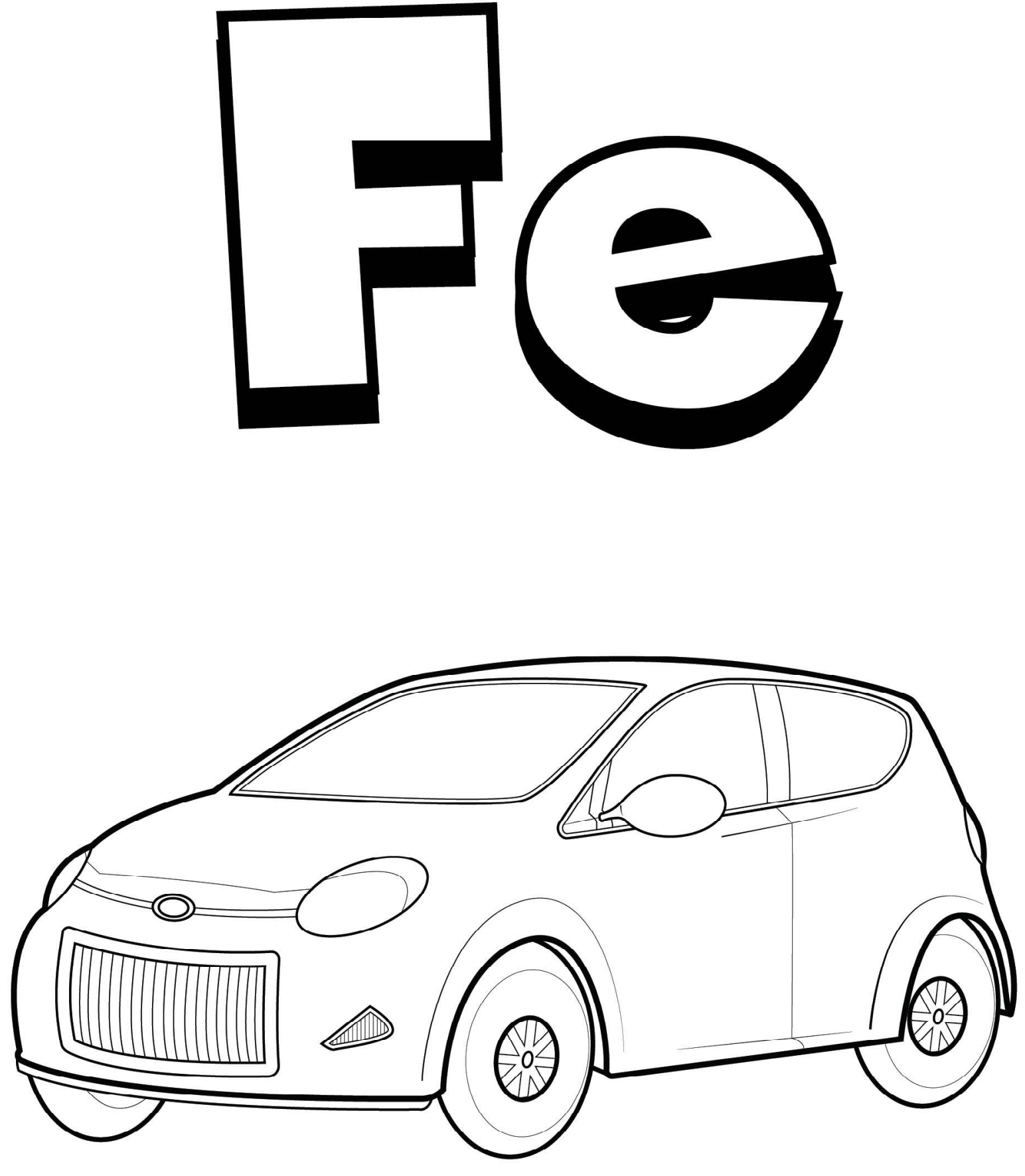

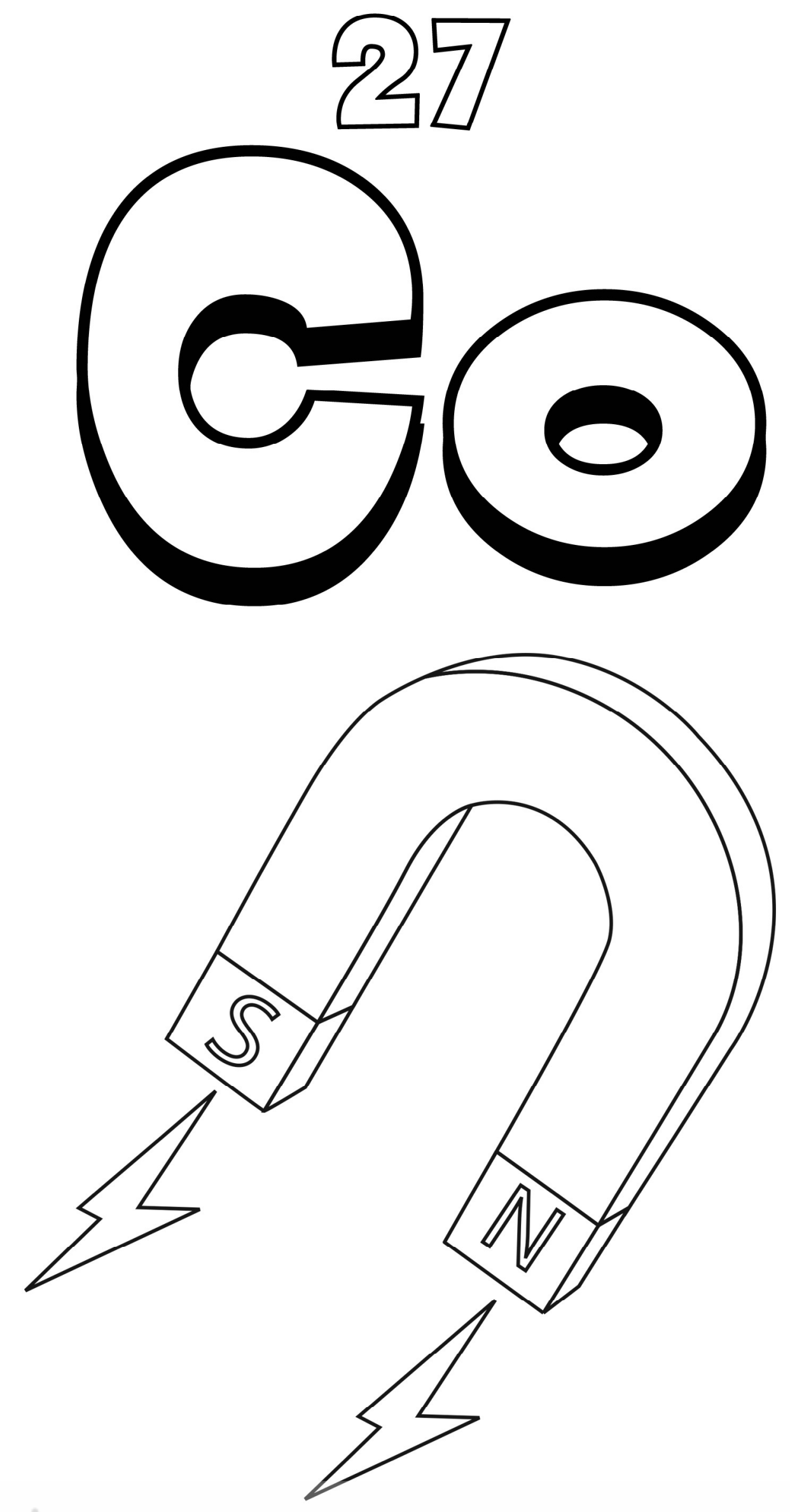


\section{8}
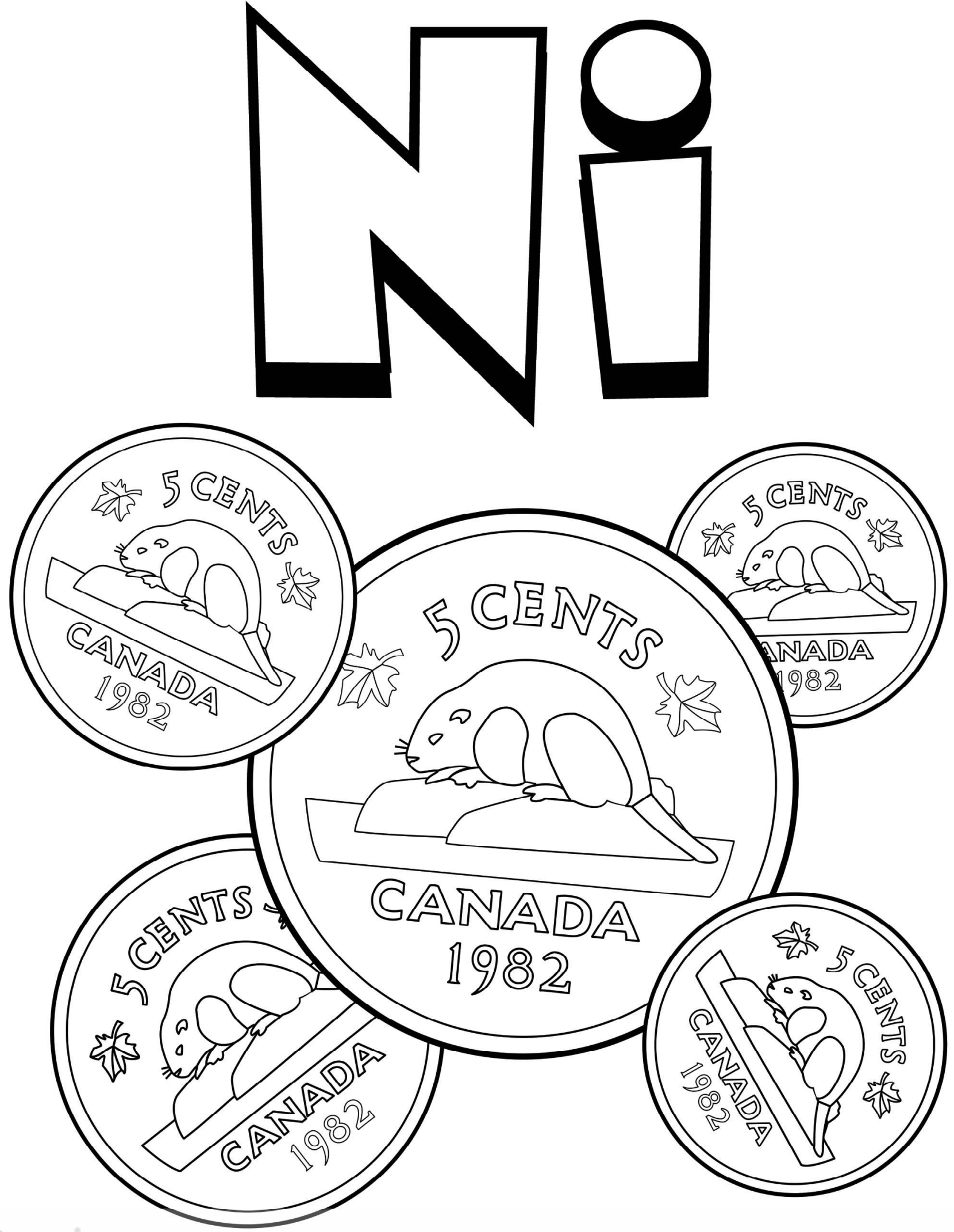


\section{잉}
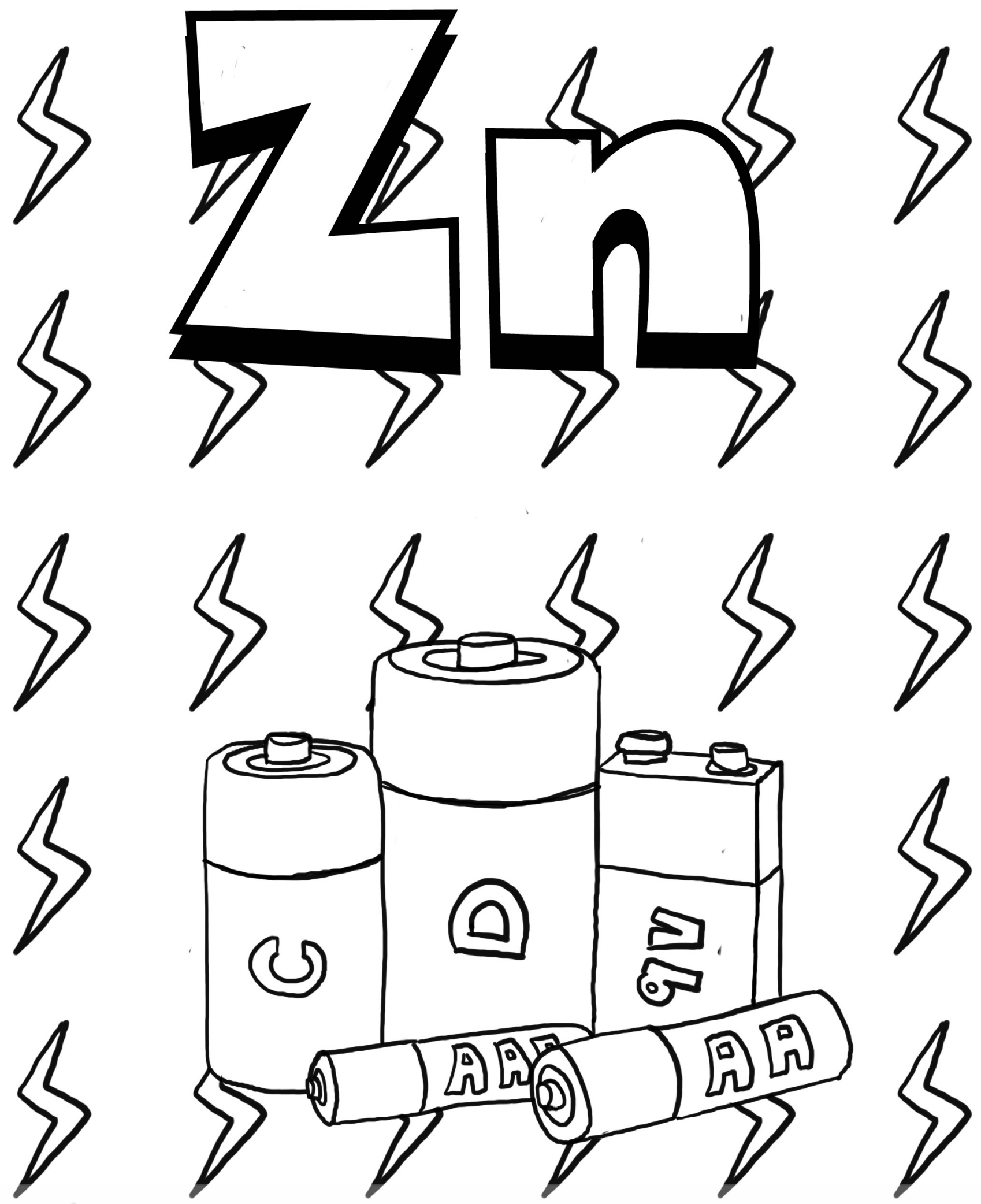


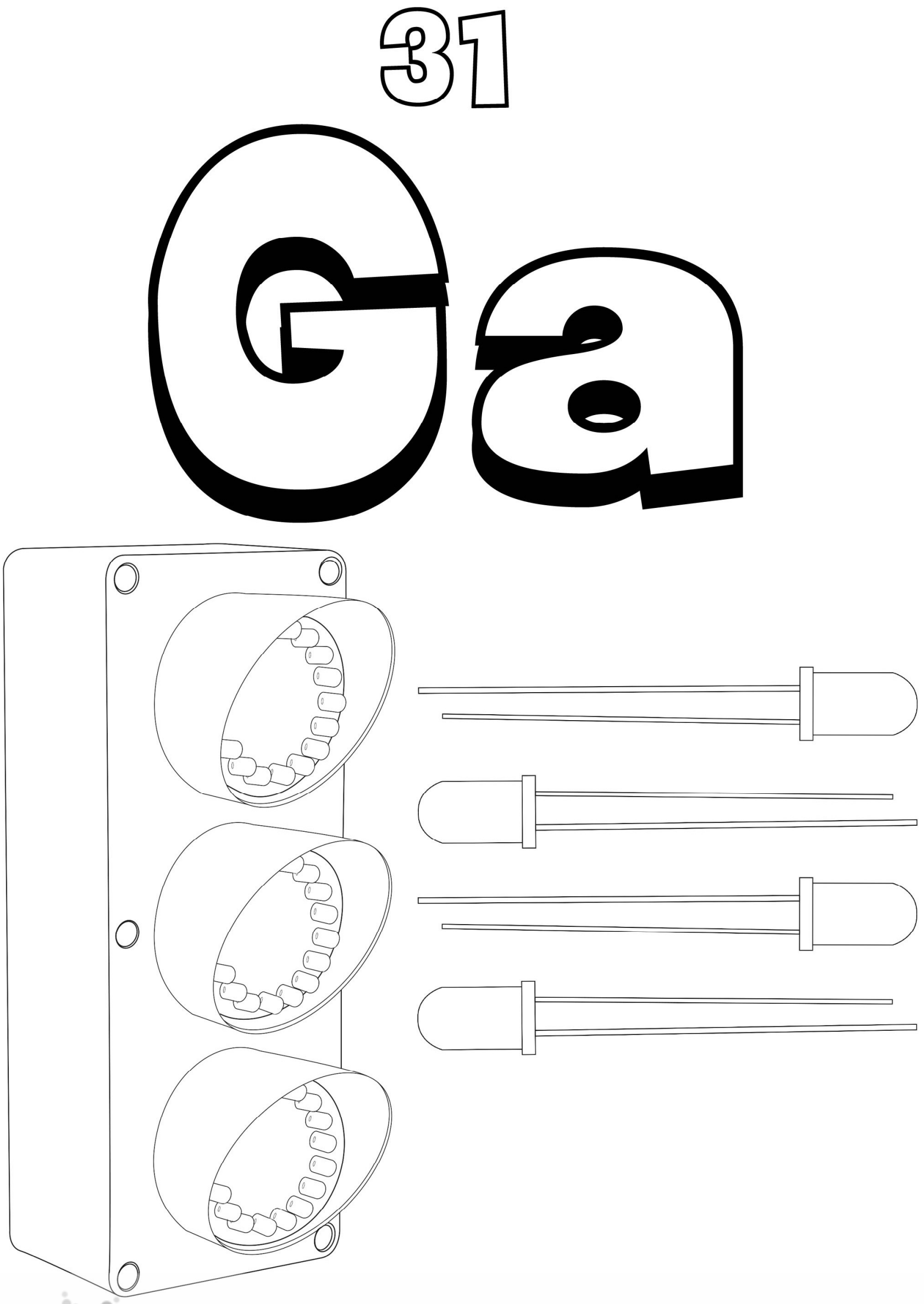




$$
\text { 요 }
$$
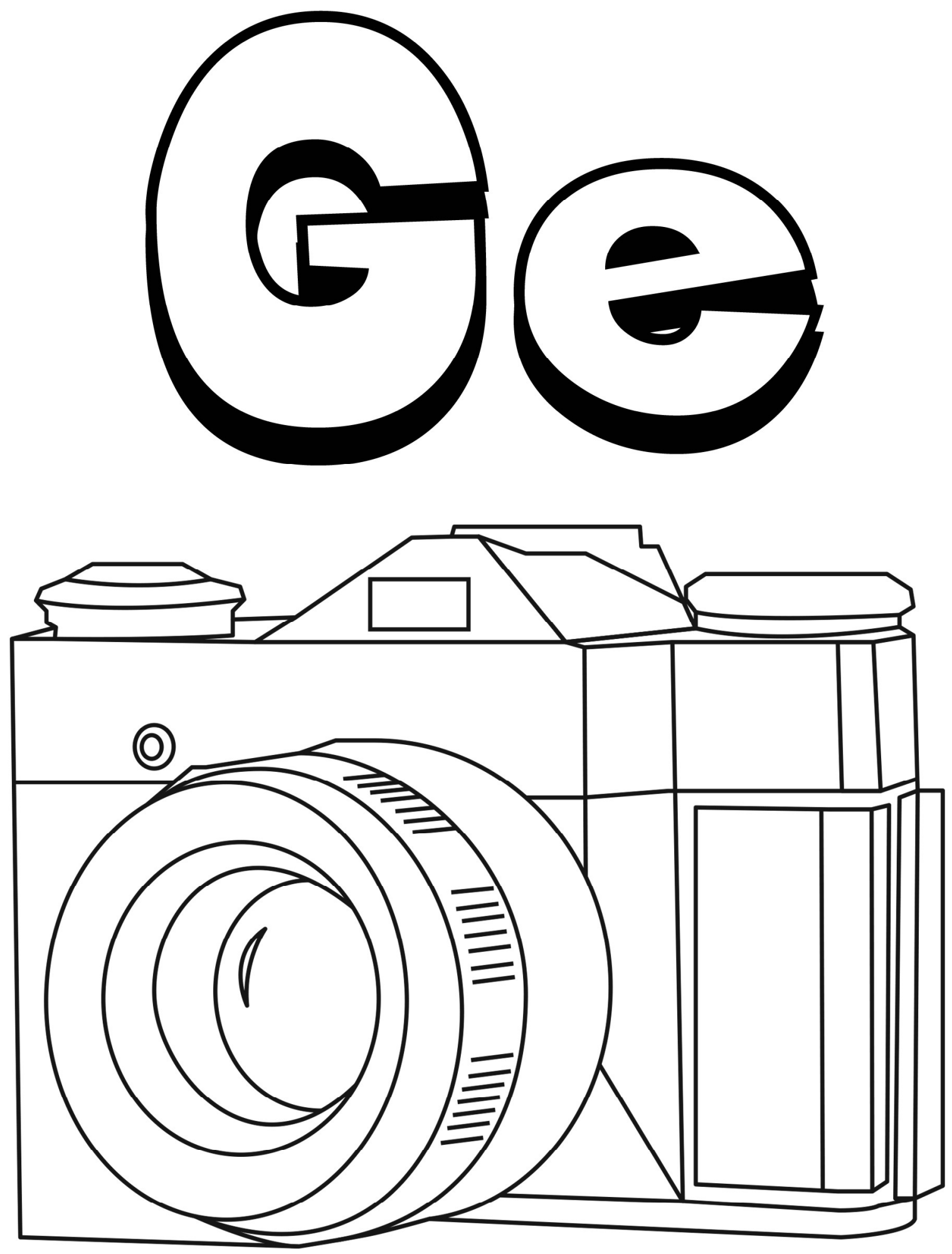


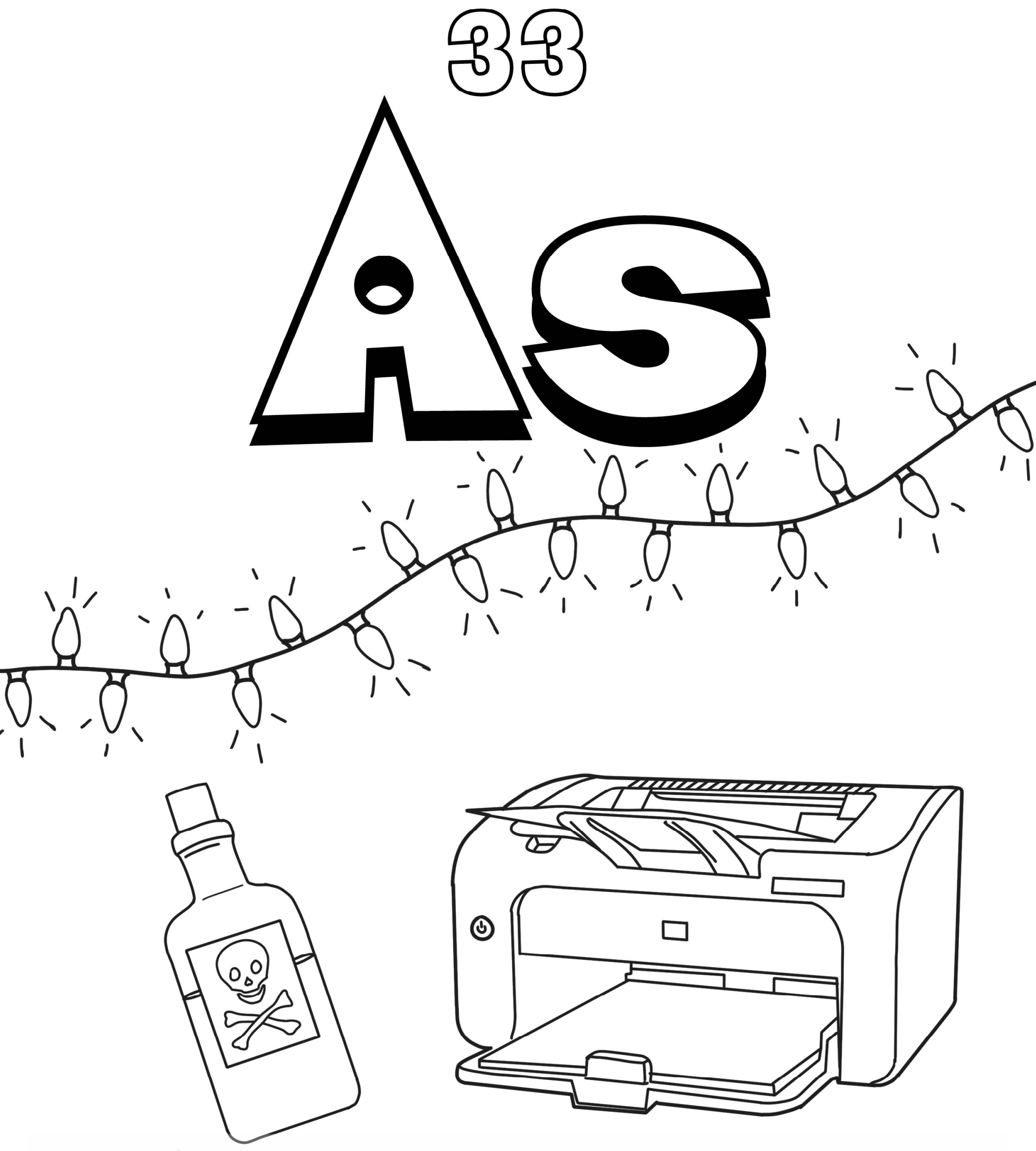




\section{4}
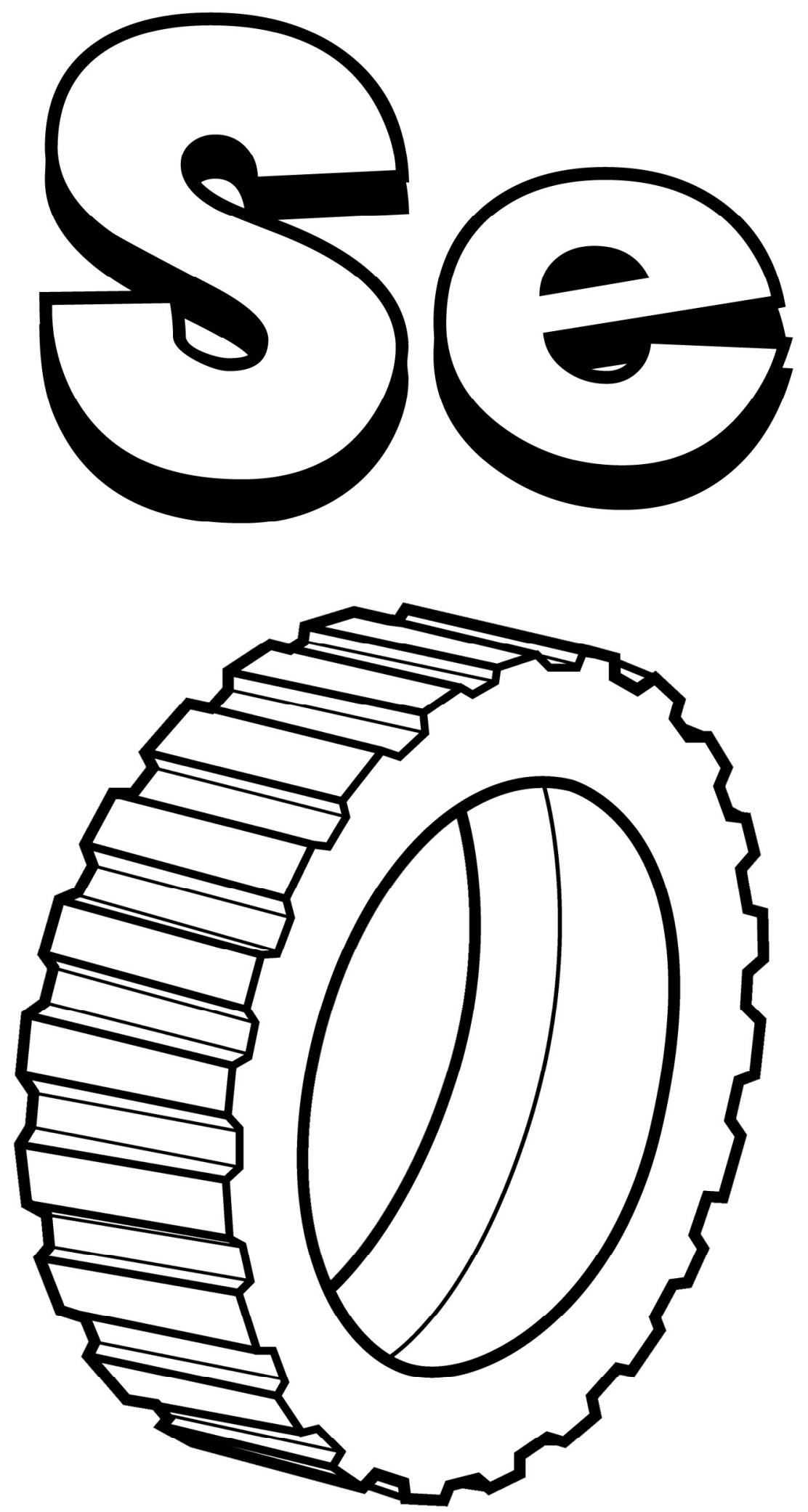


$$
05
$$
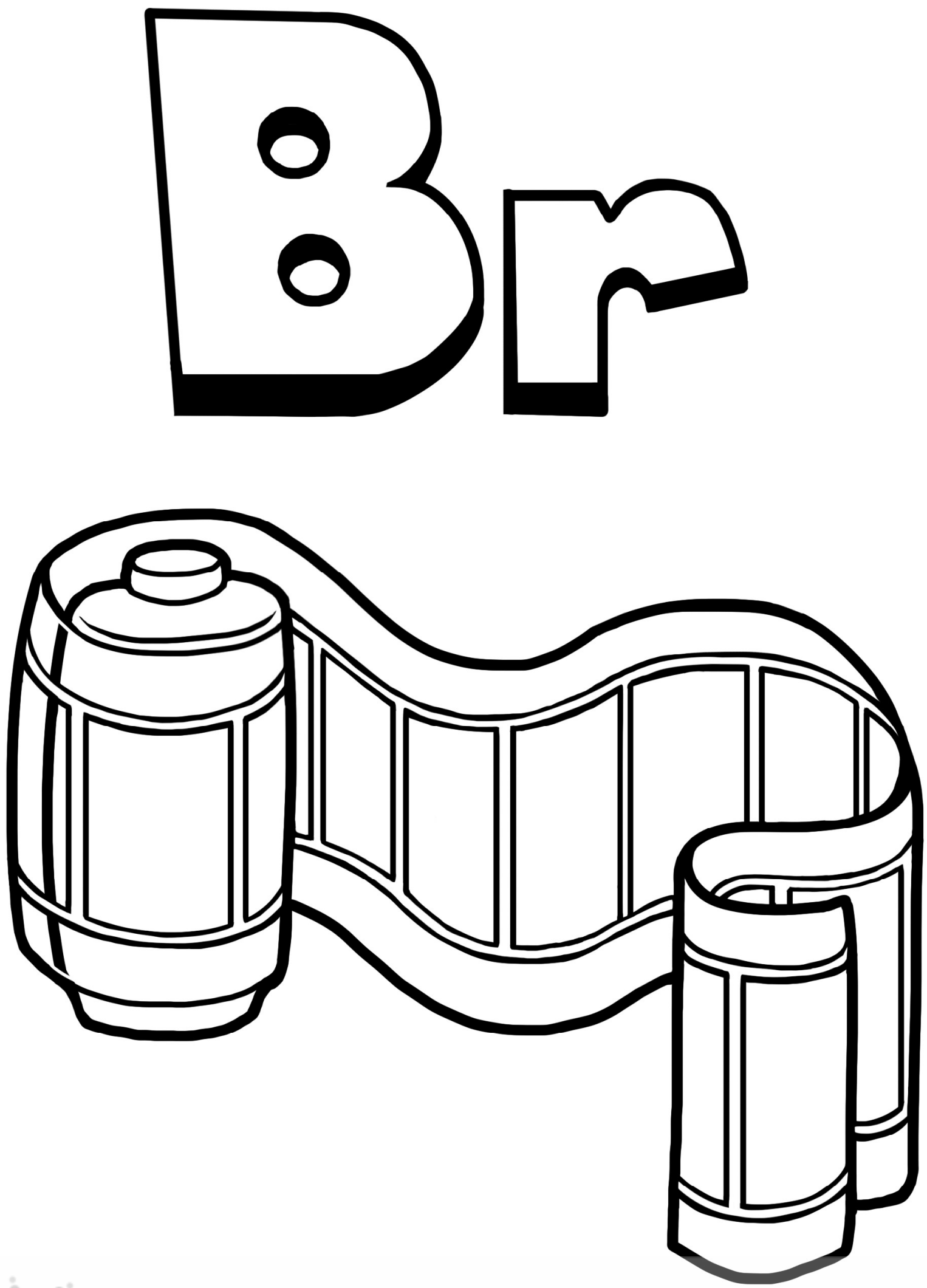


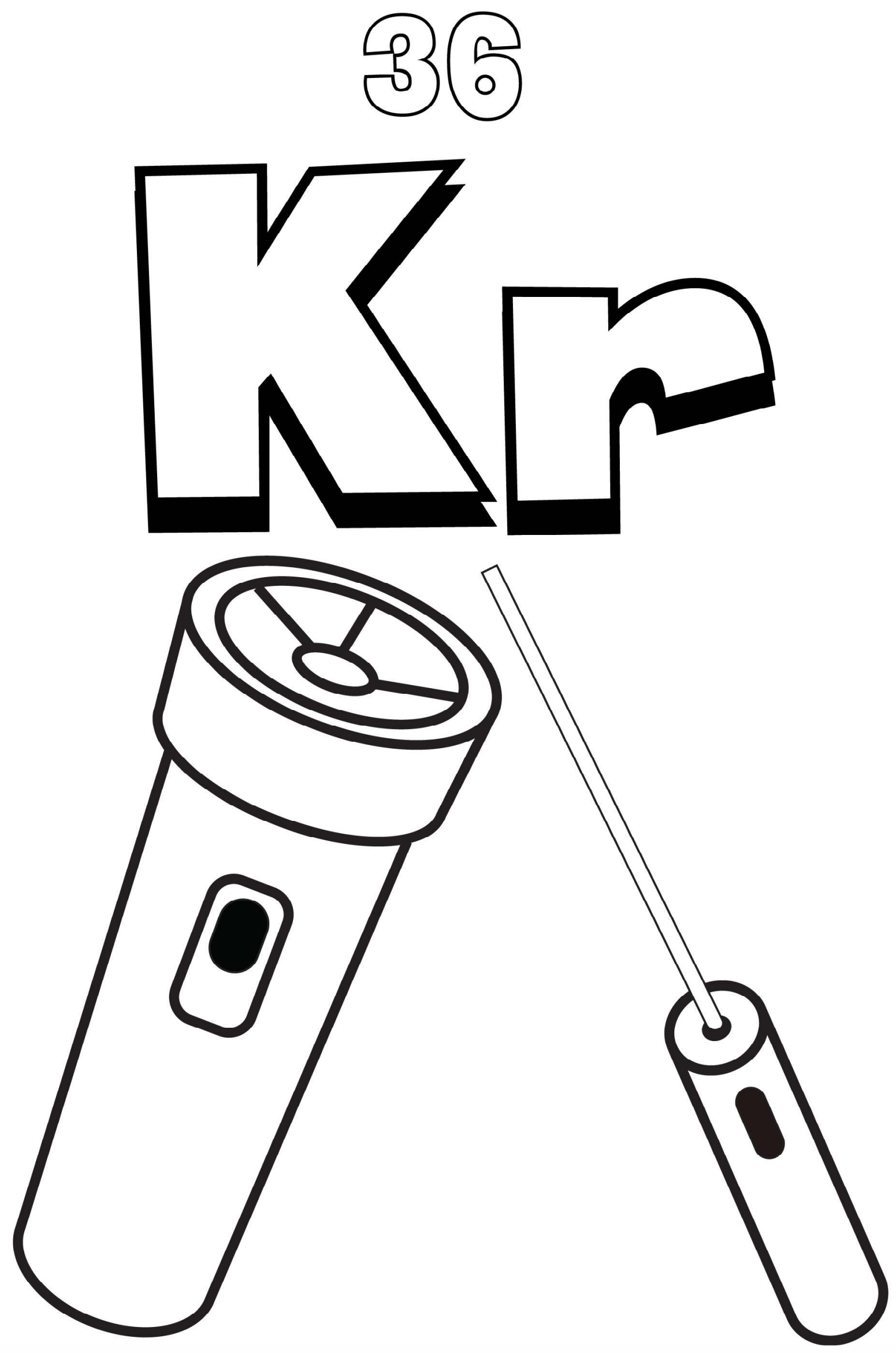




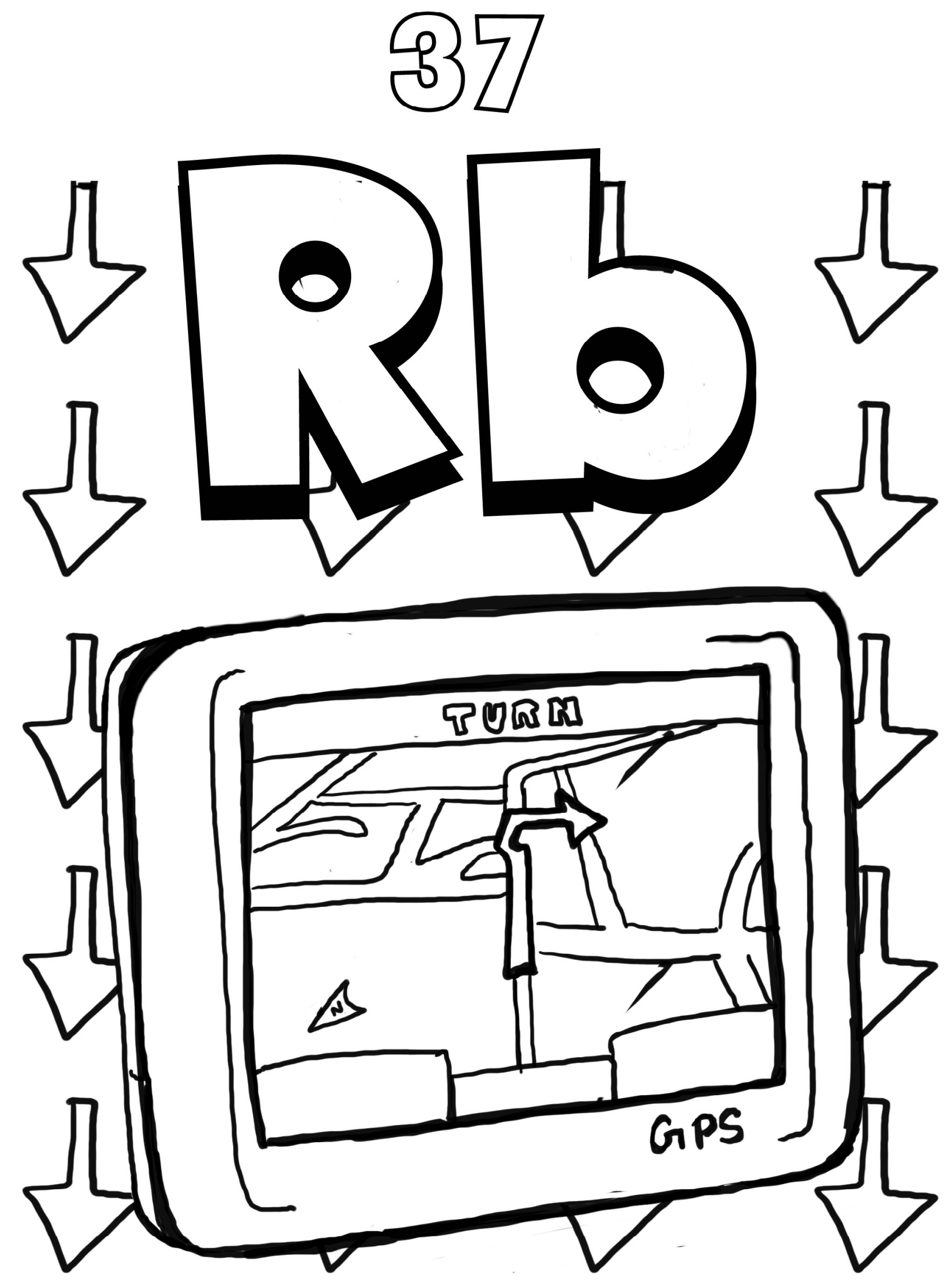




$$
\text { ๑) }
$$
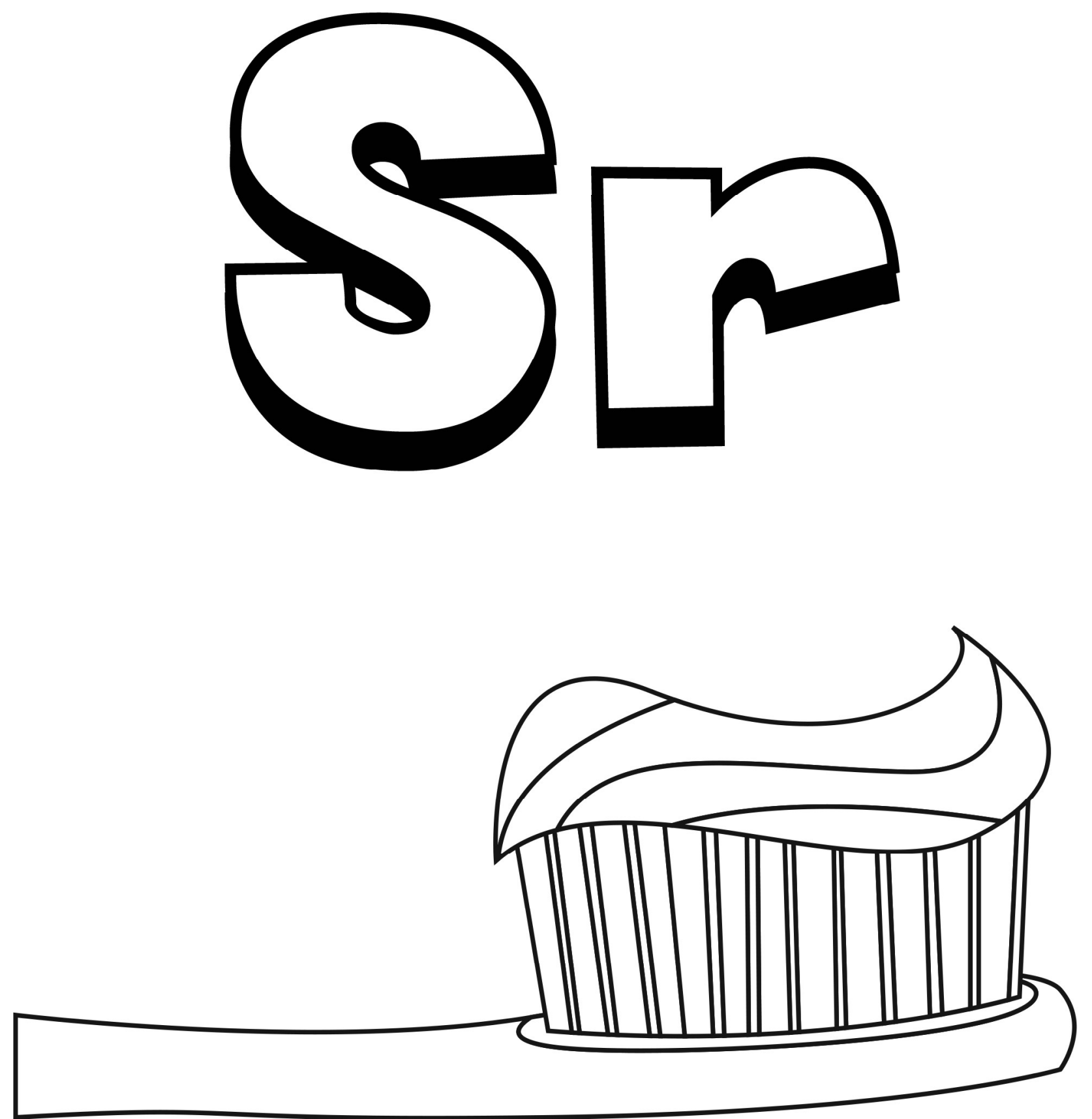


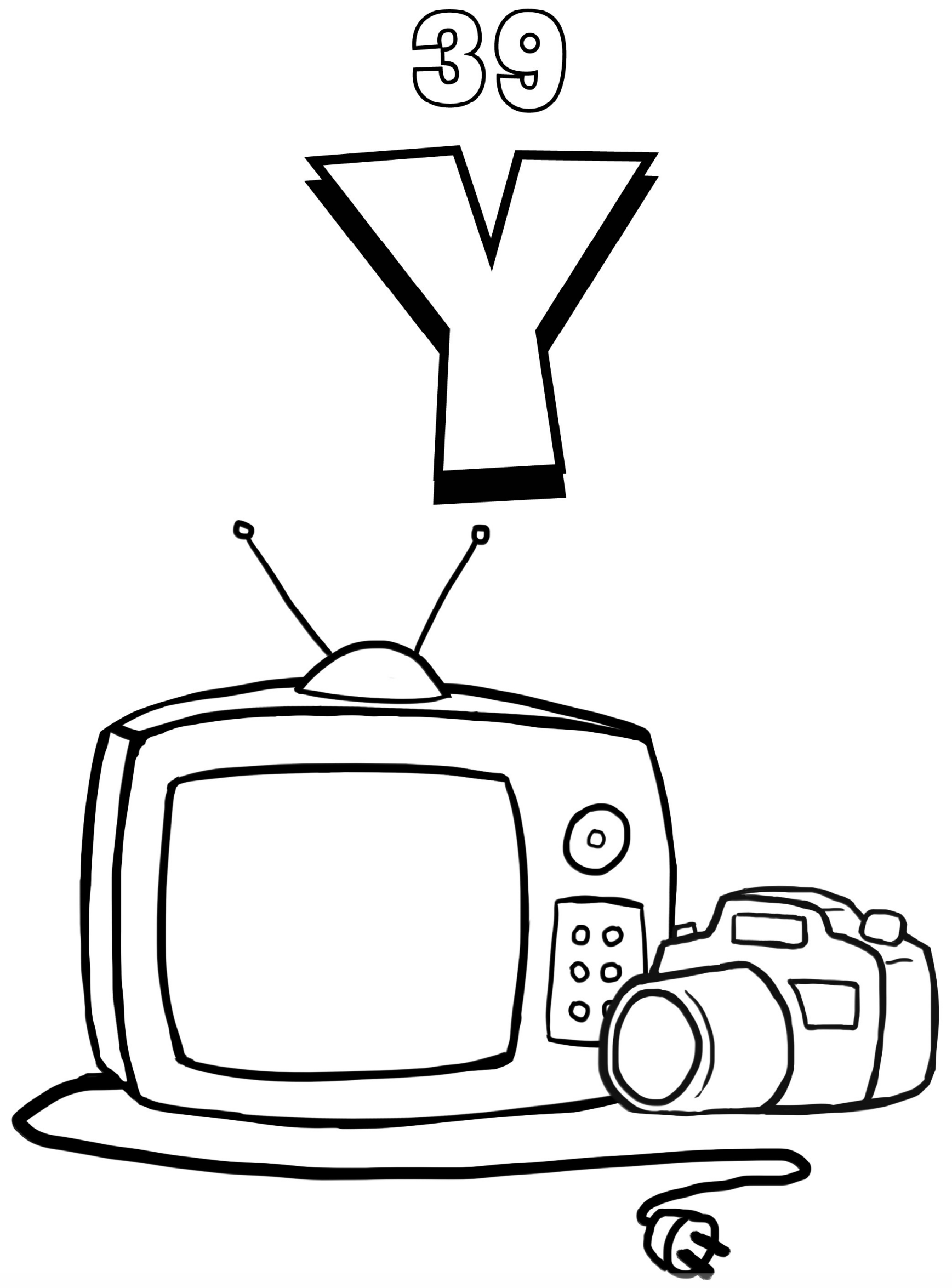




\section{0}
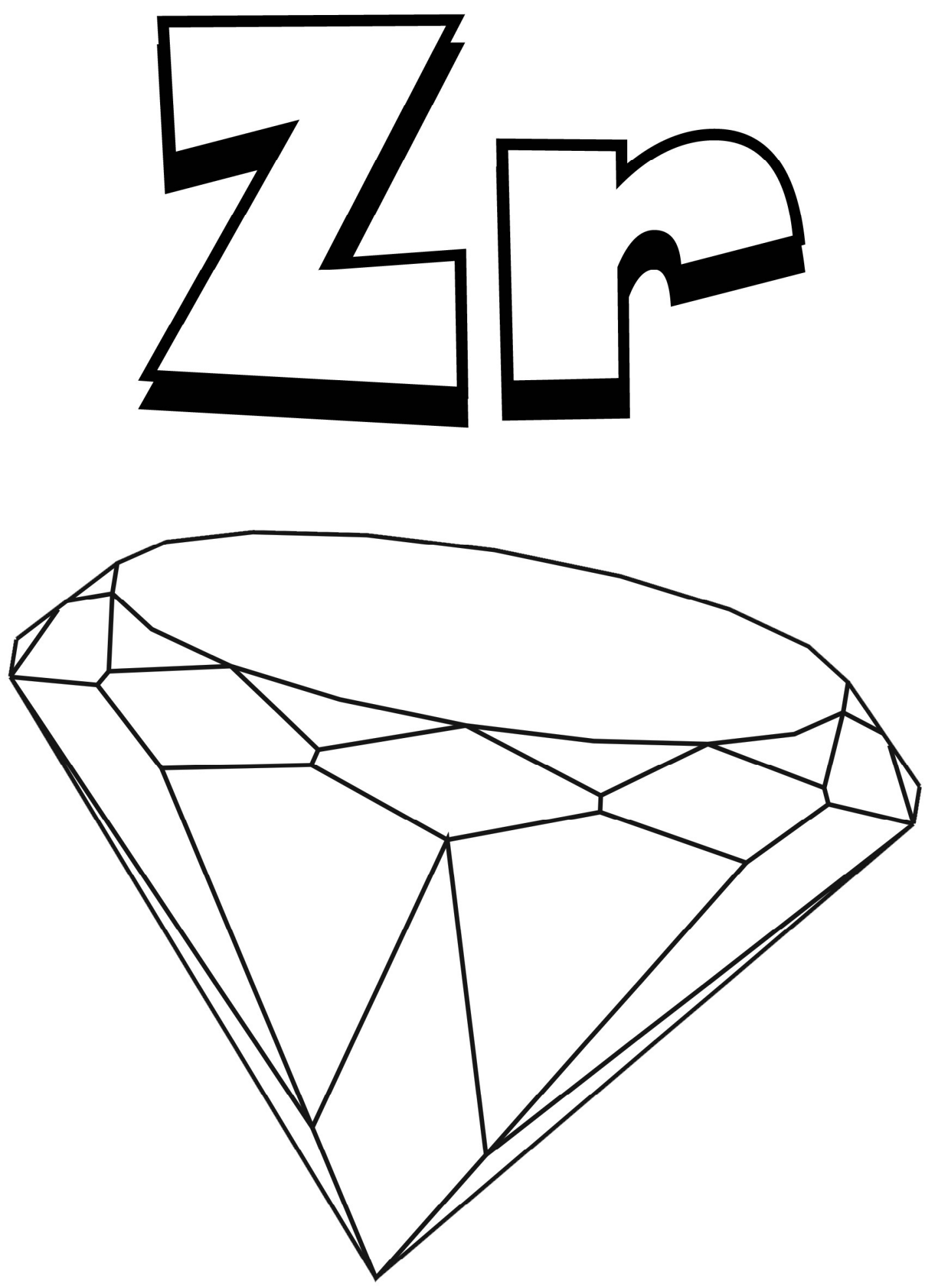

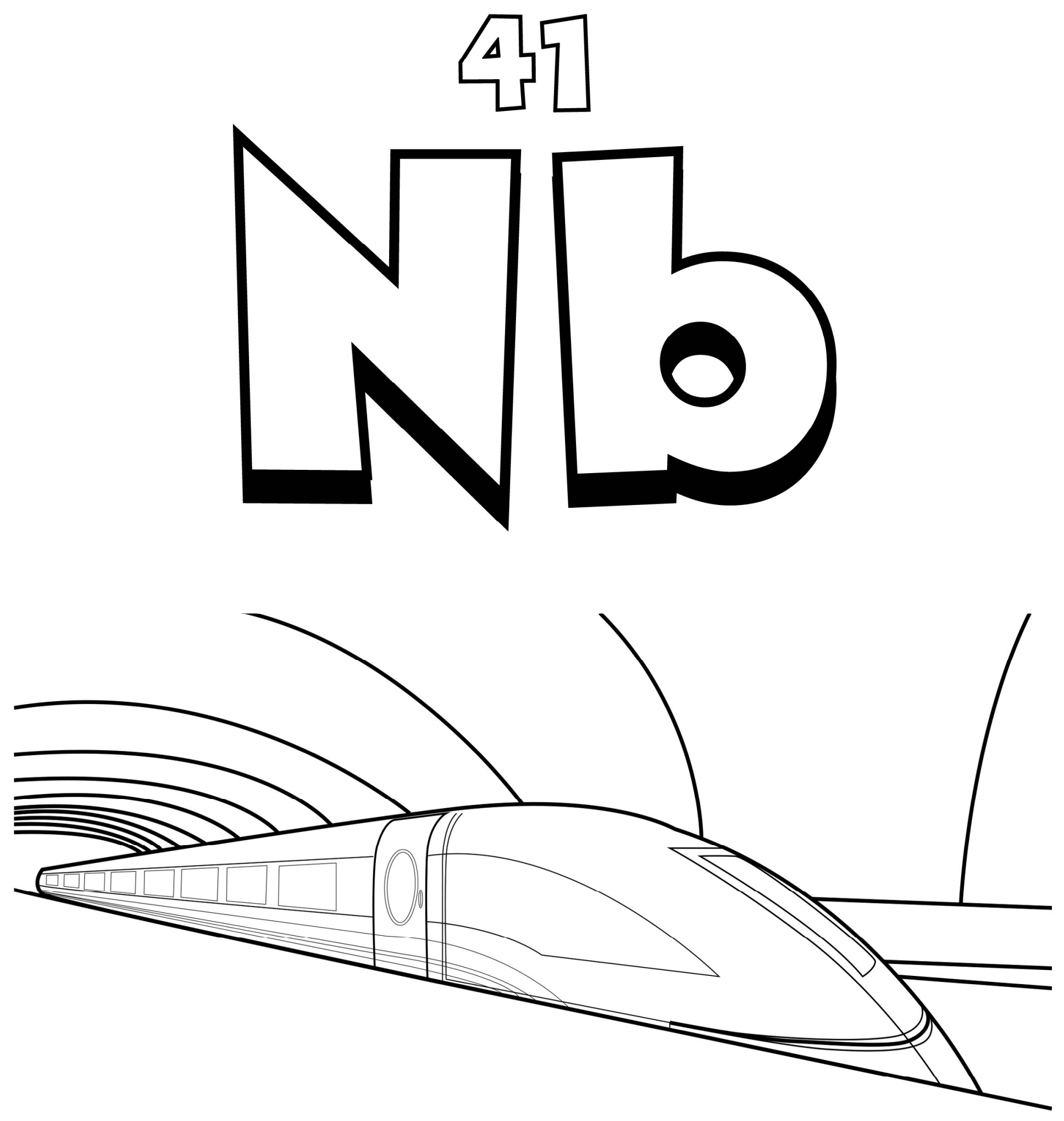


\section{2}
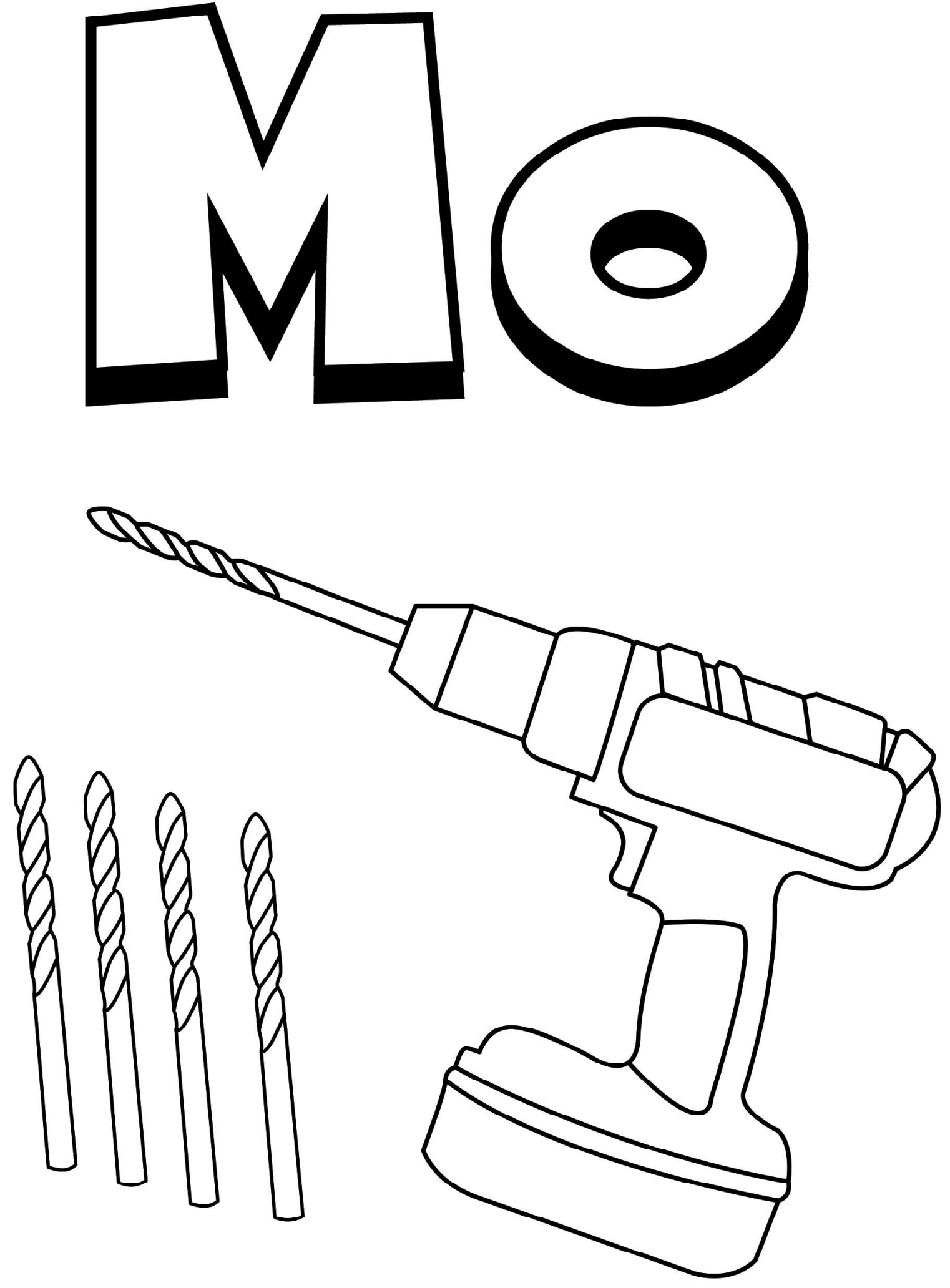


$$
4
$$
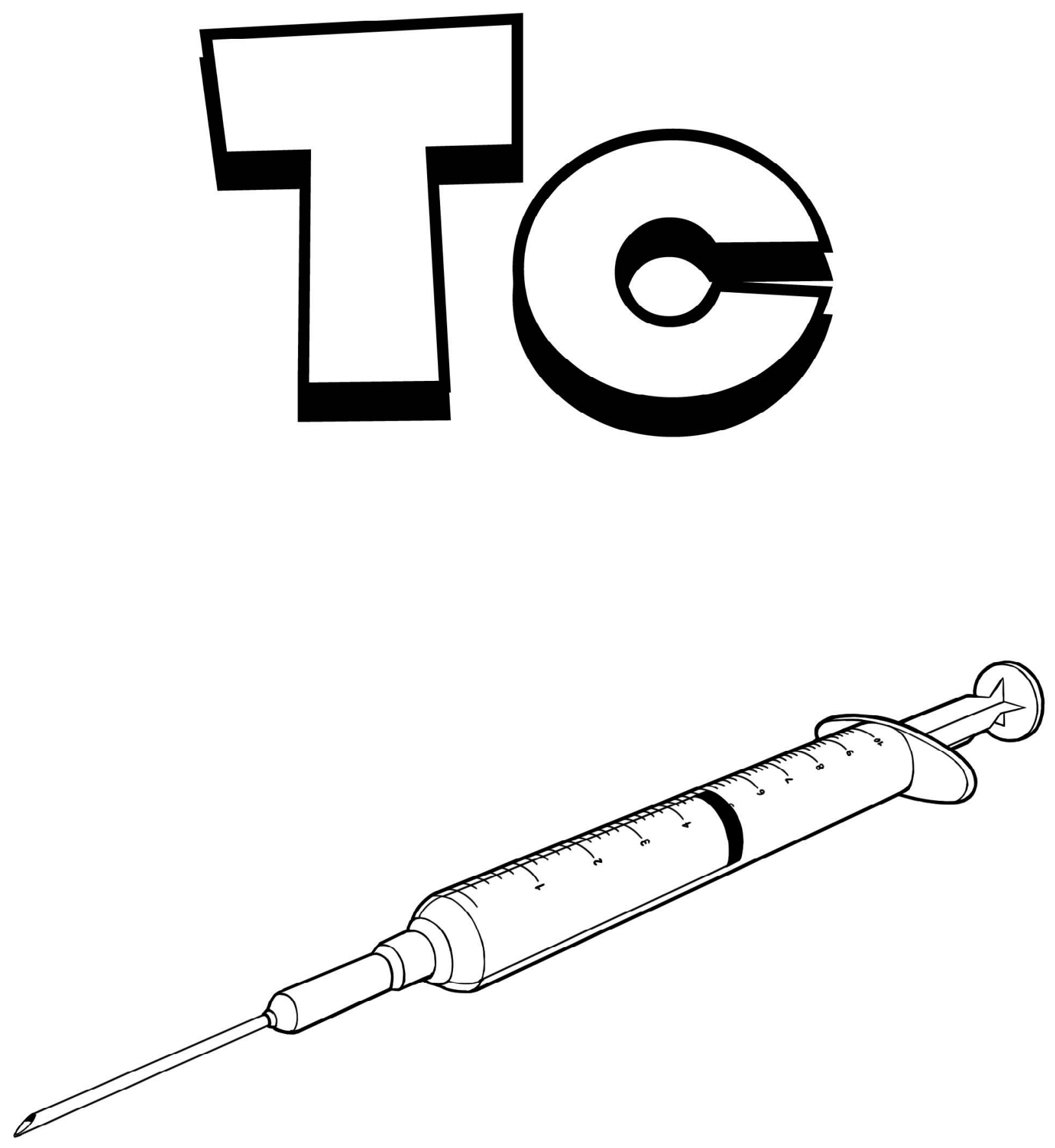


\section{4}
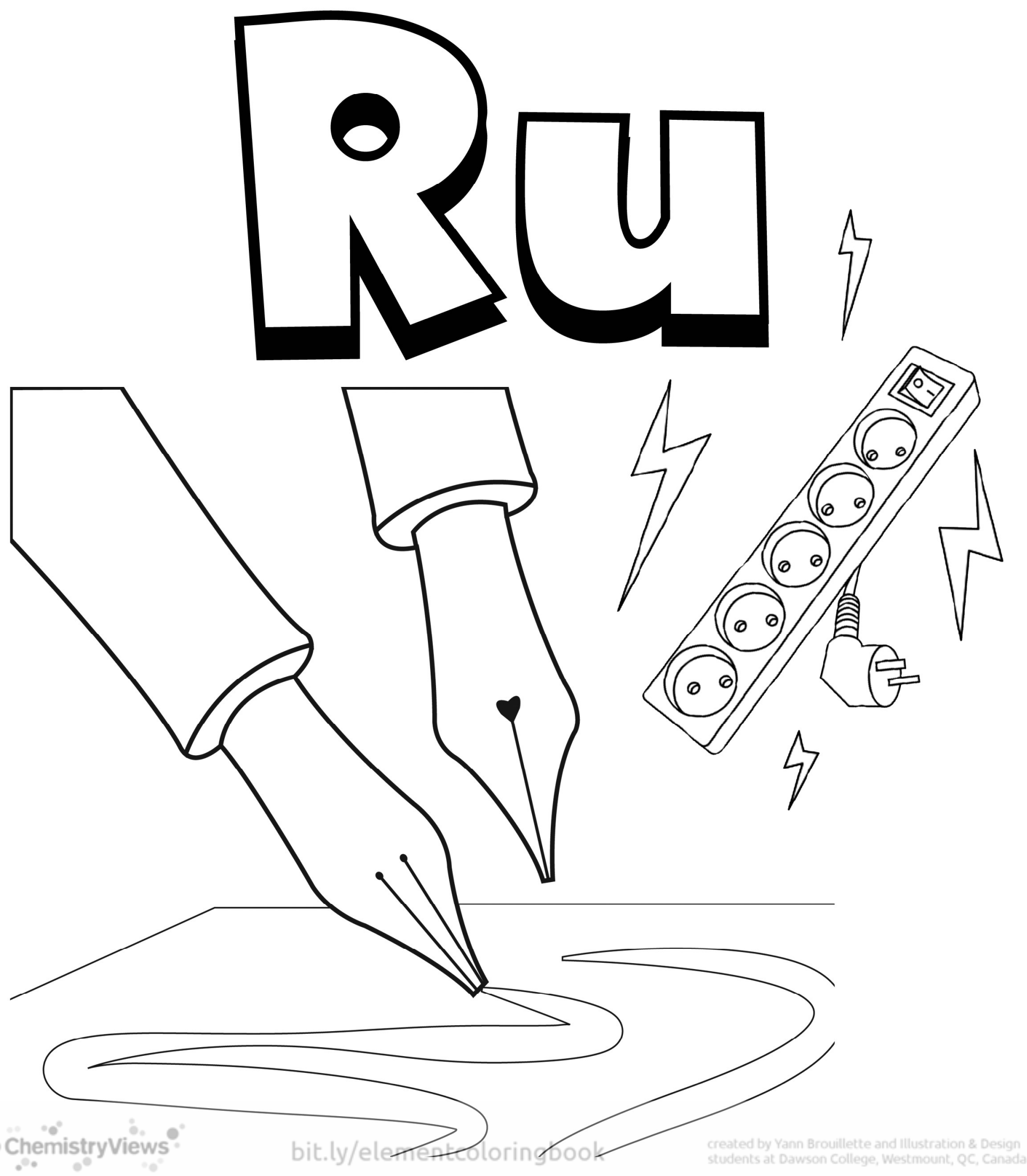


$$
45
$$
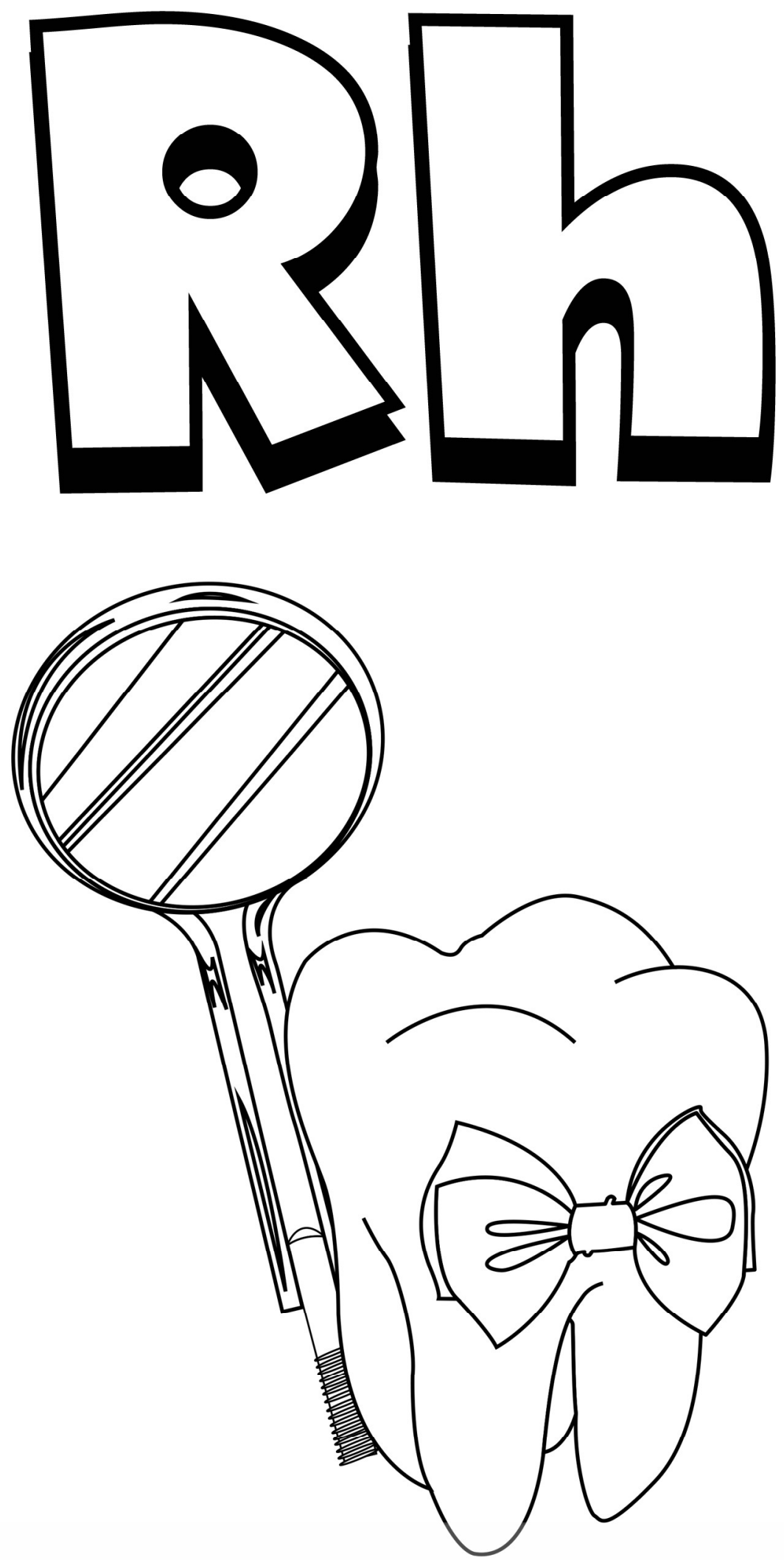


$$
43
$$
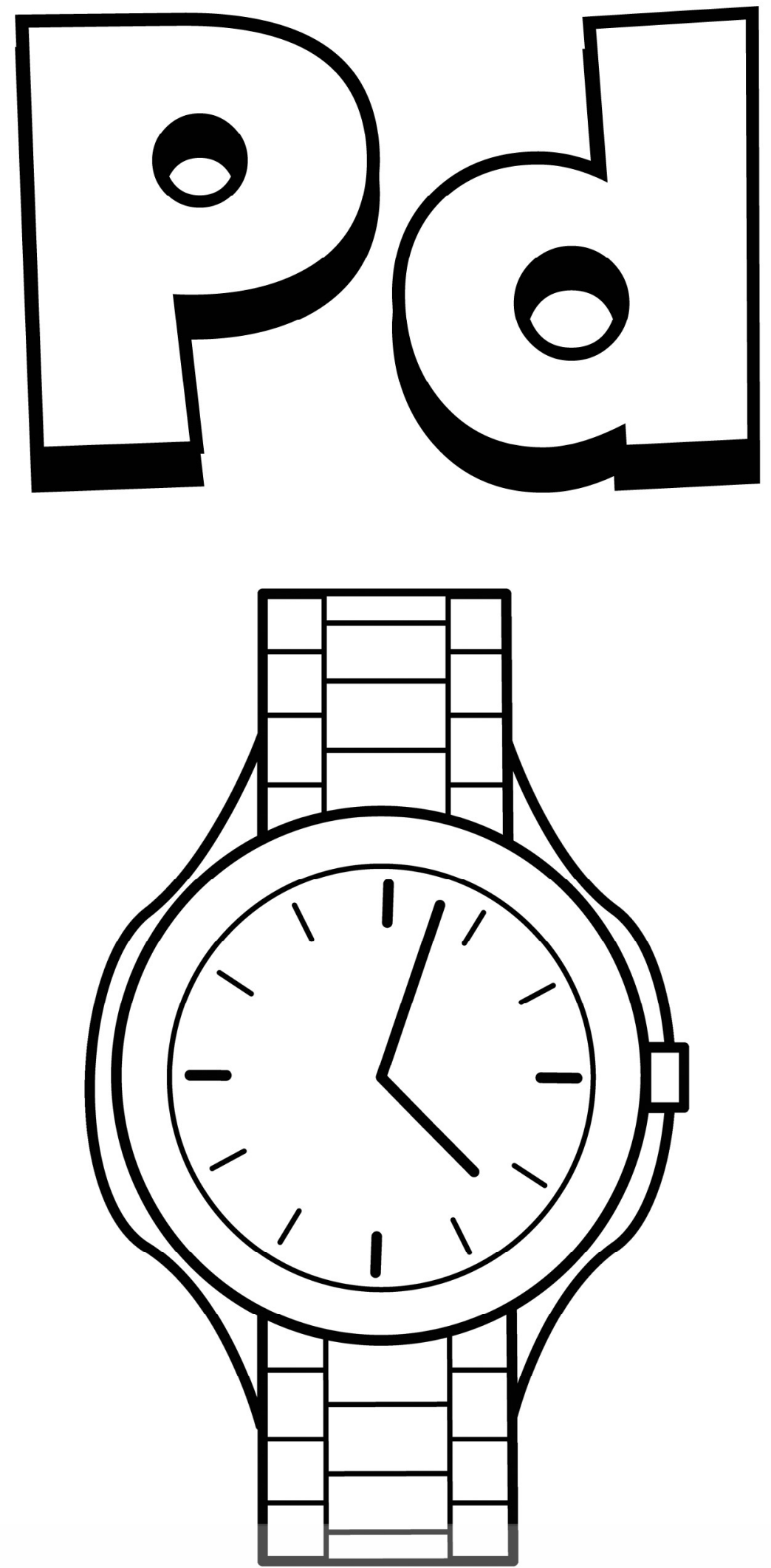


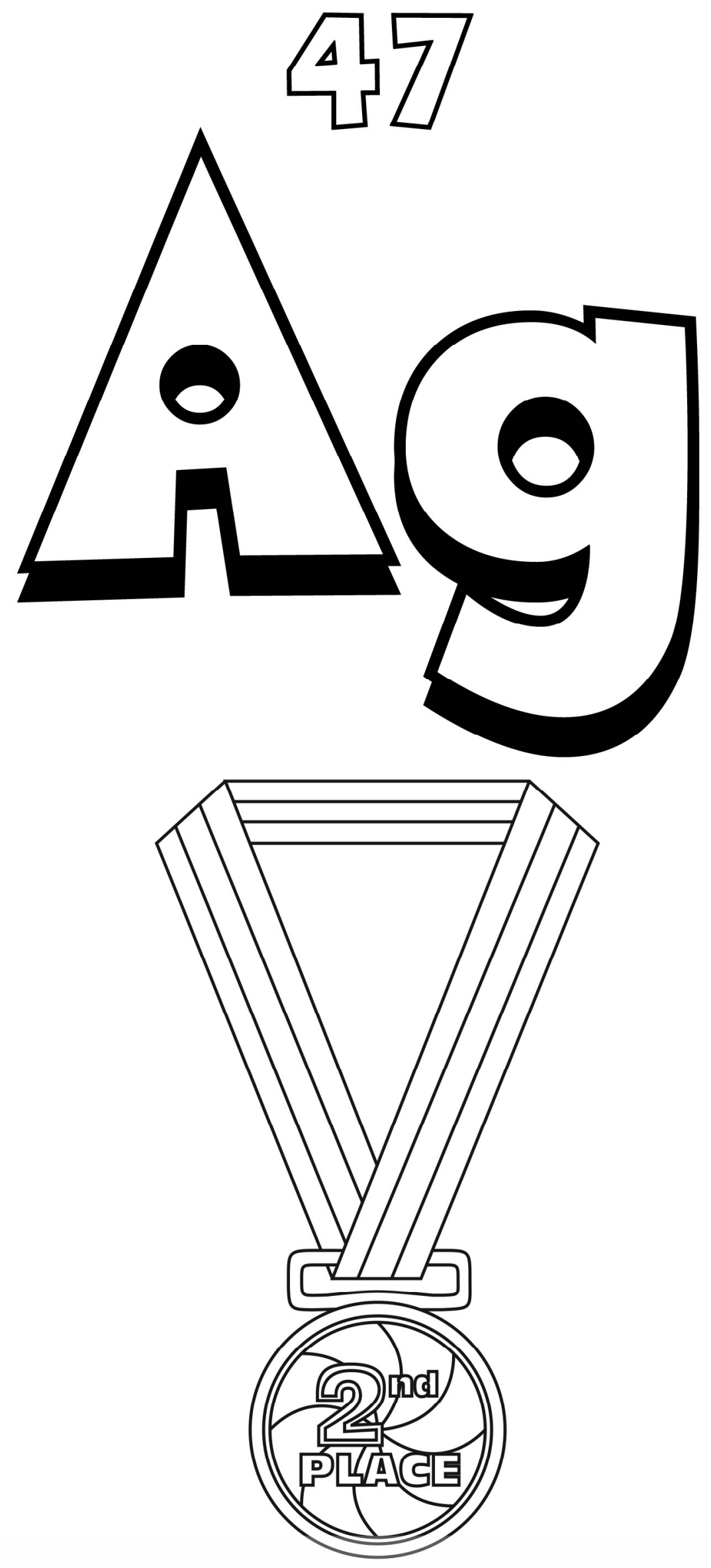



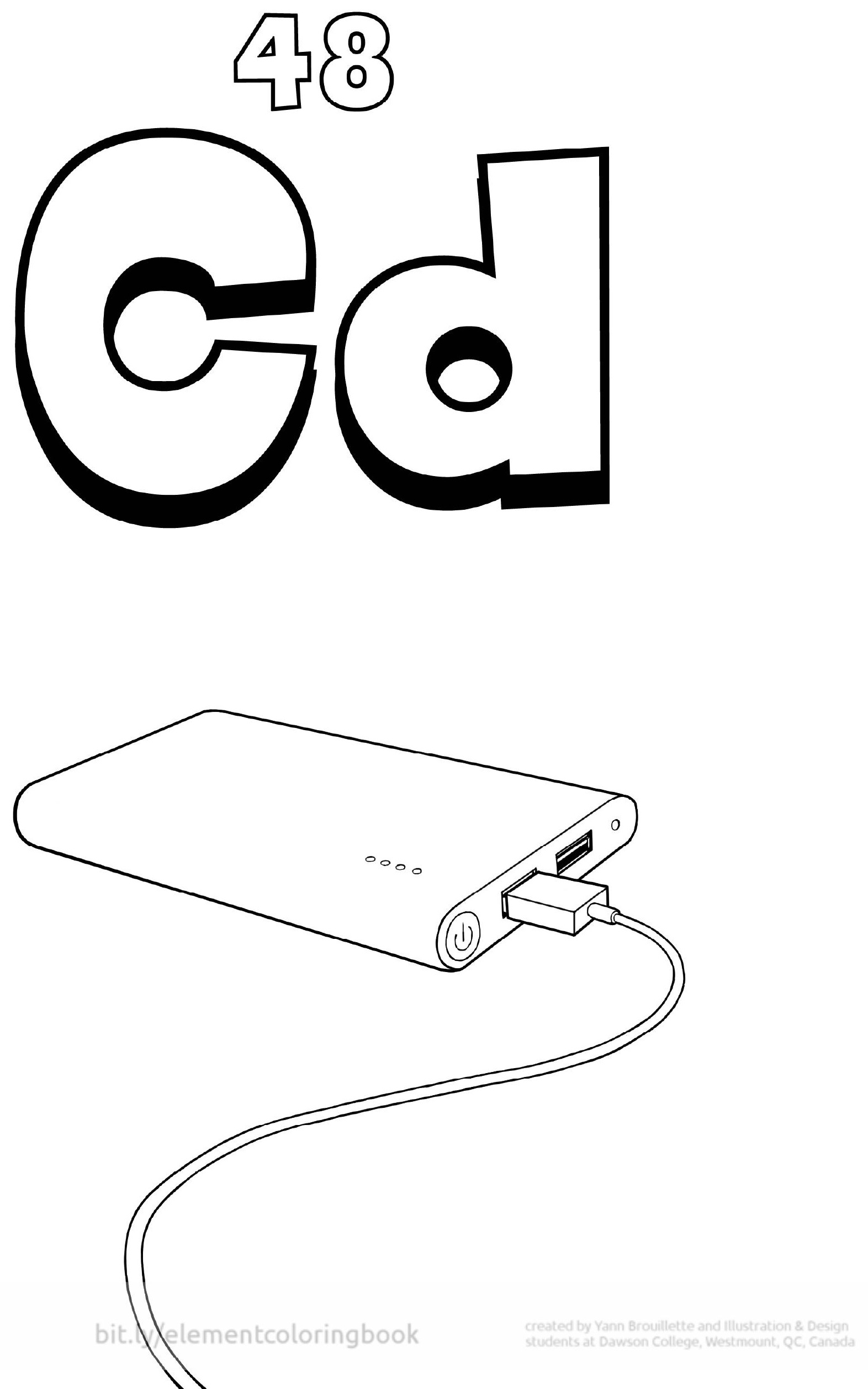
40
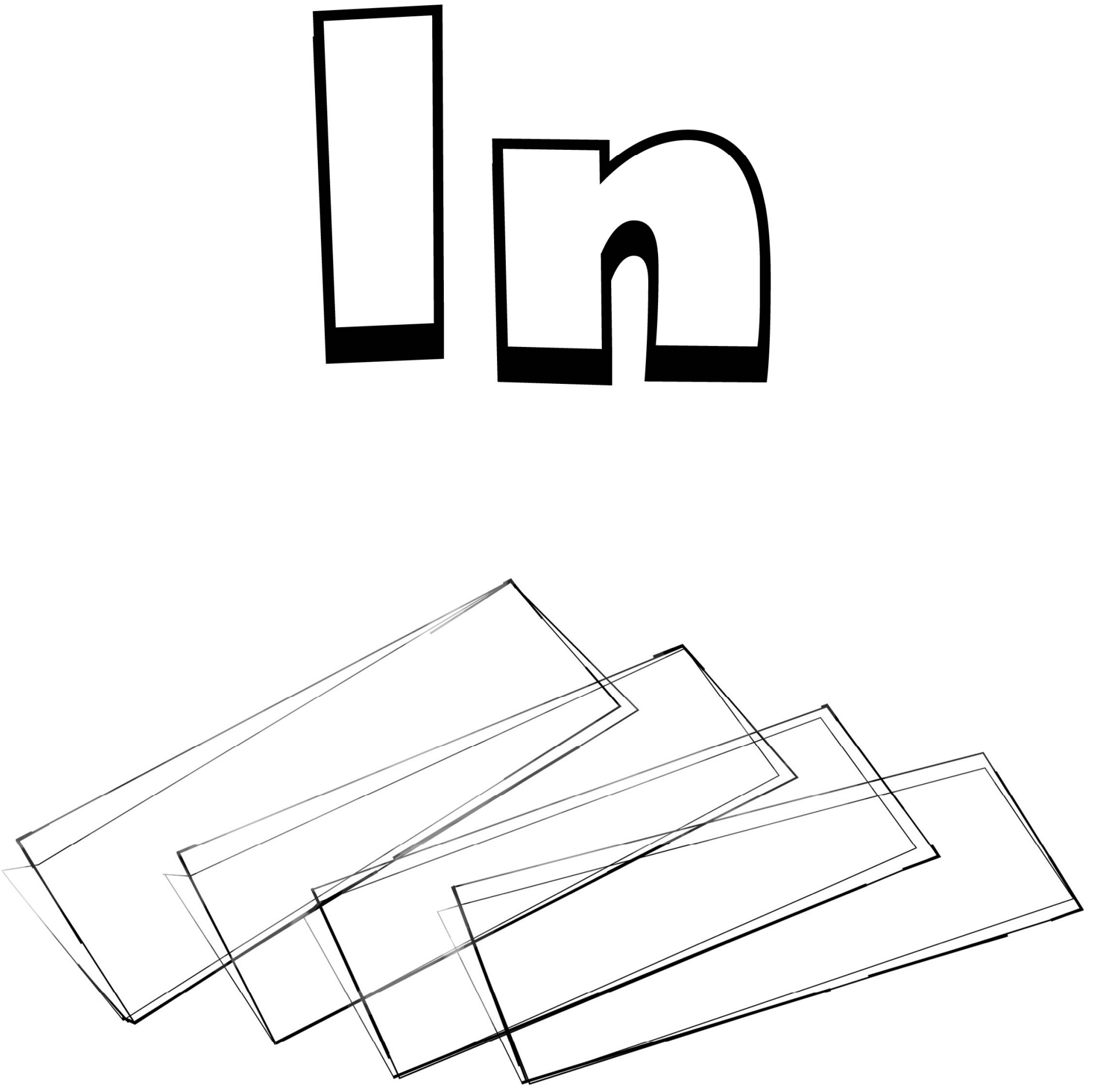


\section{0}
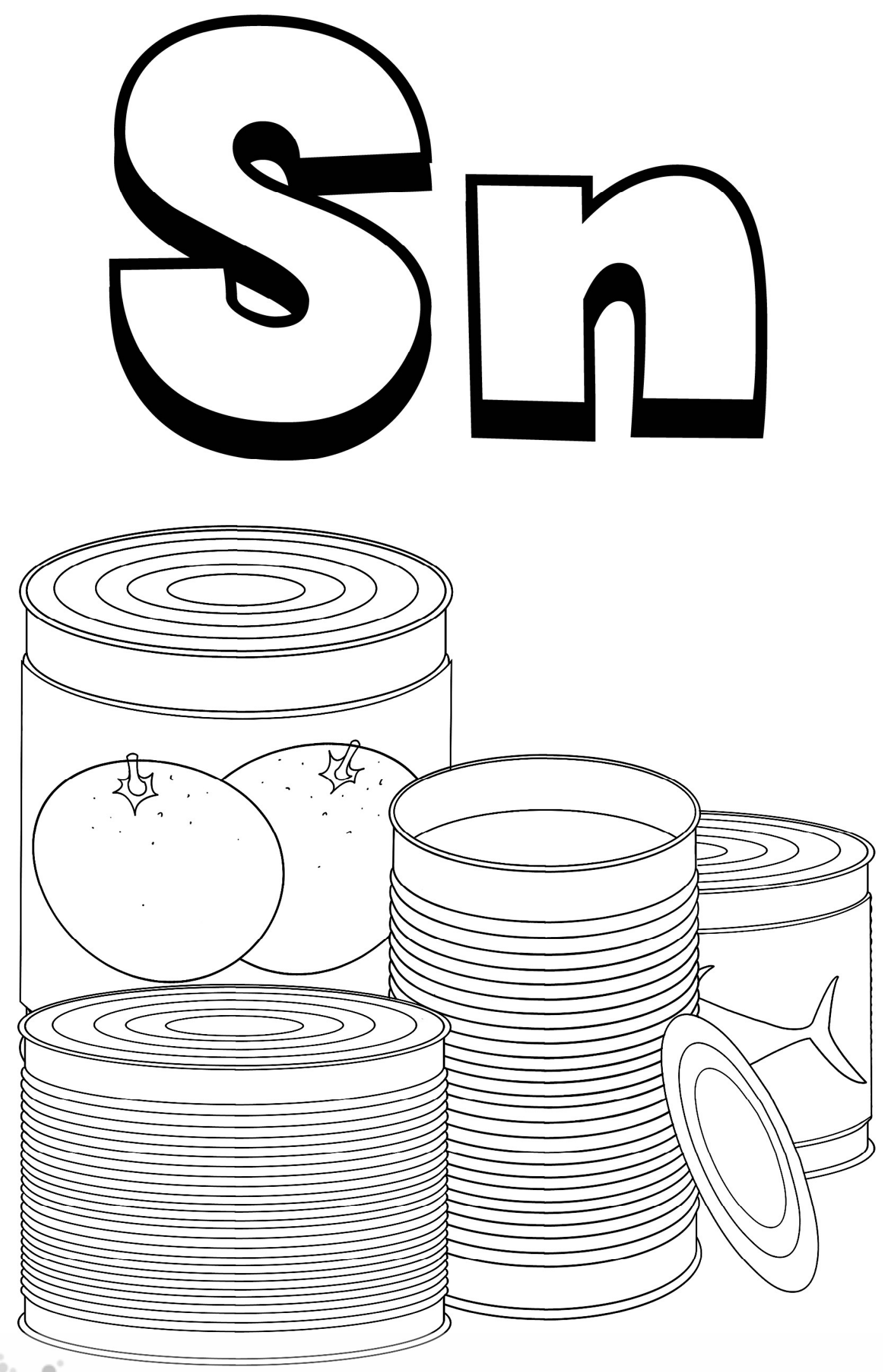


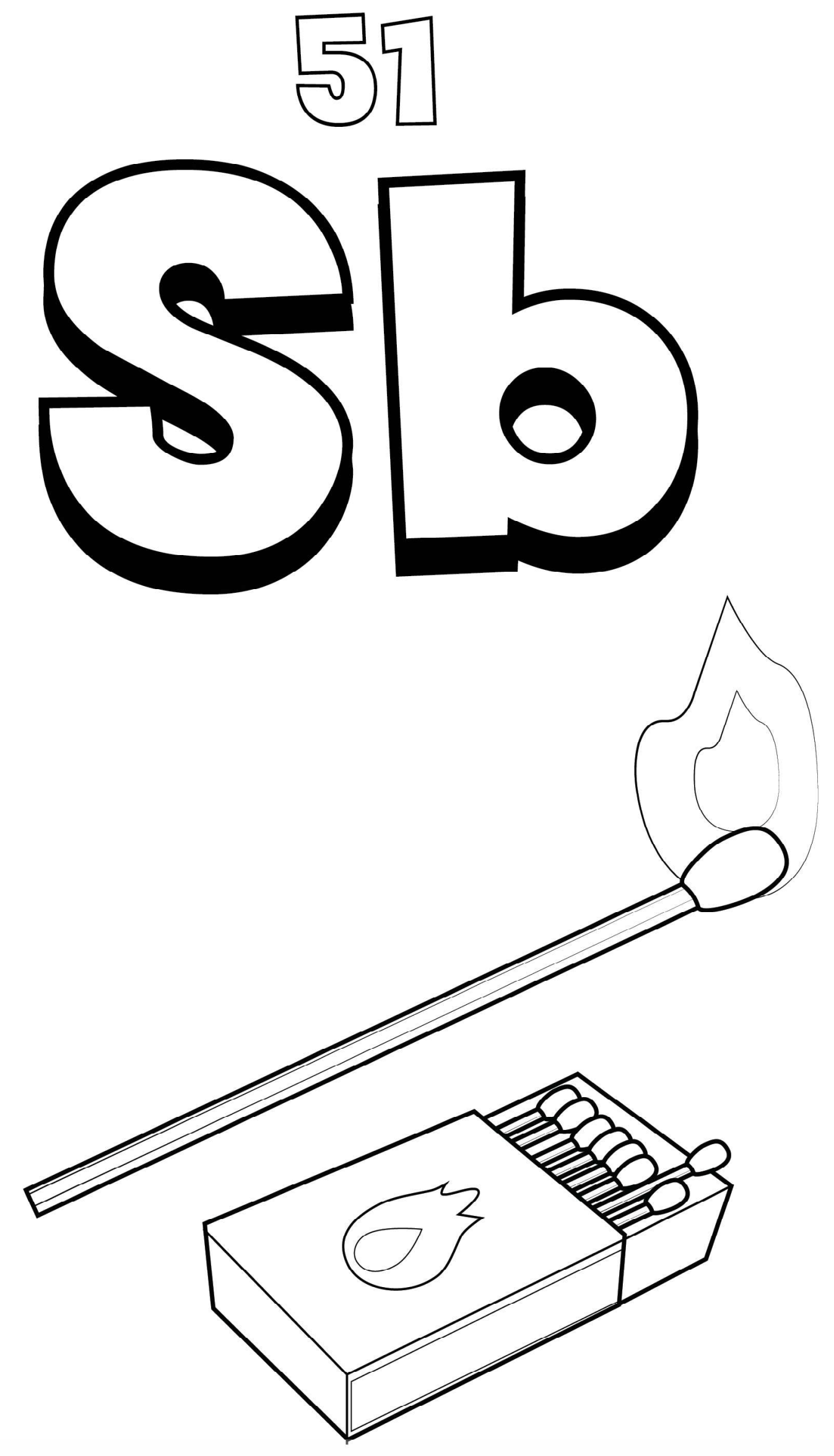




$$
52
$$
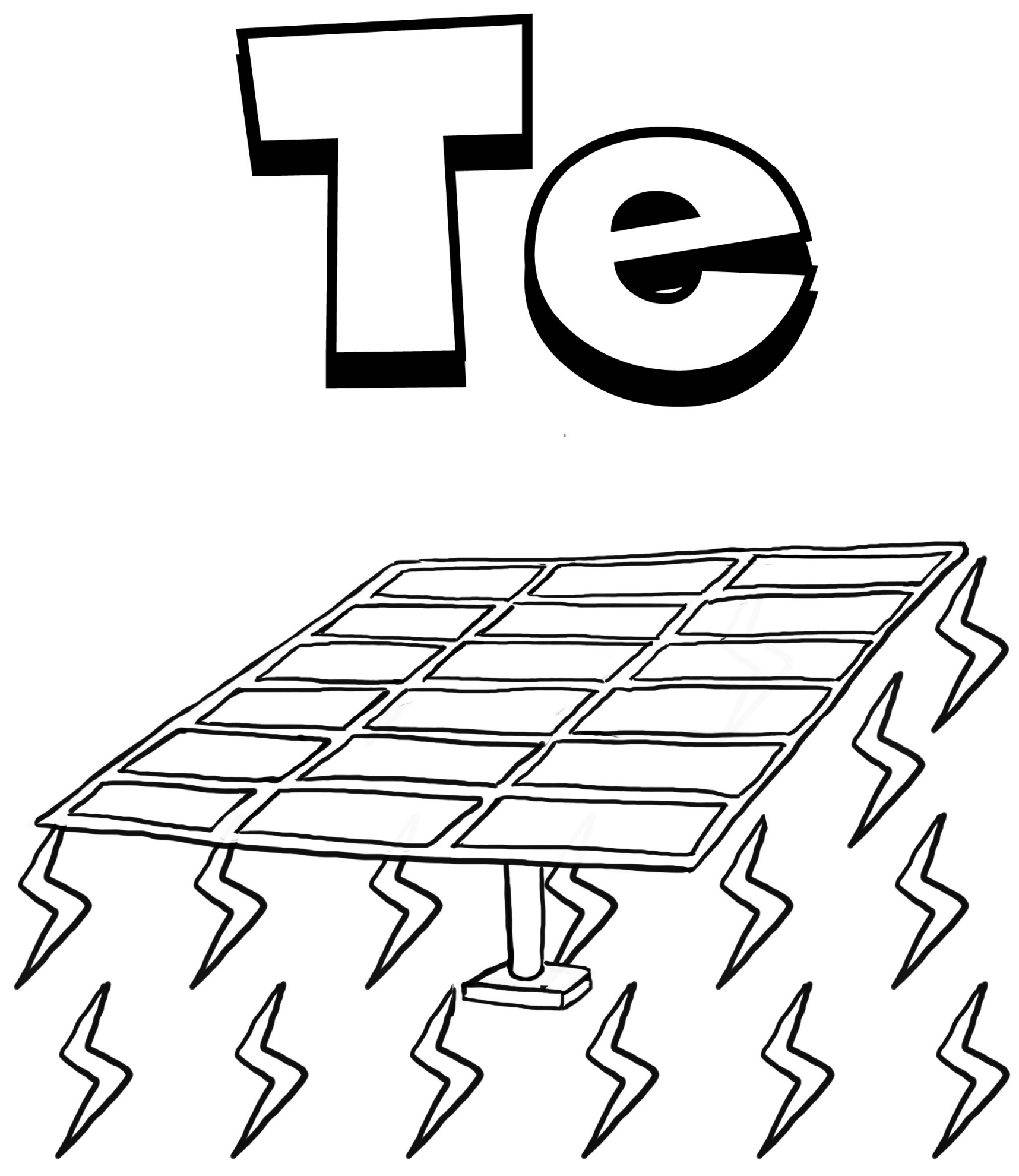

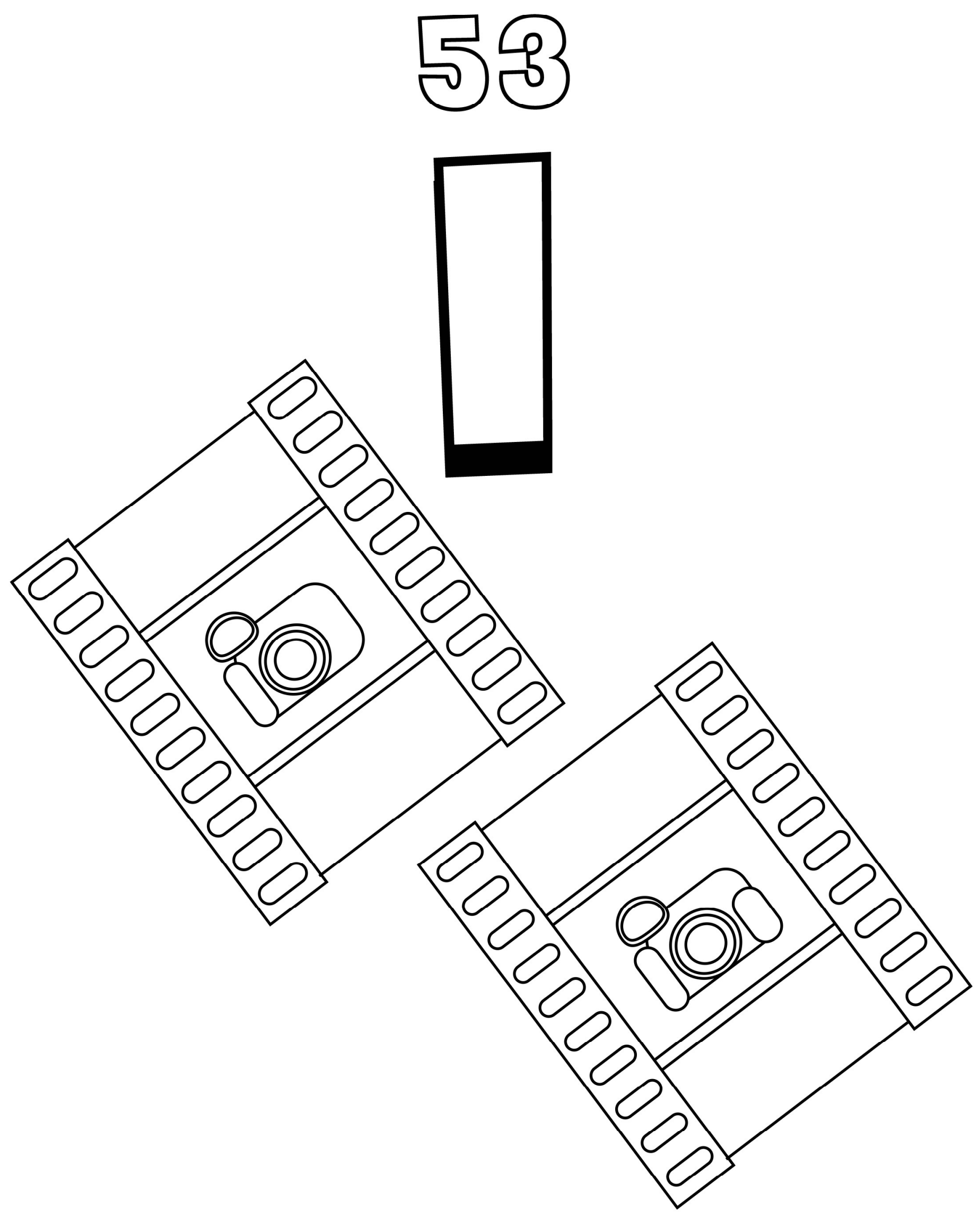


$$
54
$$
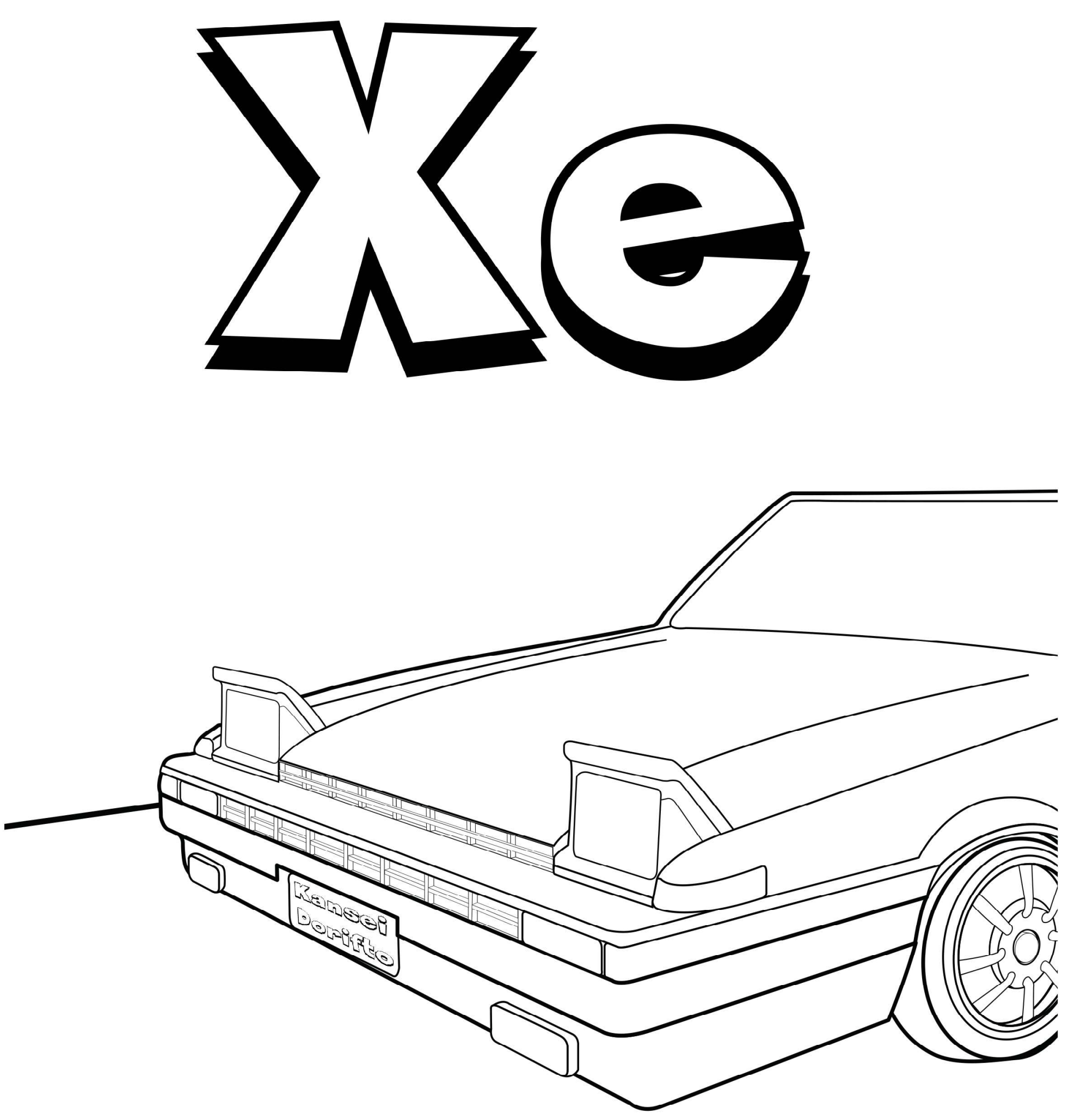


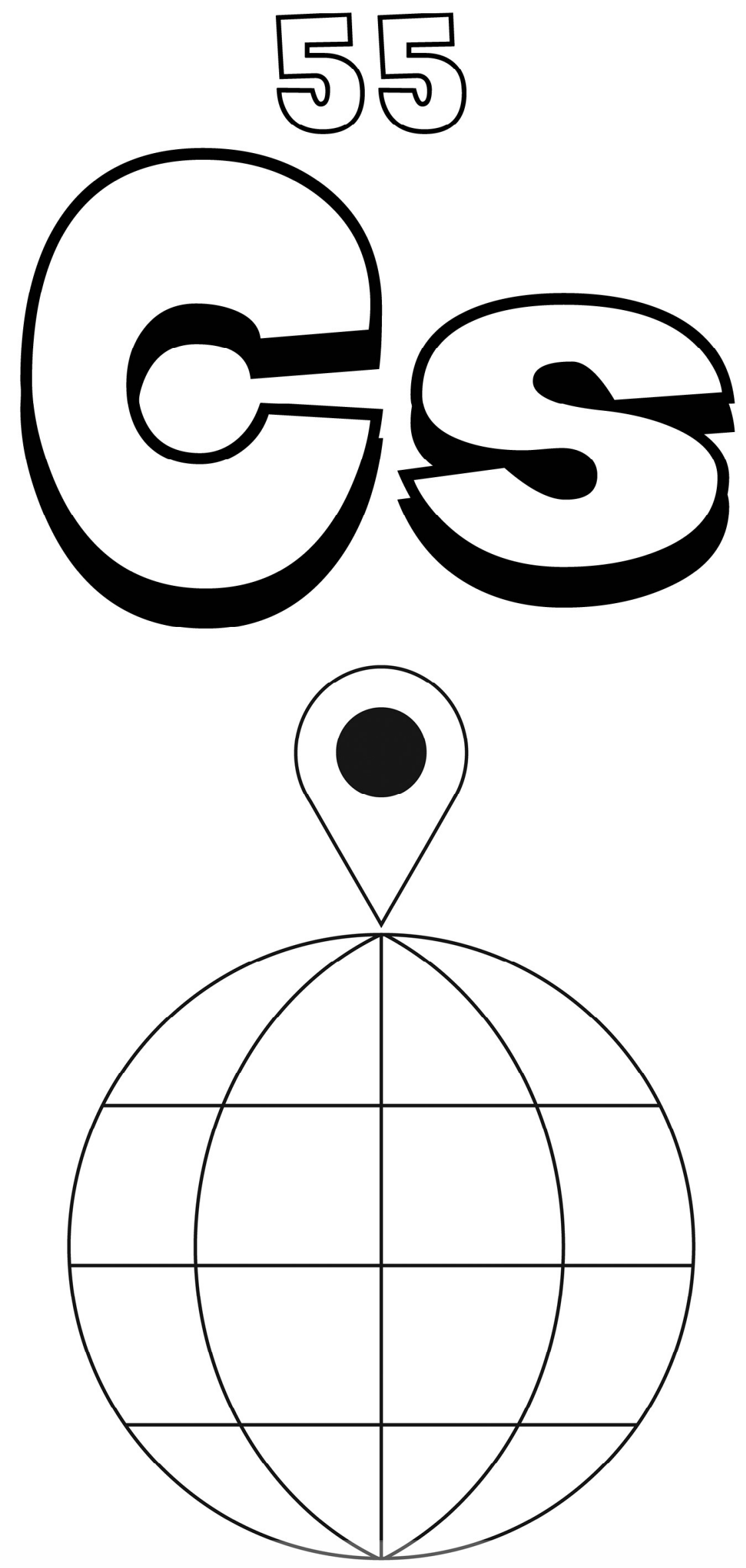




$$
50
$$
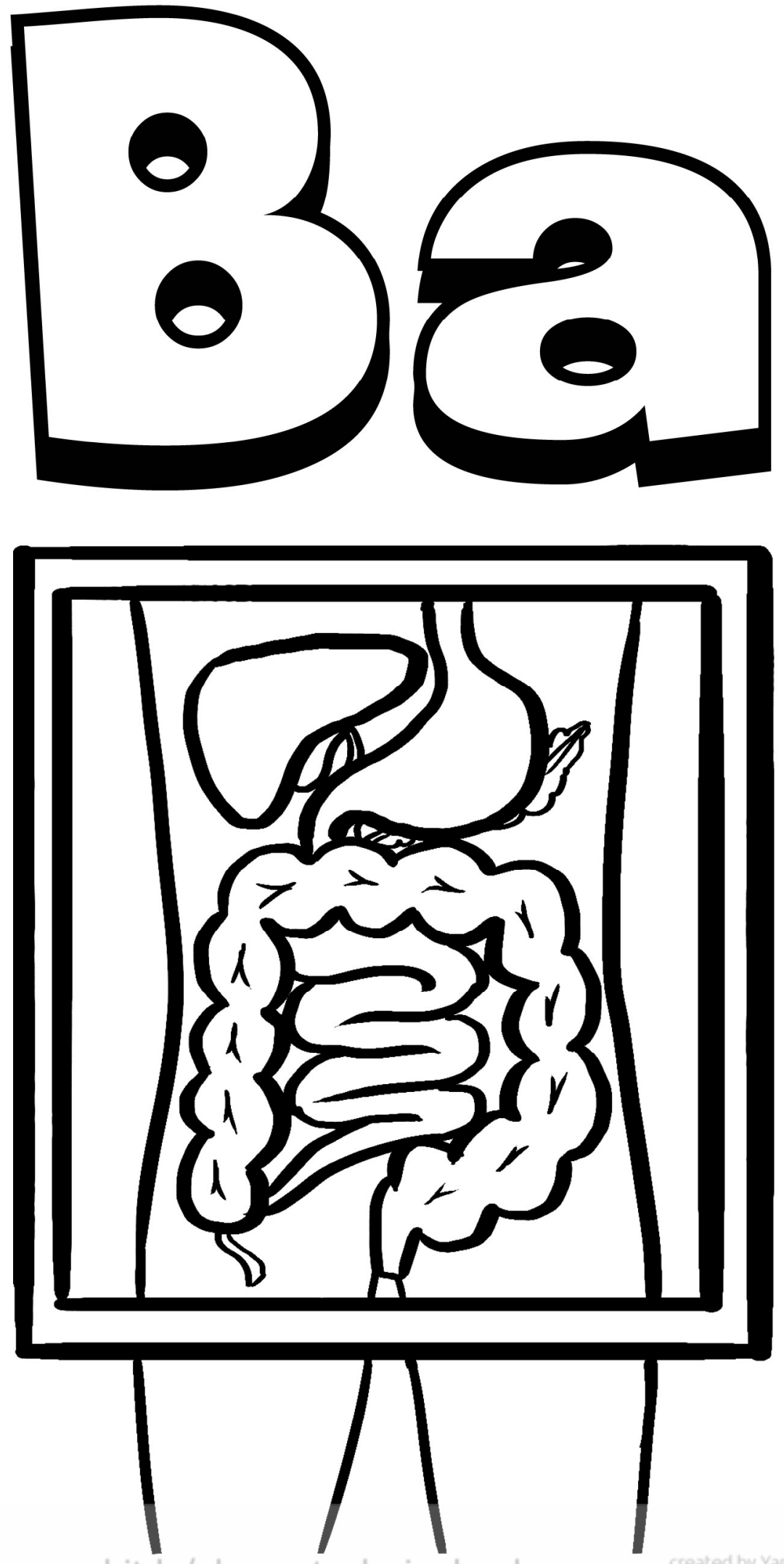


$$
\begin{array}{r}
80 \\
60
\end{array}
$$




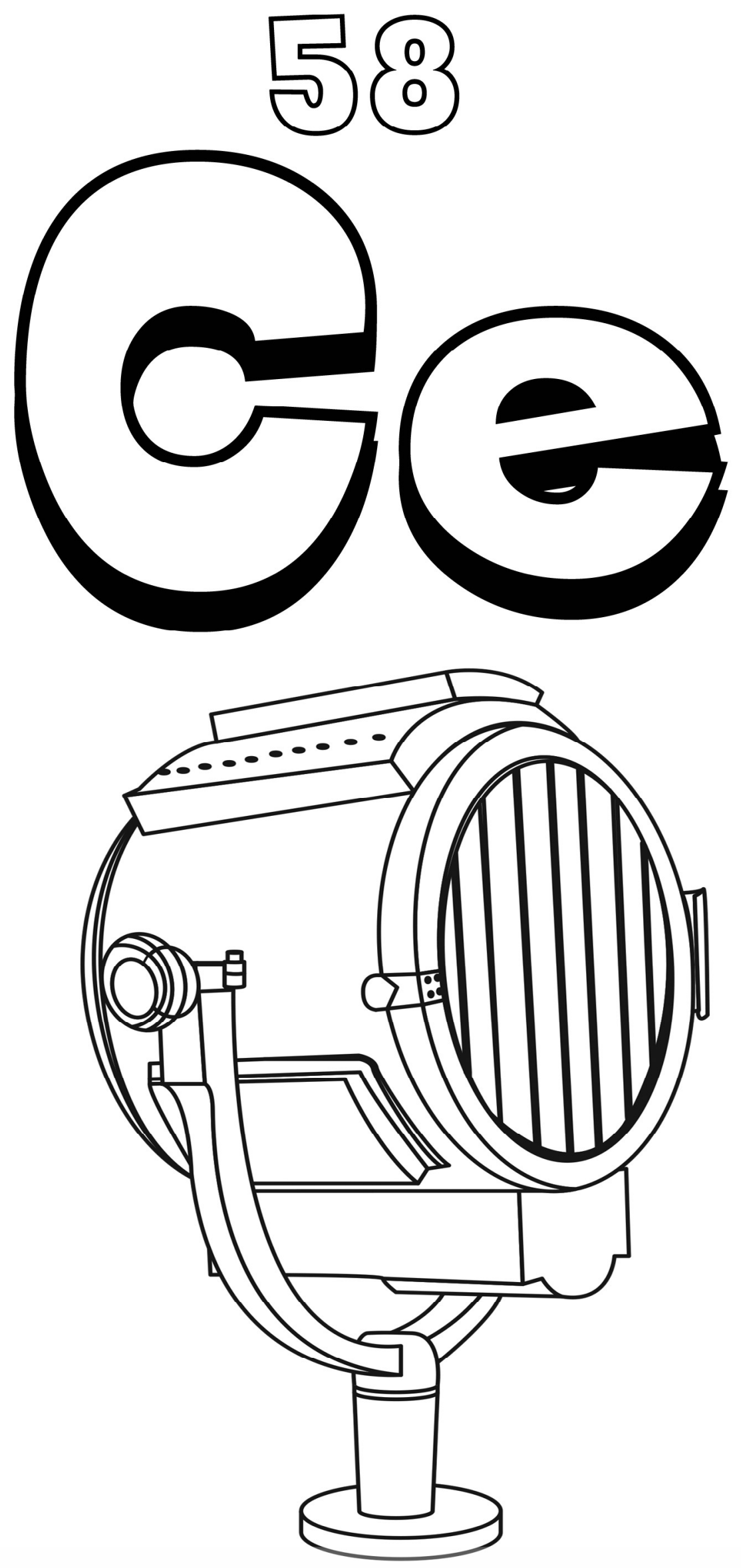




$$
50
$$
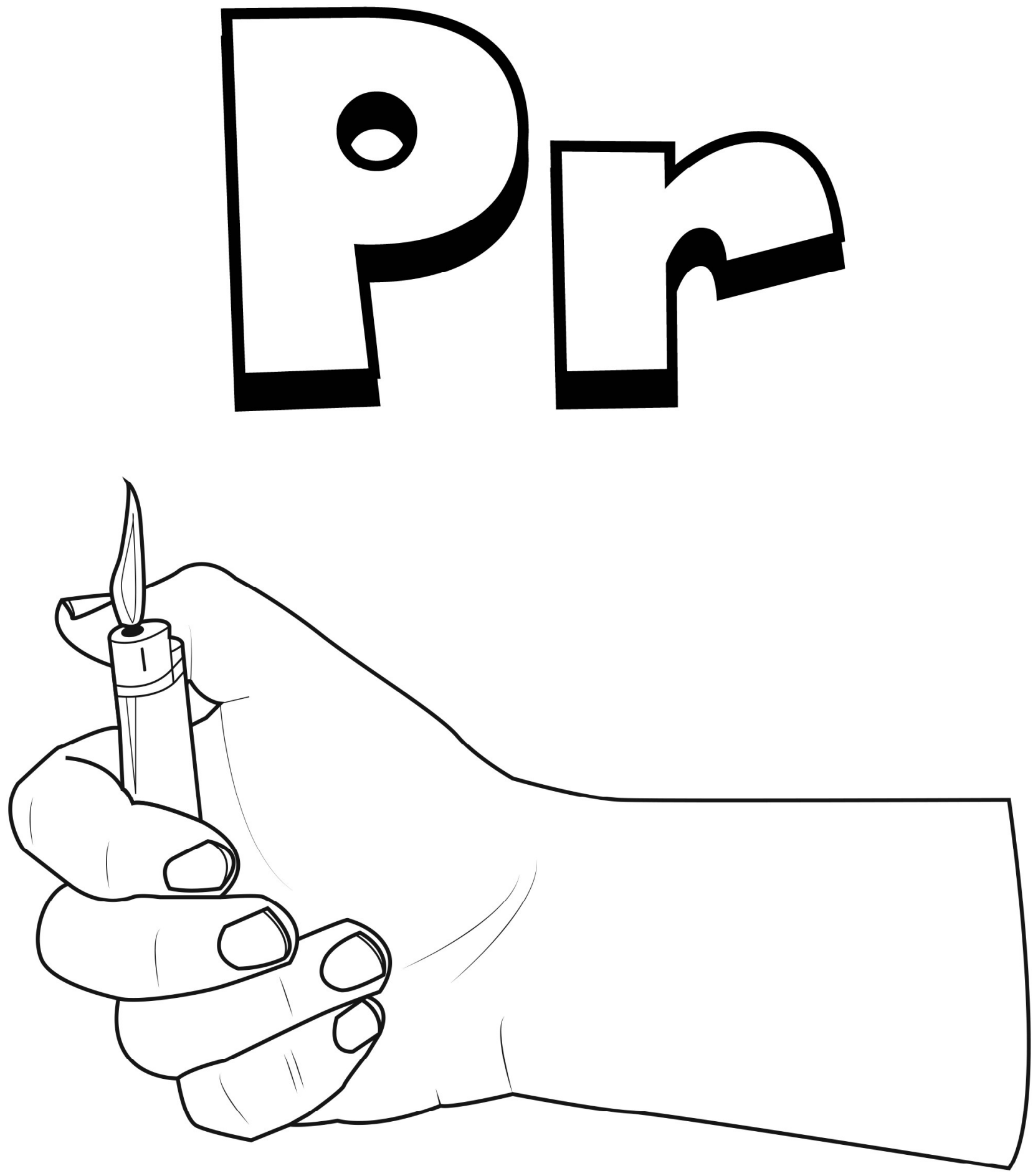


$$
\text { ค0) }
$$
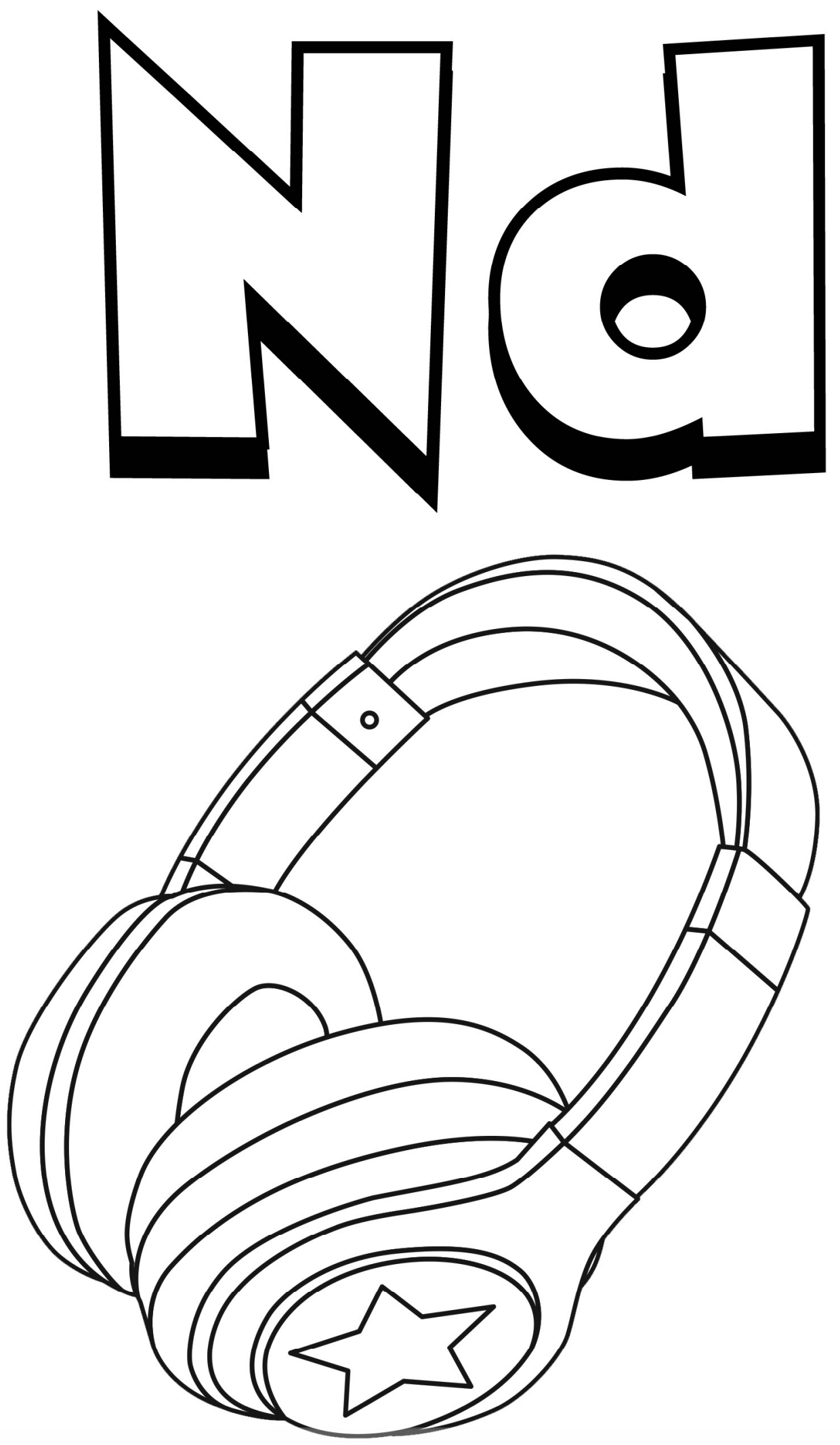


$$
\text { ๑ొ }
$$
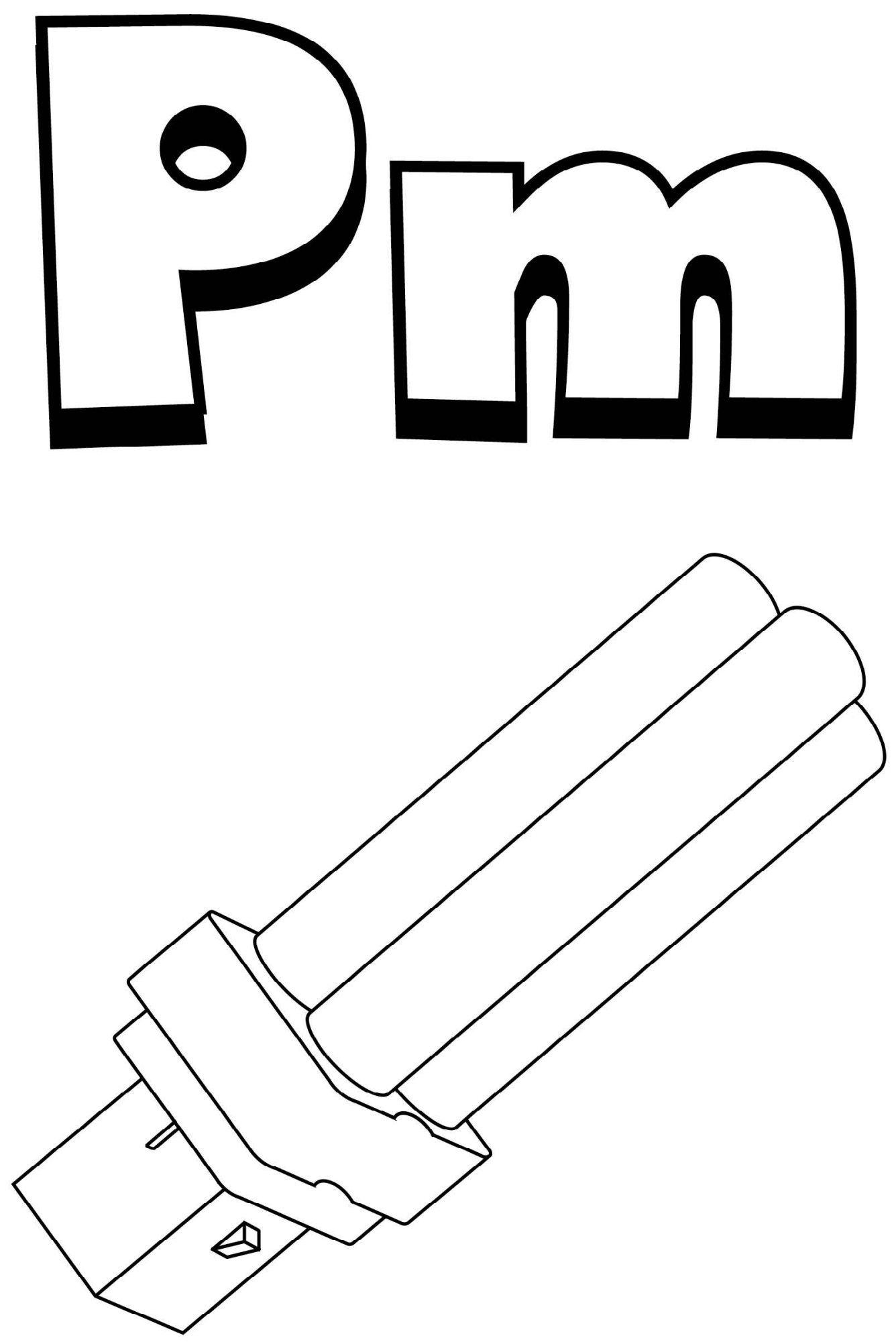


$$
\text { ๑2) }
$$
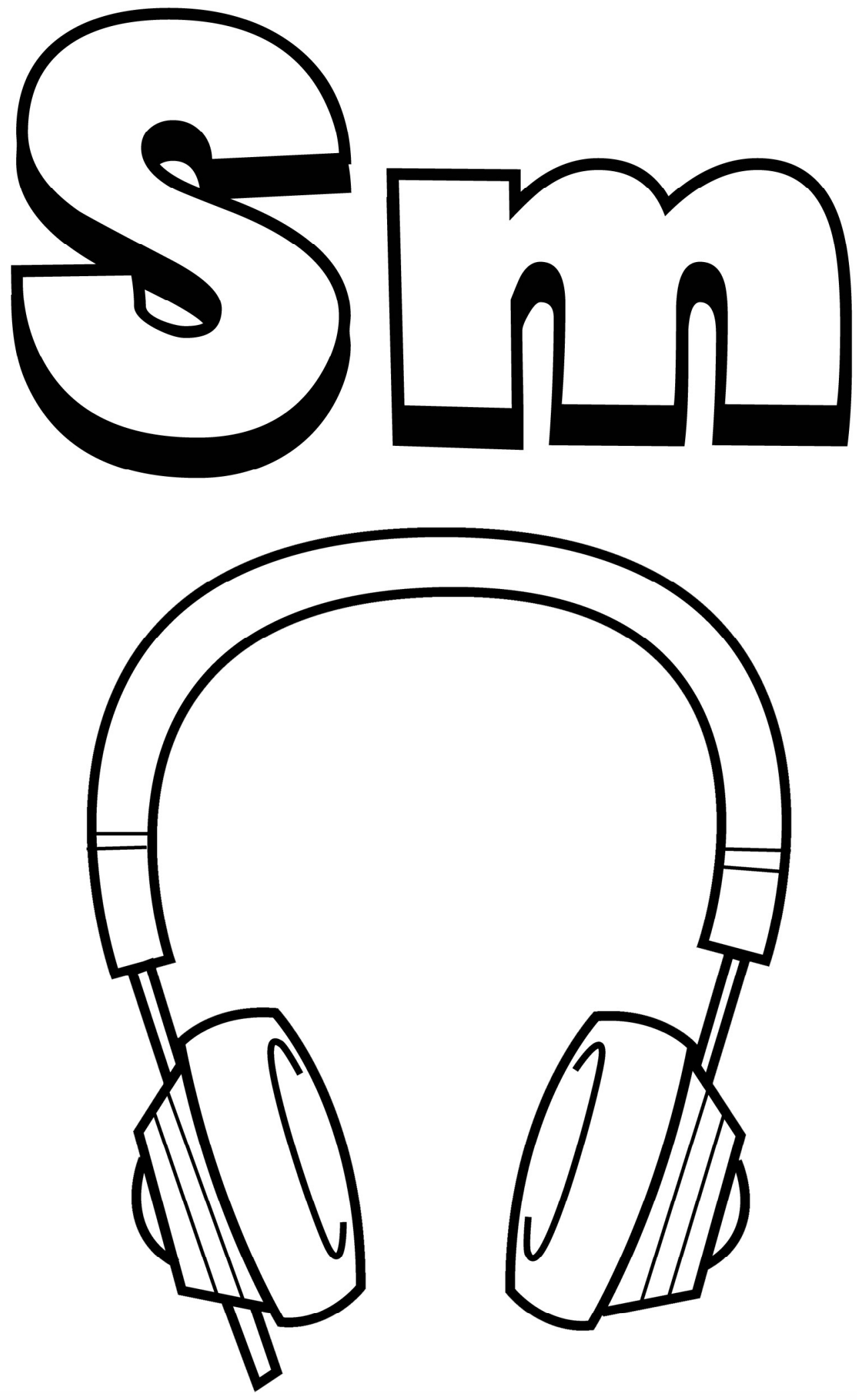


$$
\text { ๑ே) }
$$
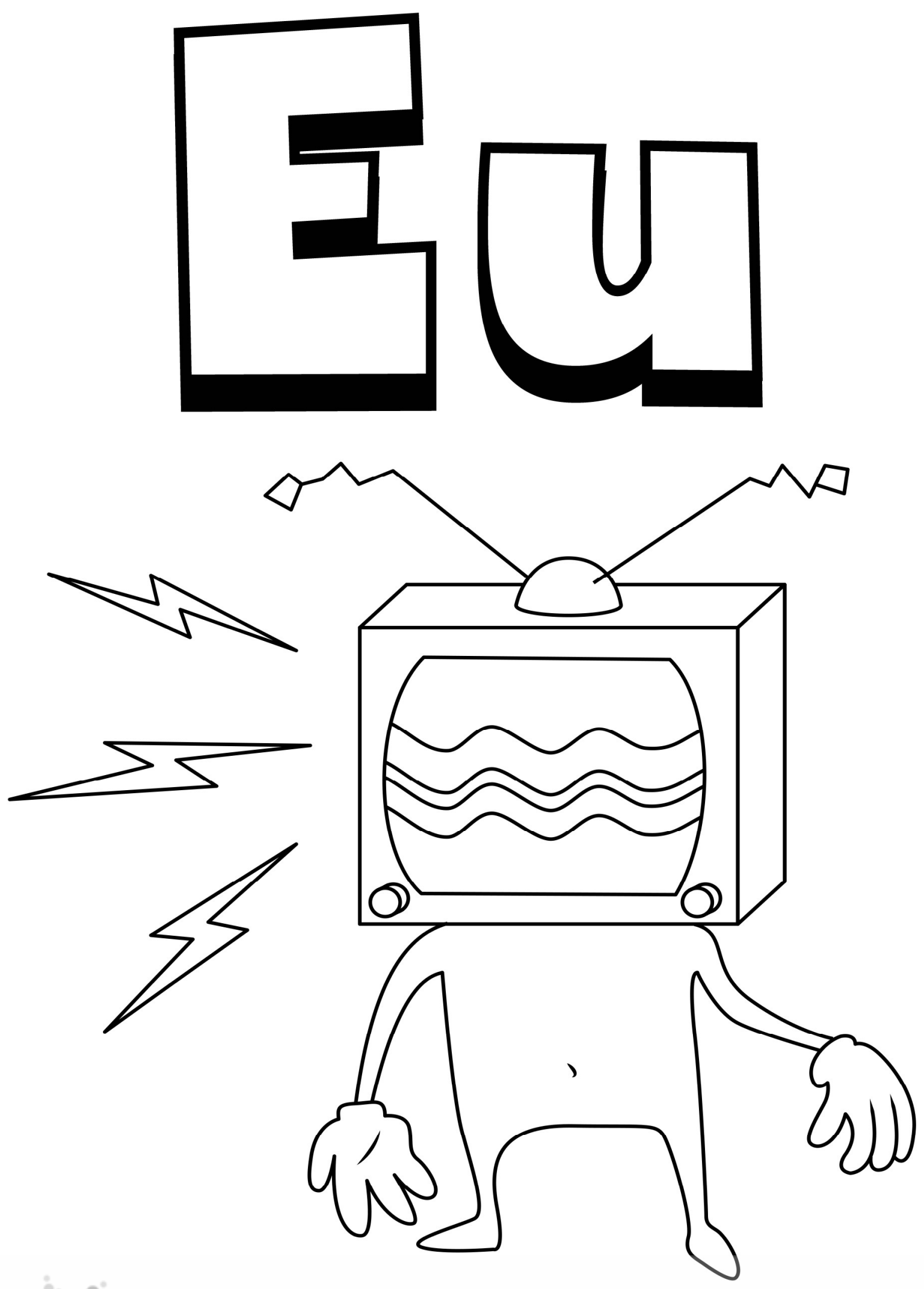


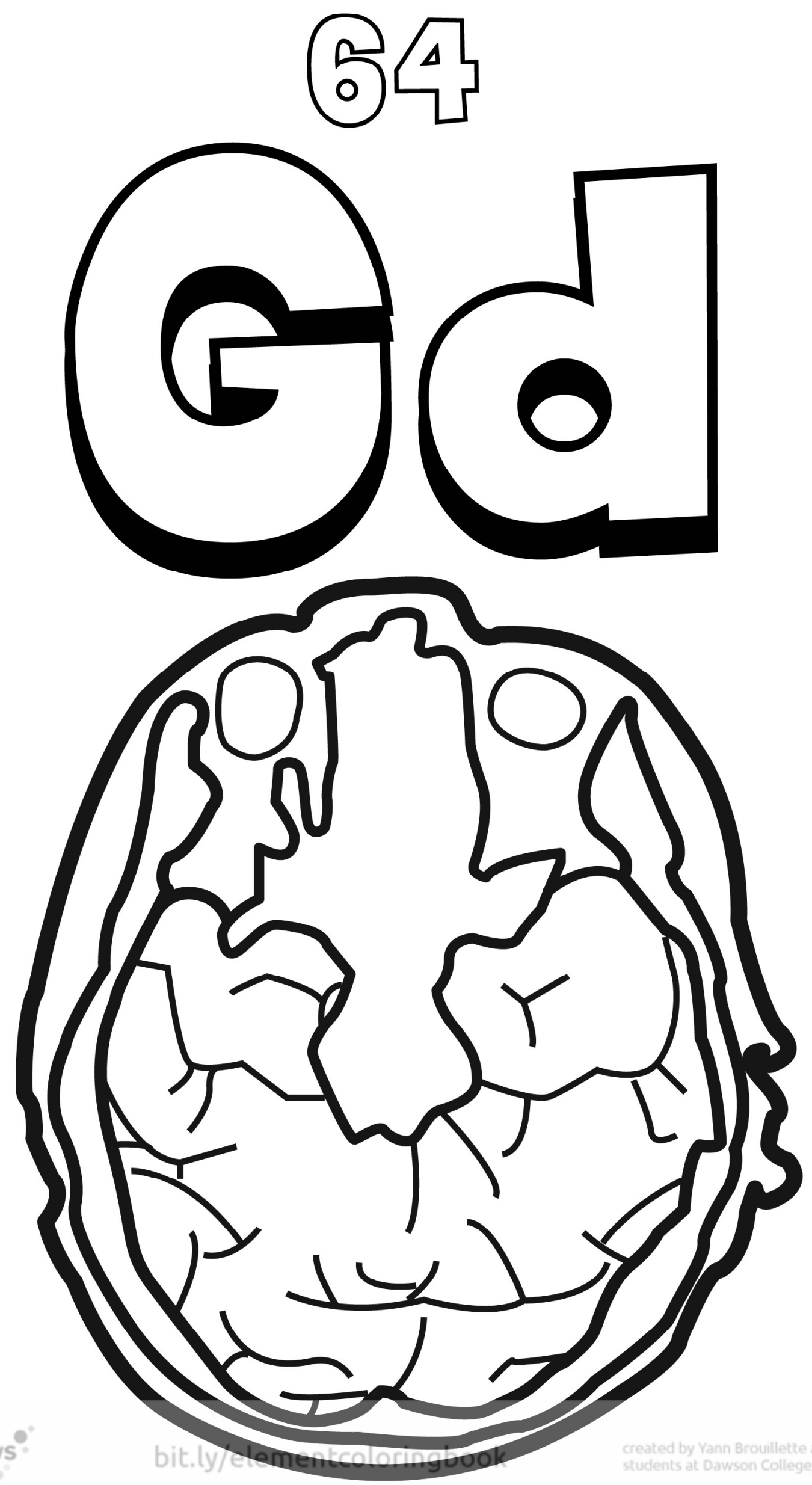




$$
\text { ๑5 }
$$

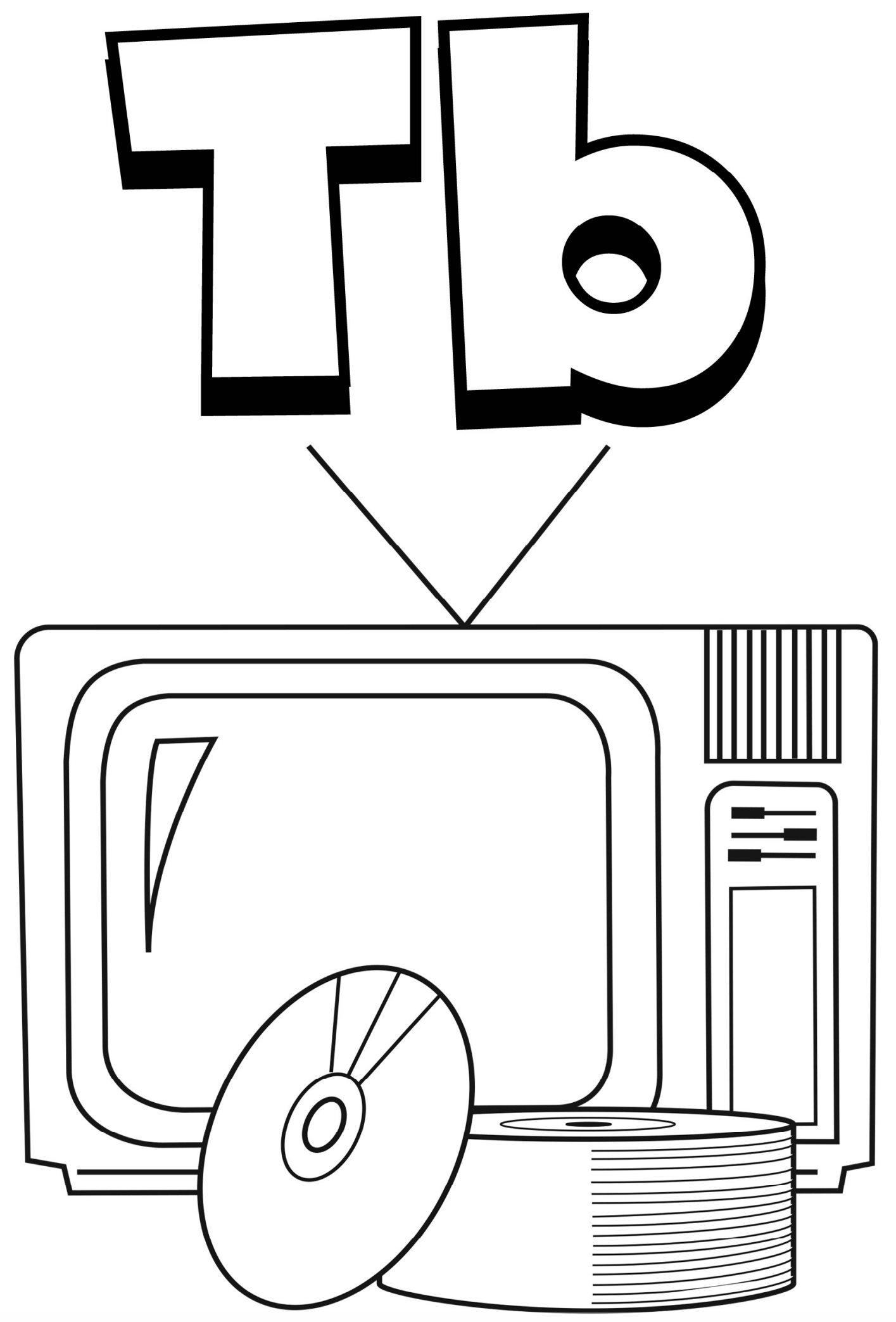




$$
D_{r y}^{\infty}
$$




$$
04
$$
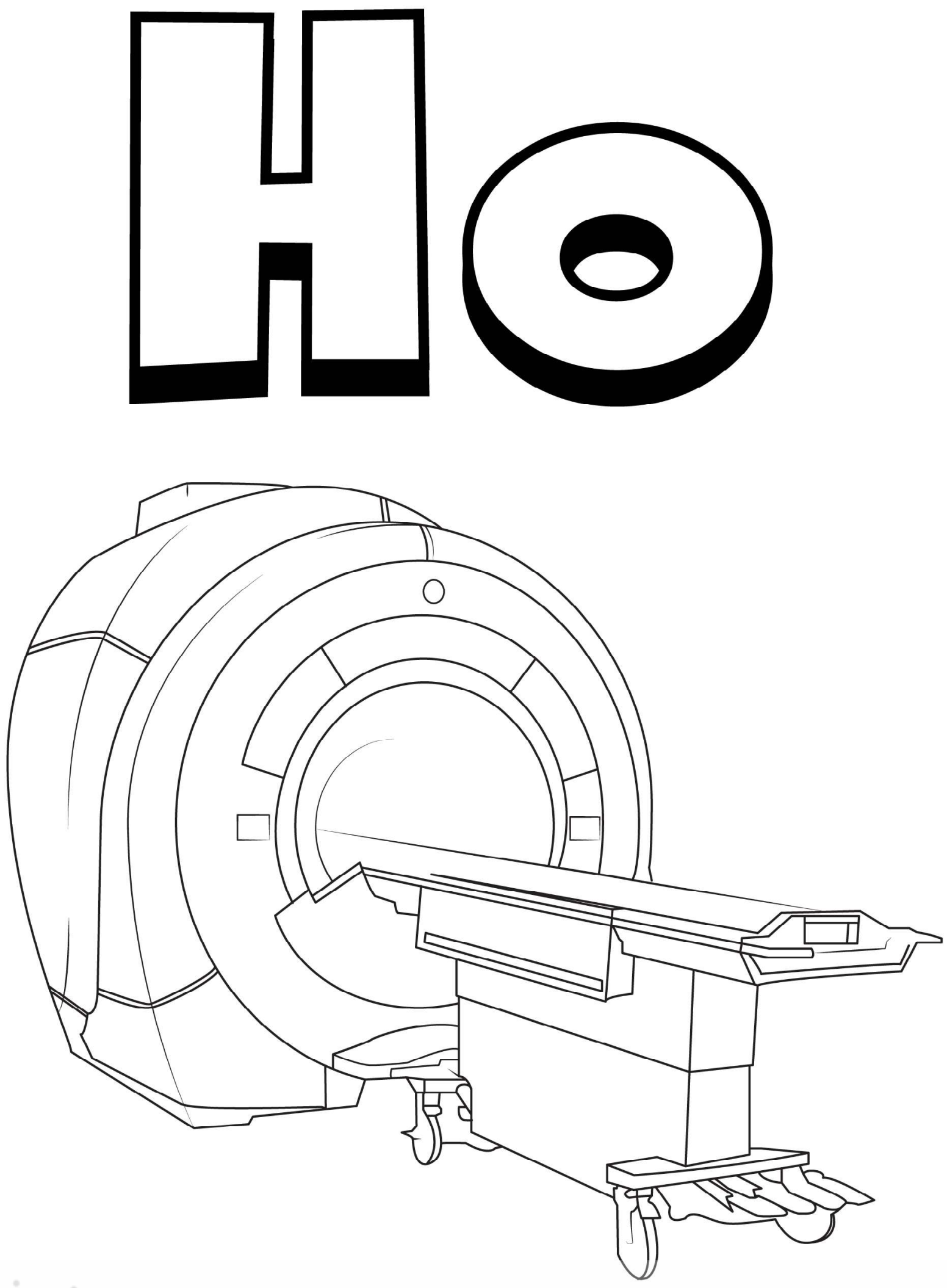


$$
\text { ๑ே0 }
$$
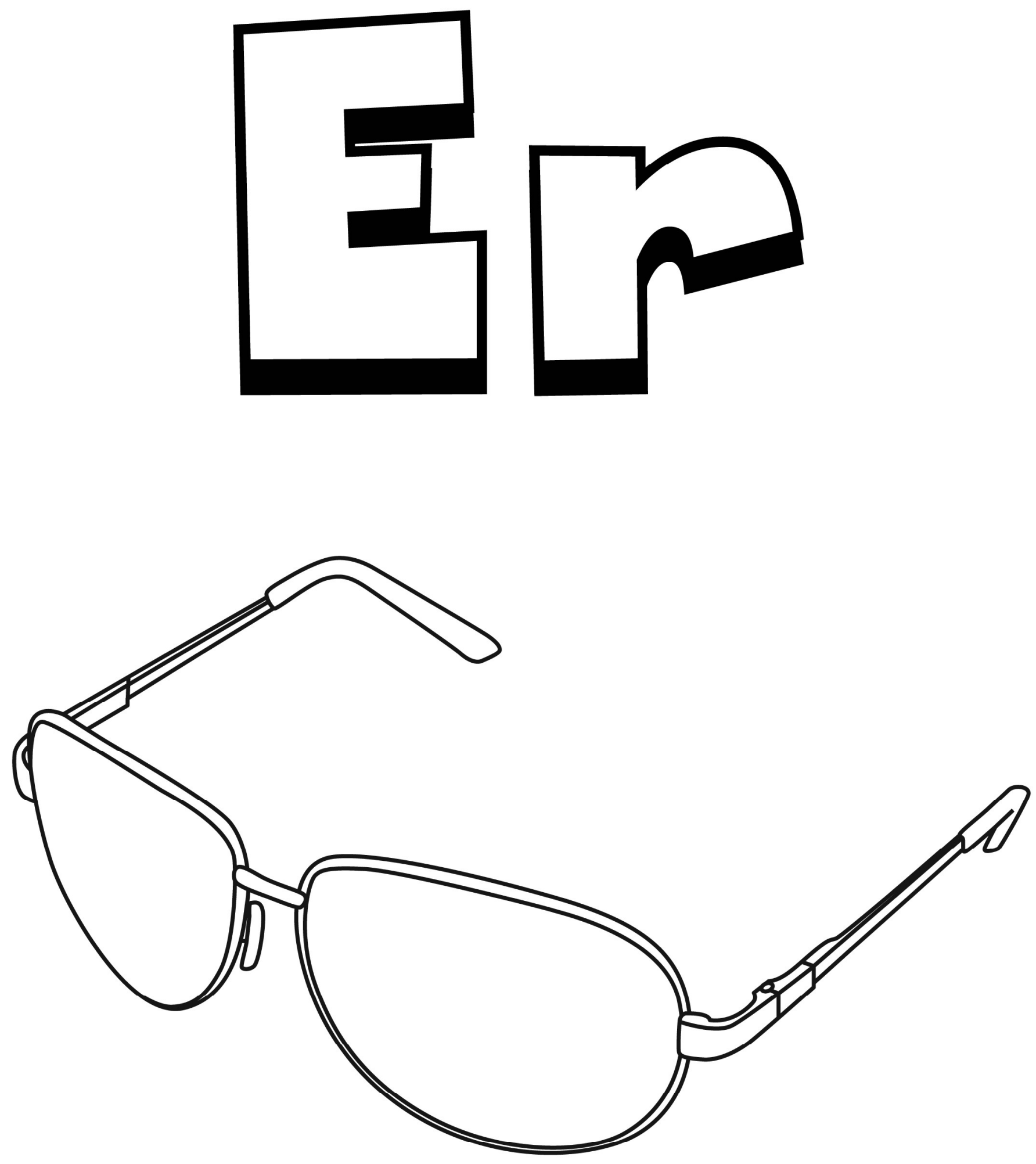


\section{ஒீல}
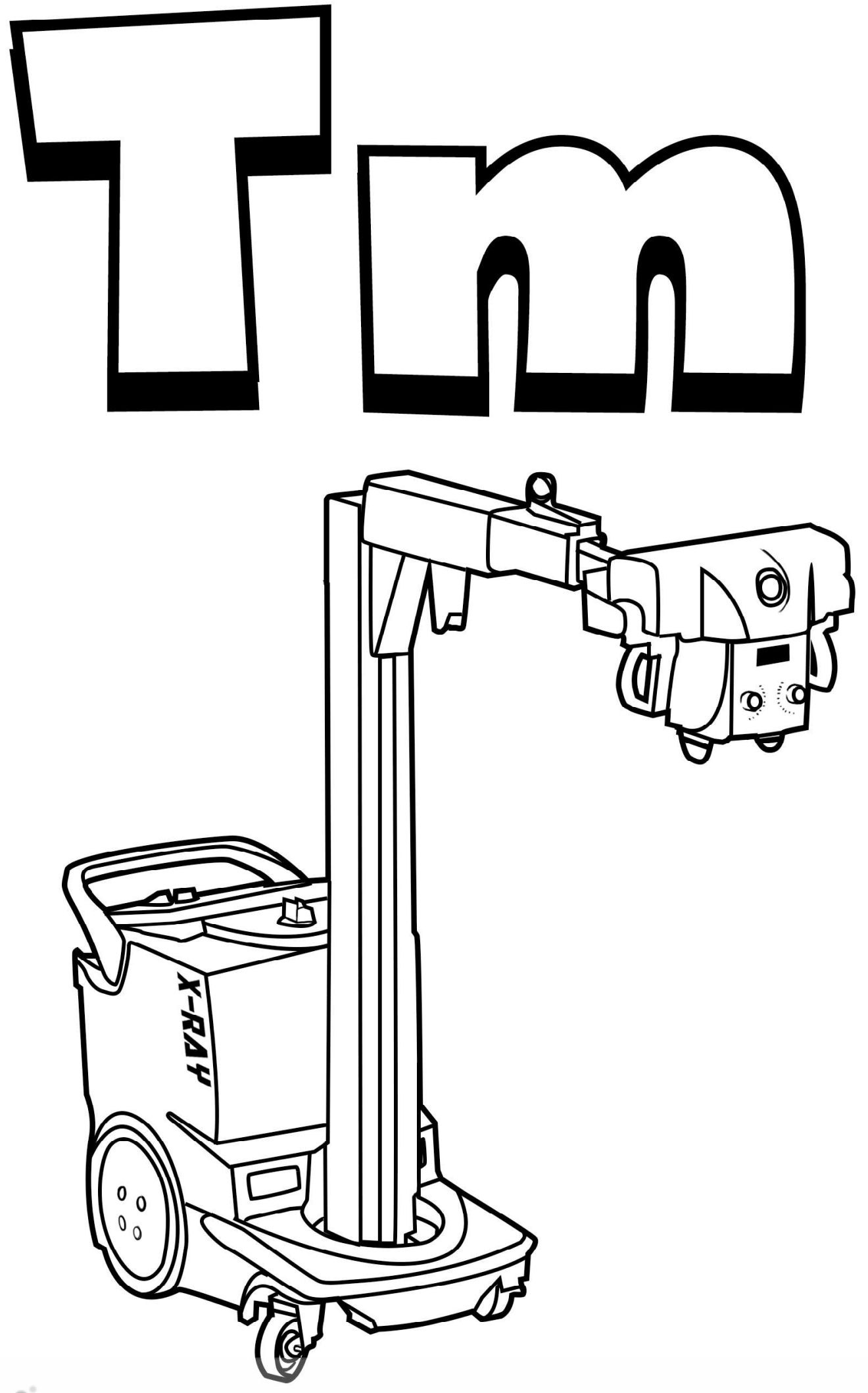


\section{0}
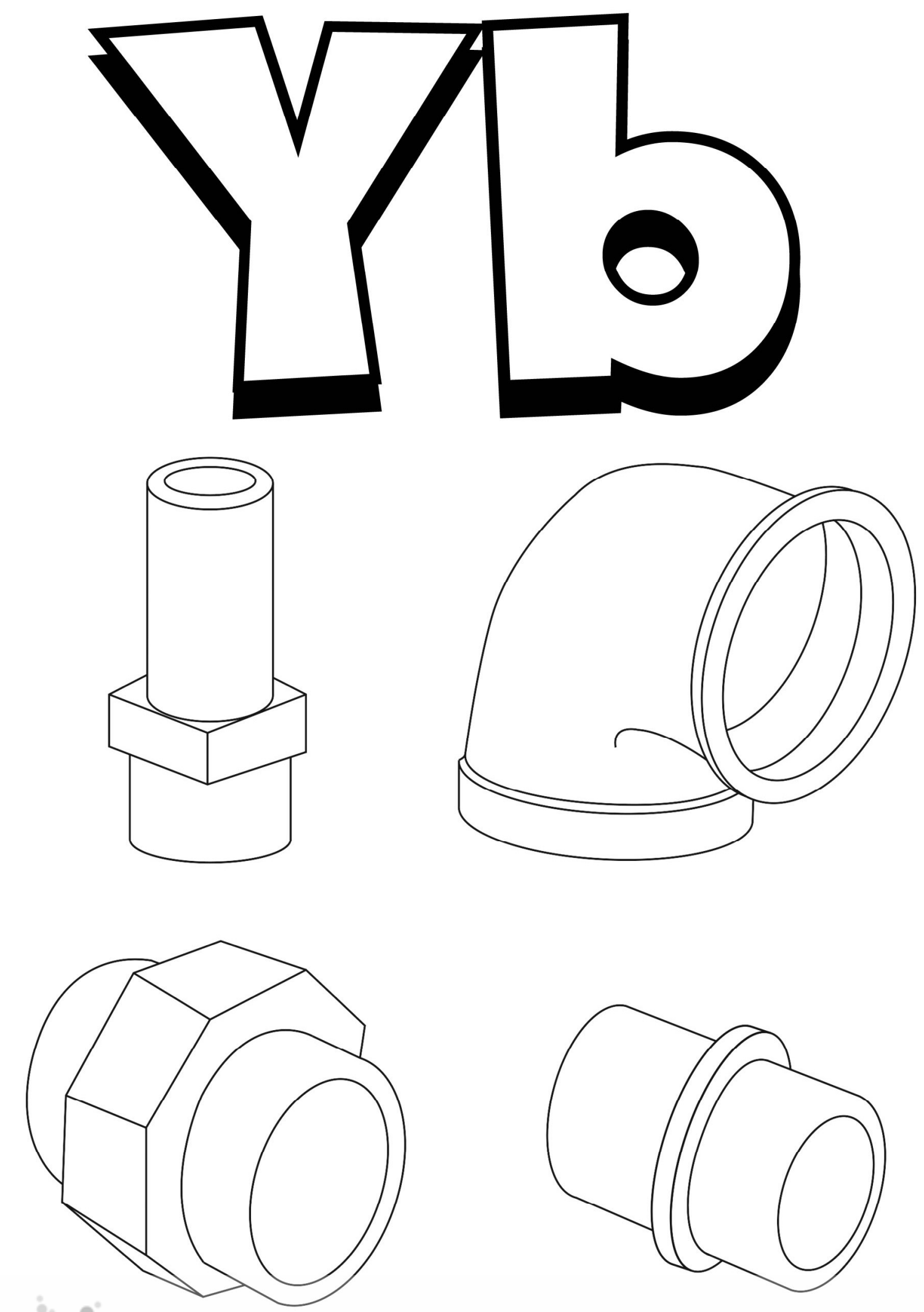

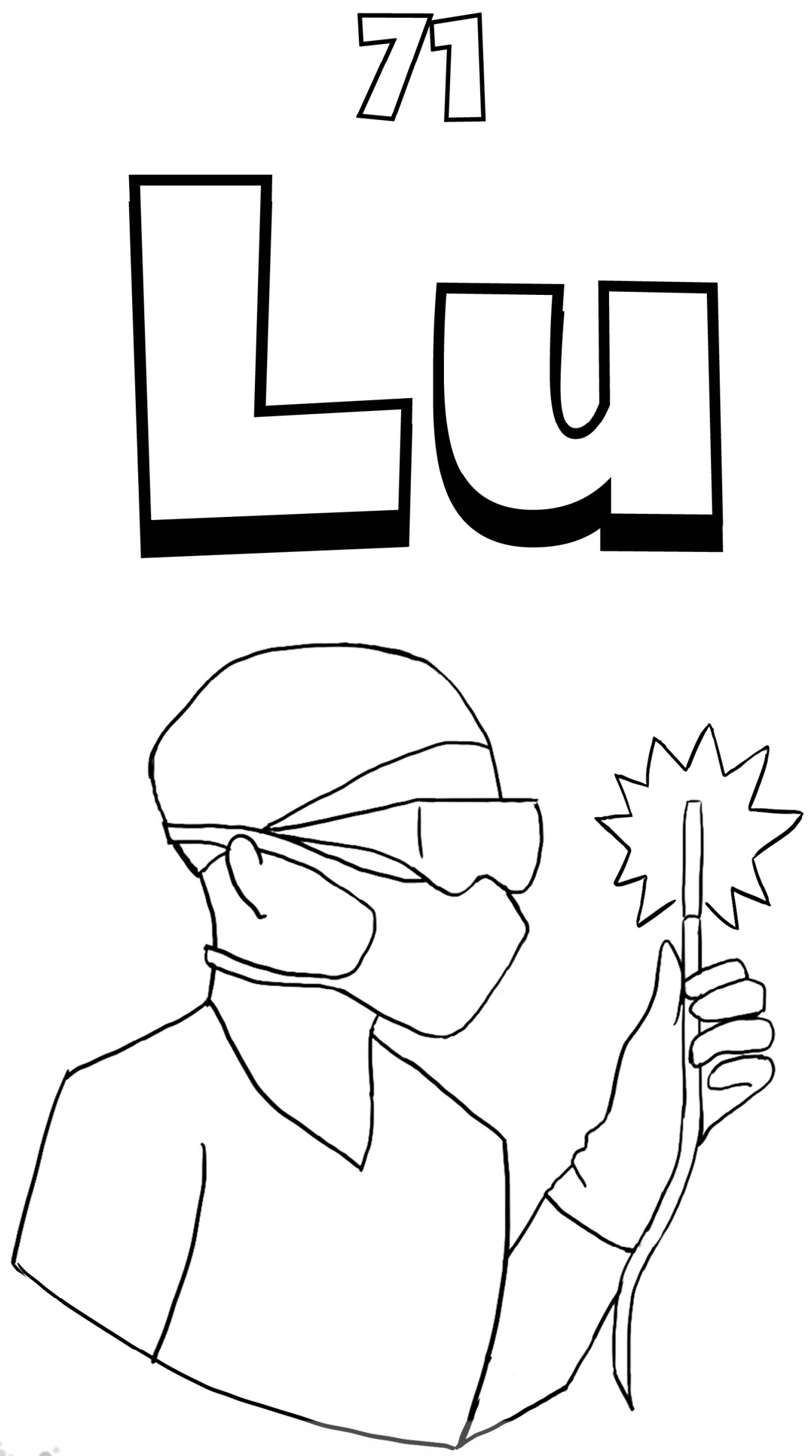

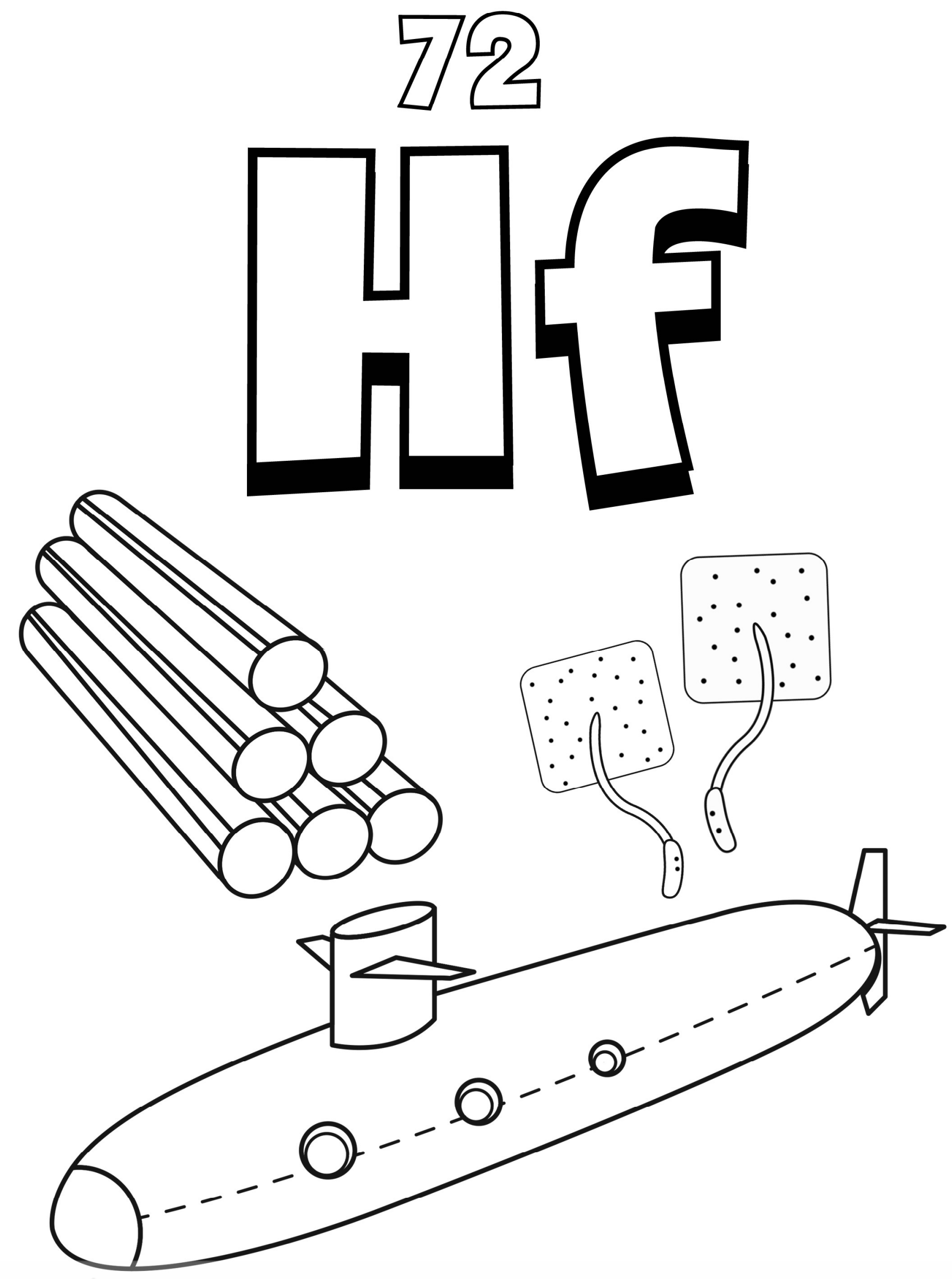


$$
\text { 7/8 }
$$
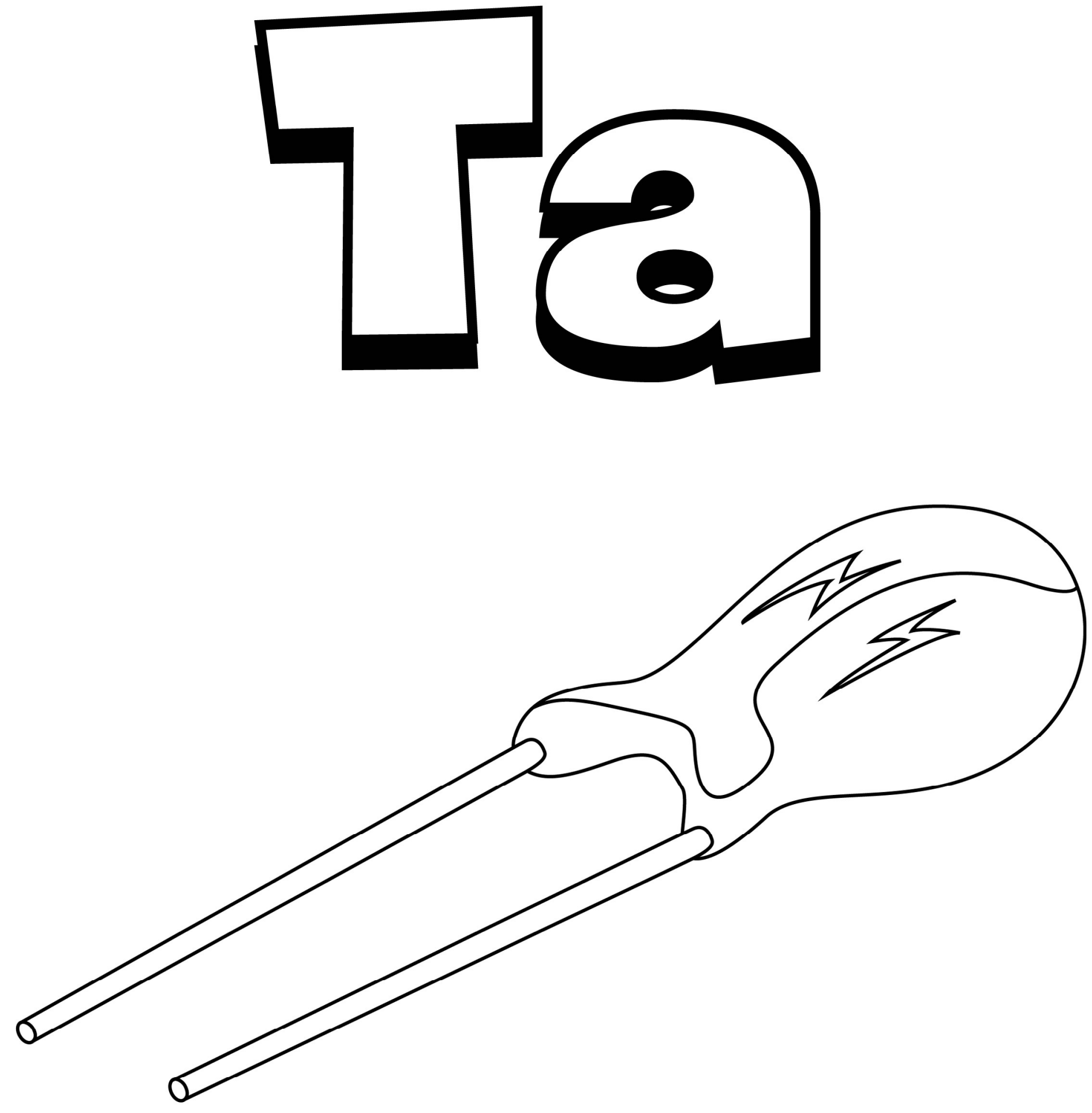


\section{4}
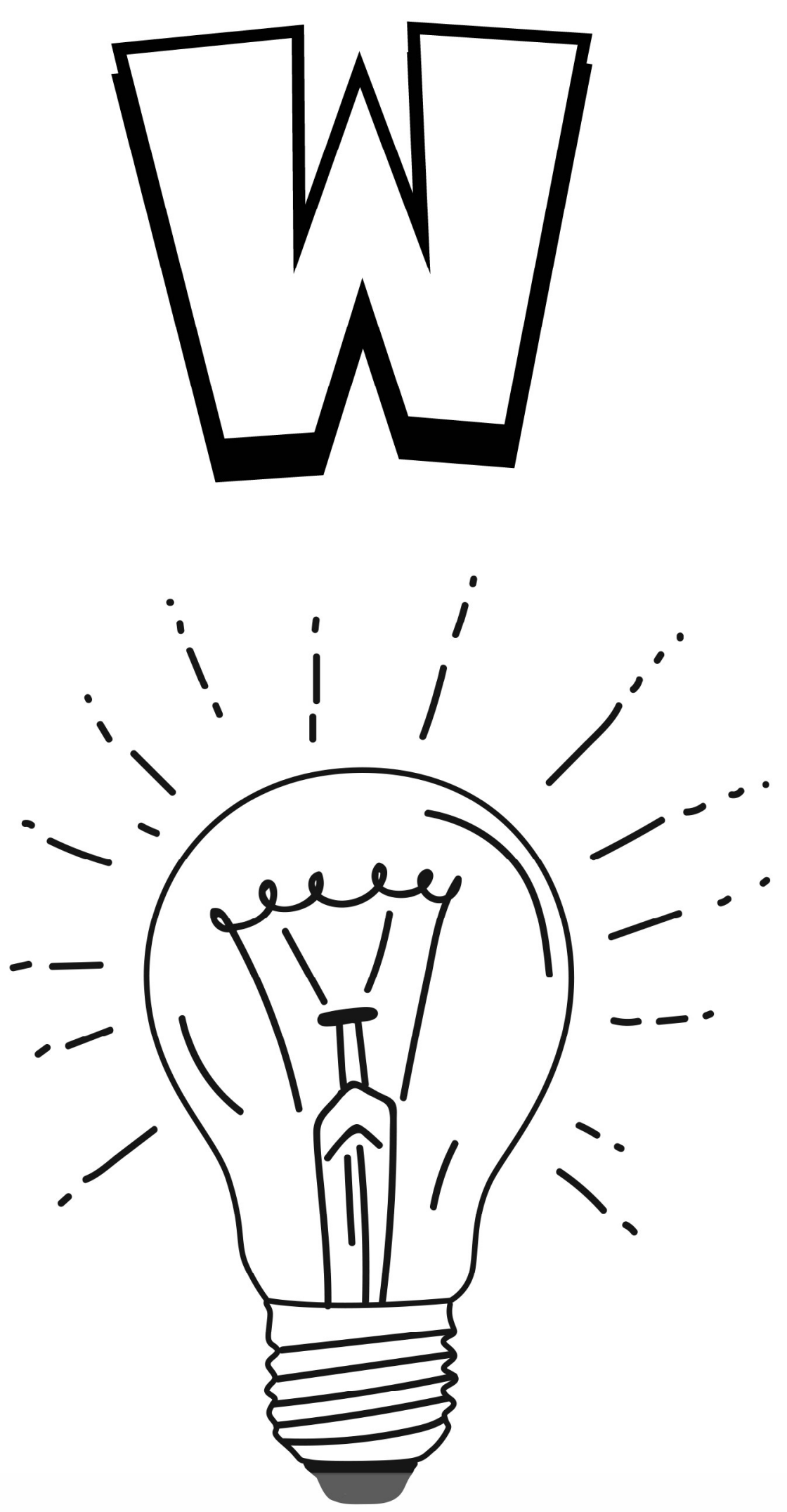


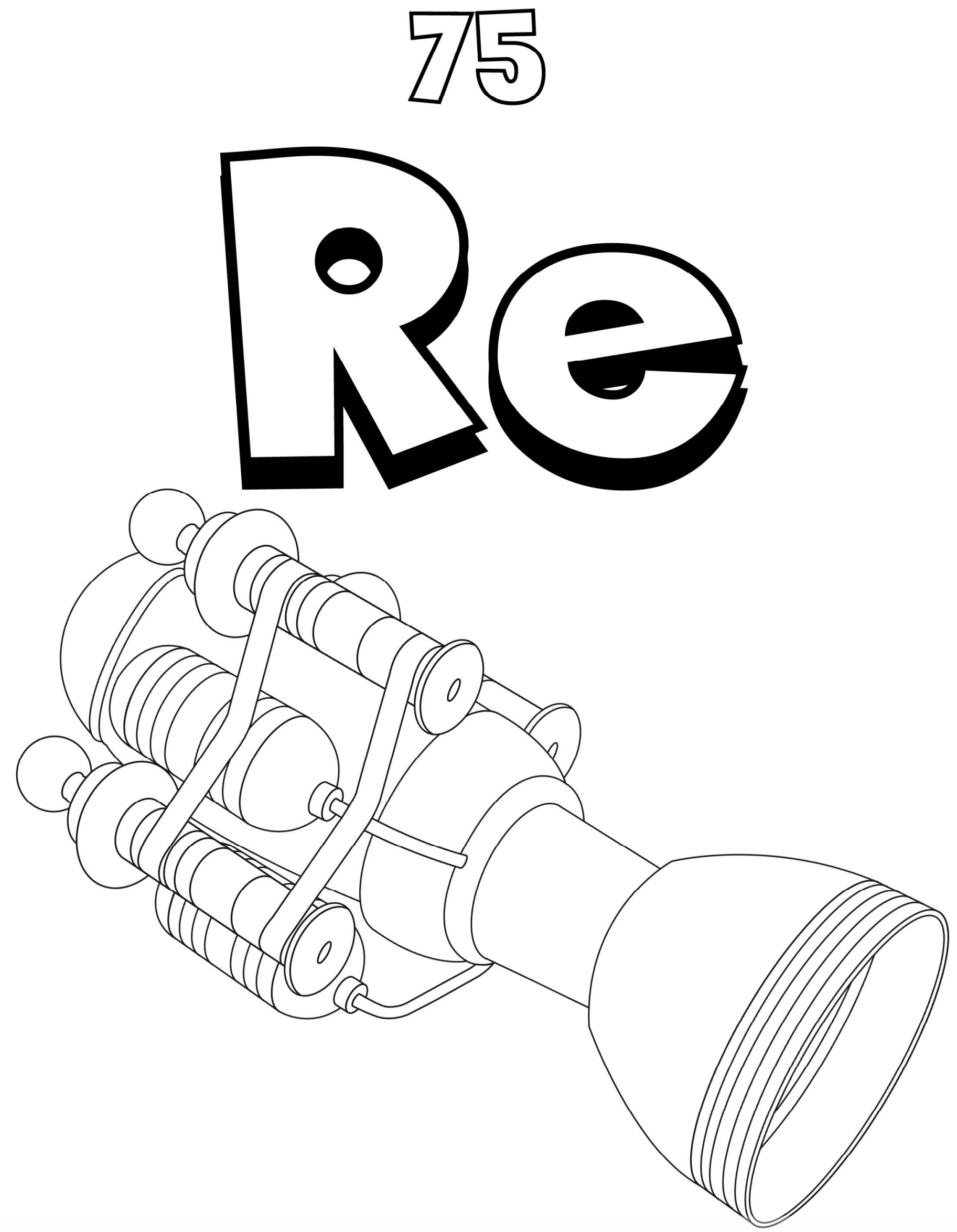




\section{7)}
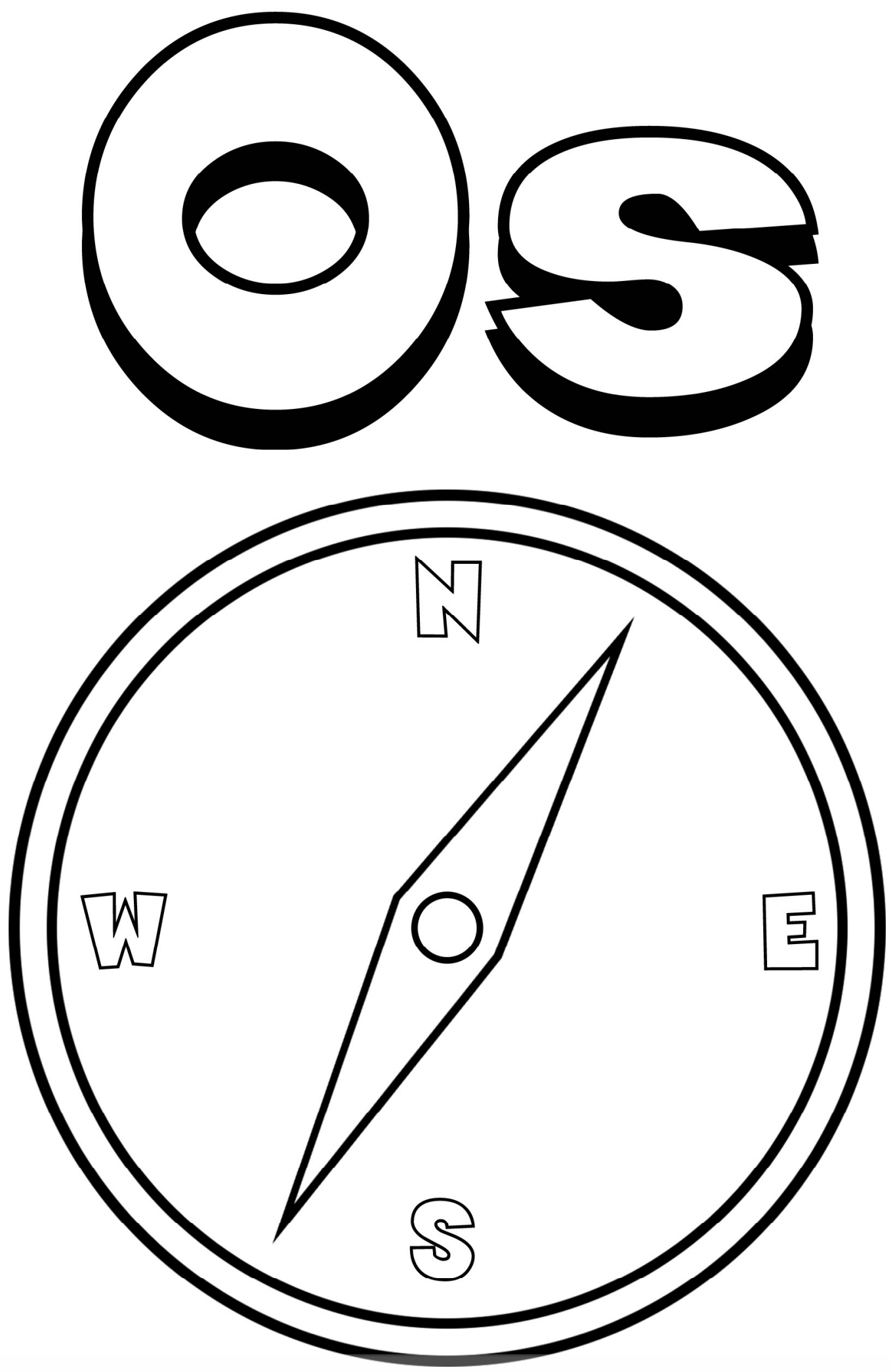

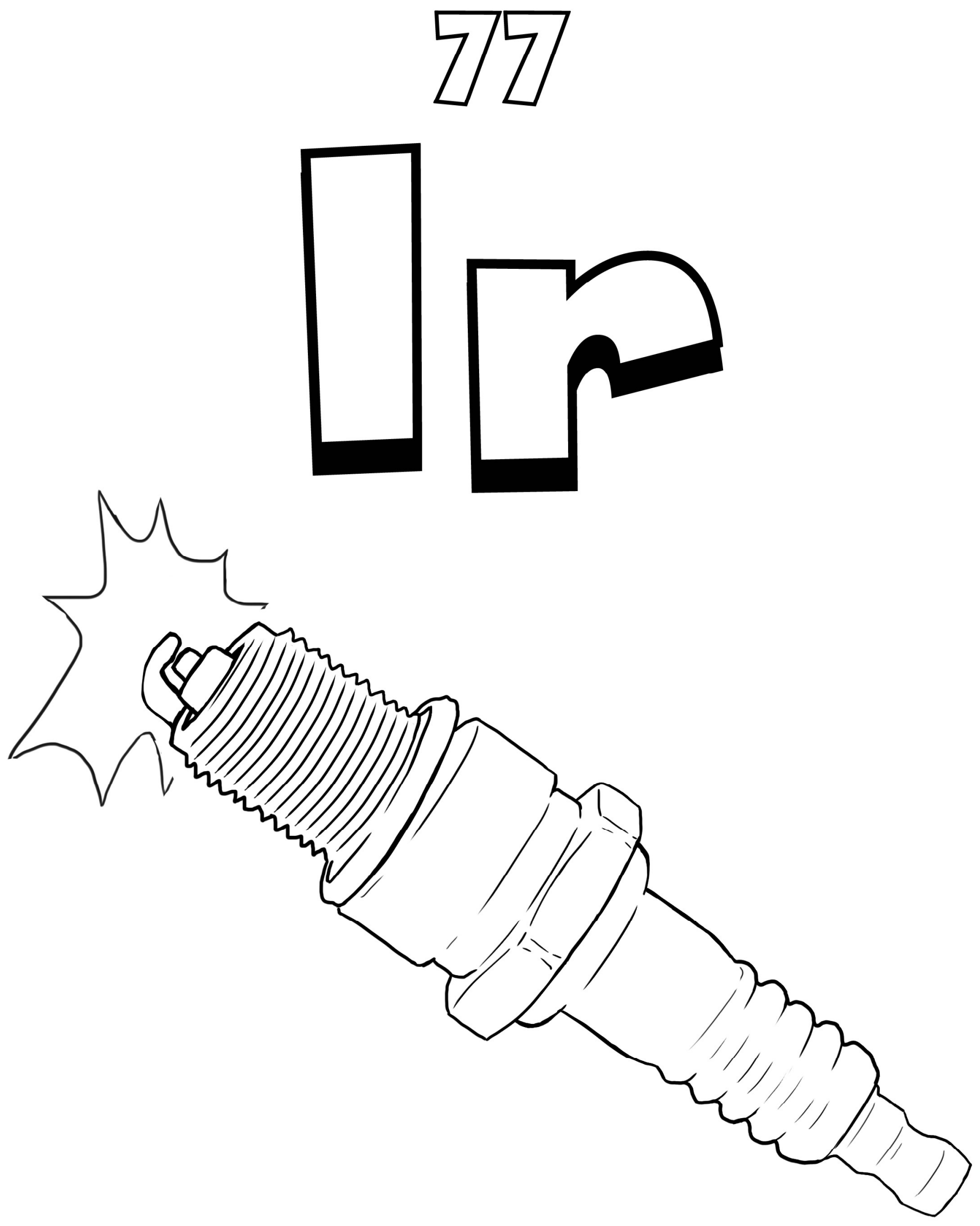

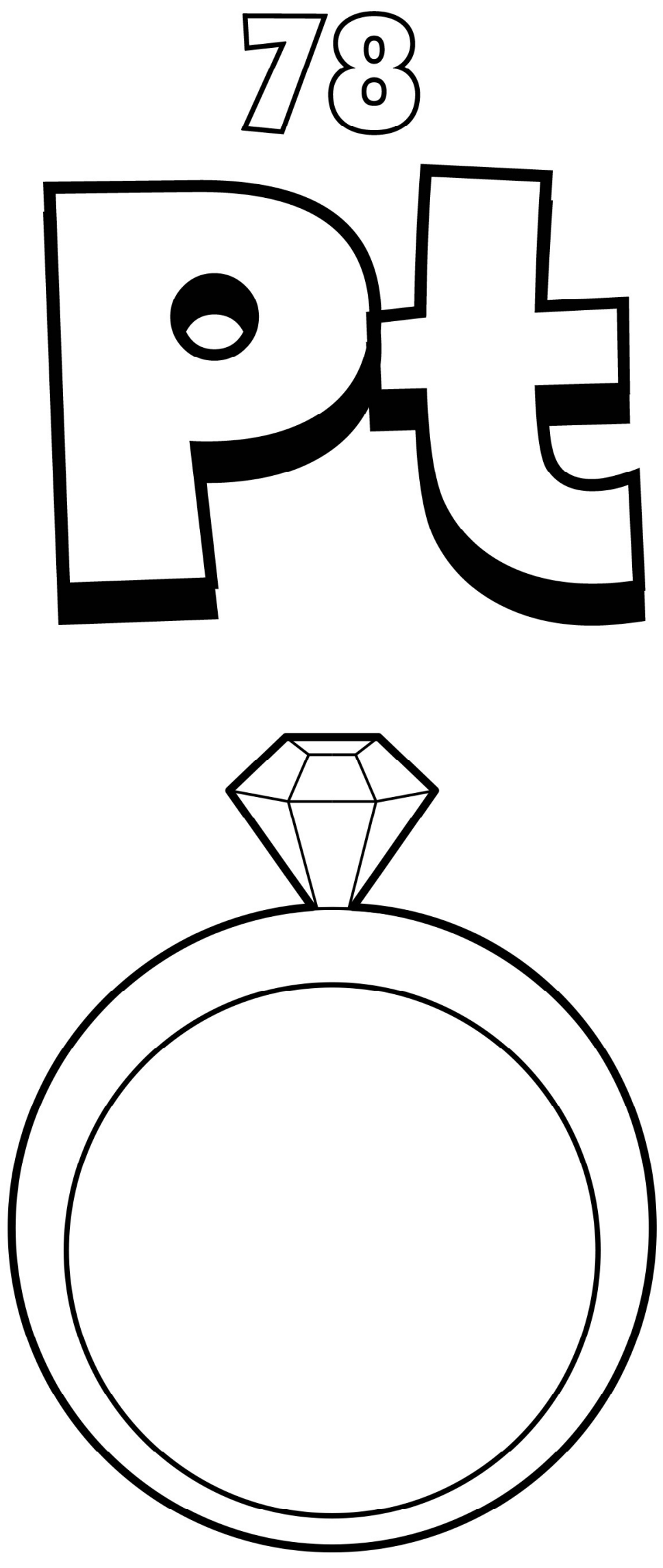

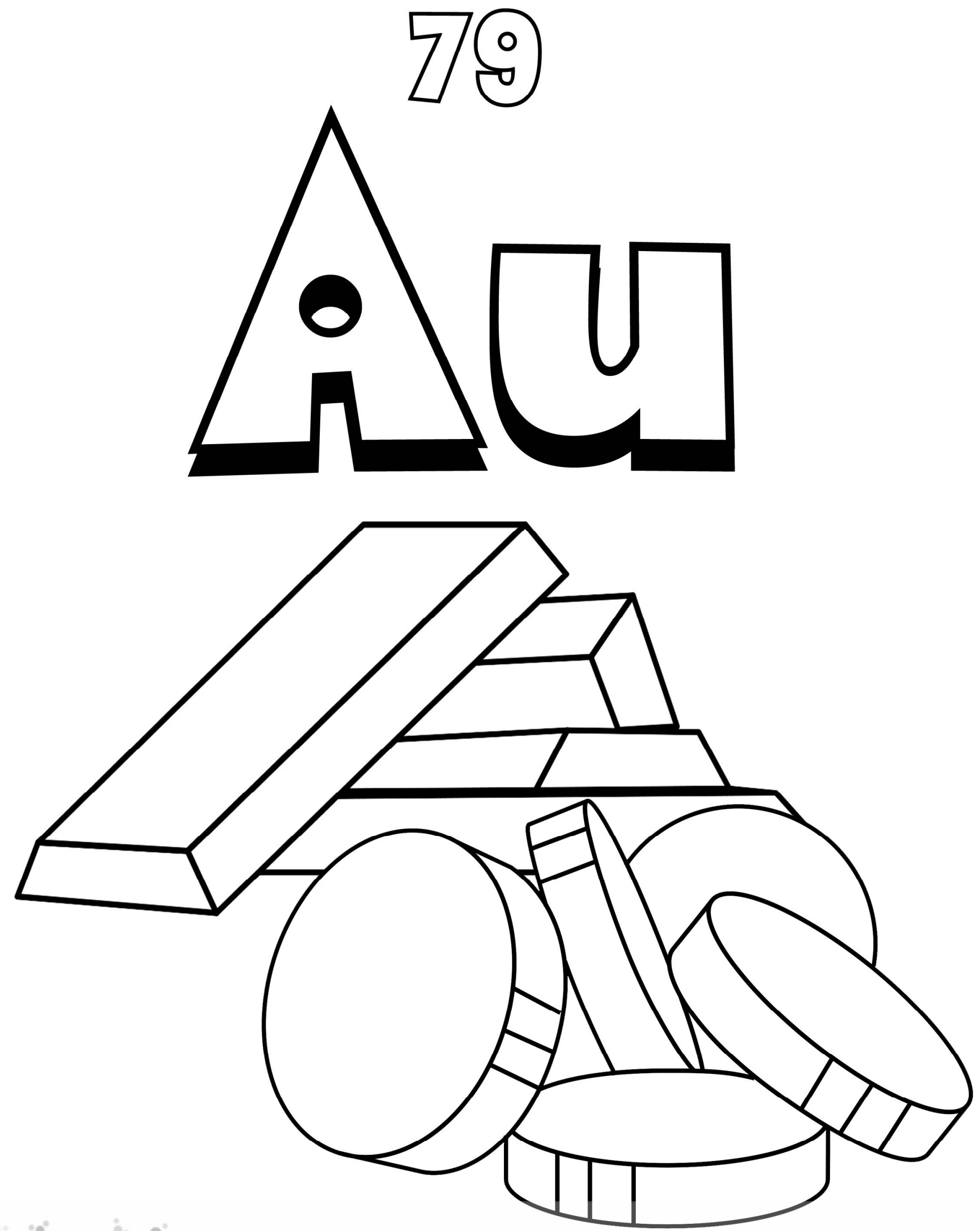


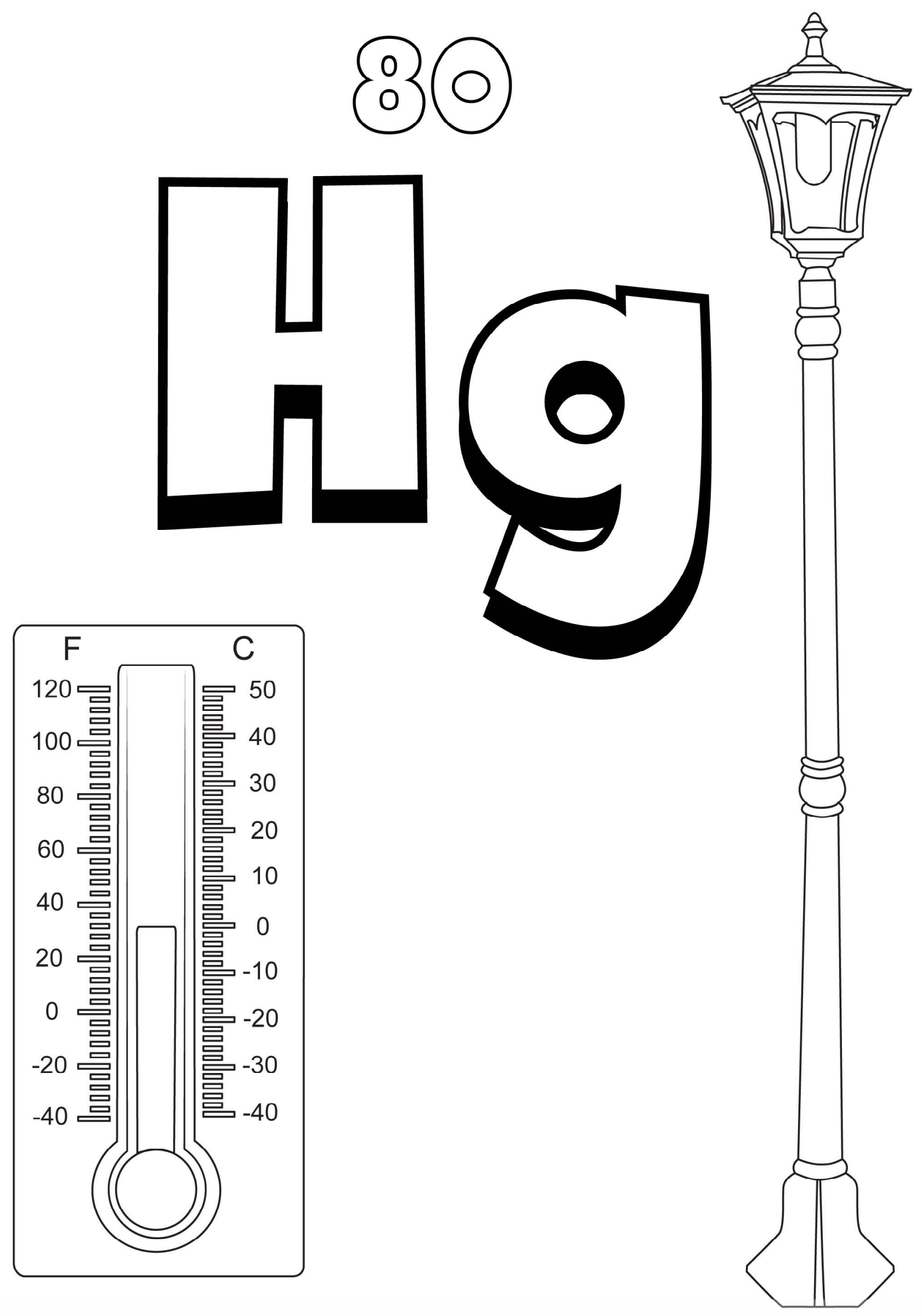




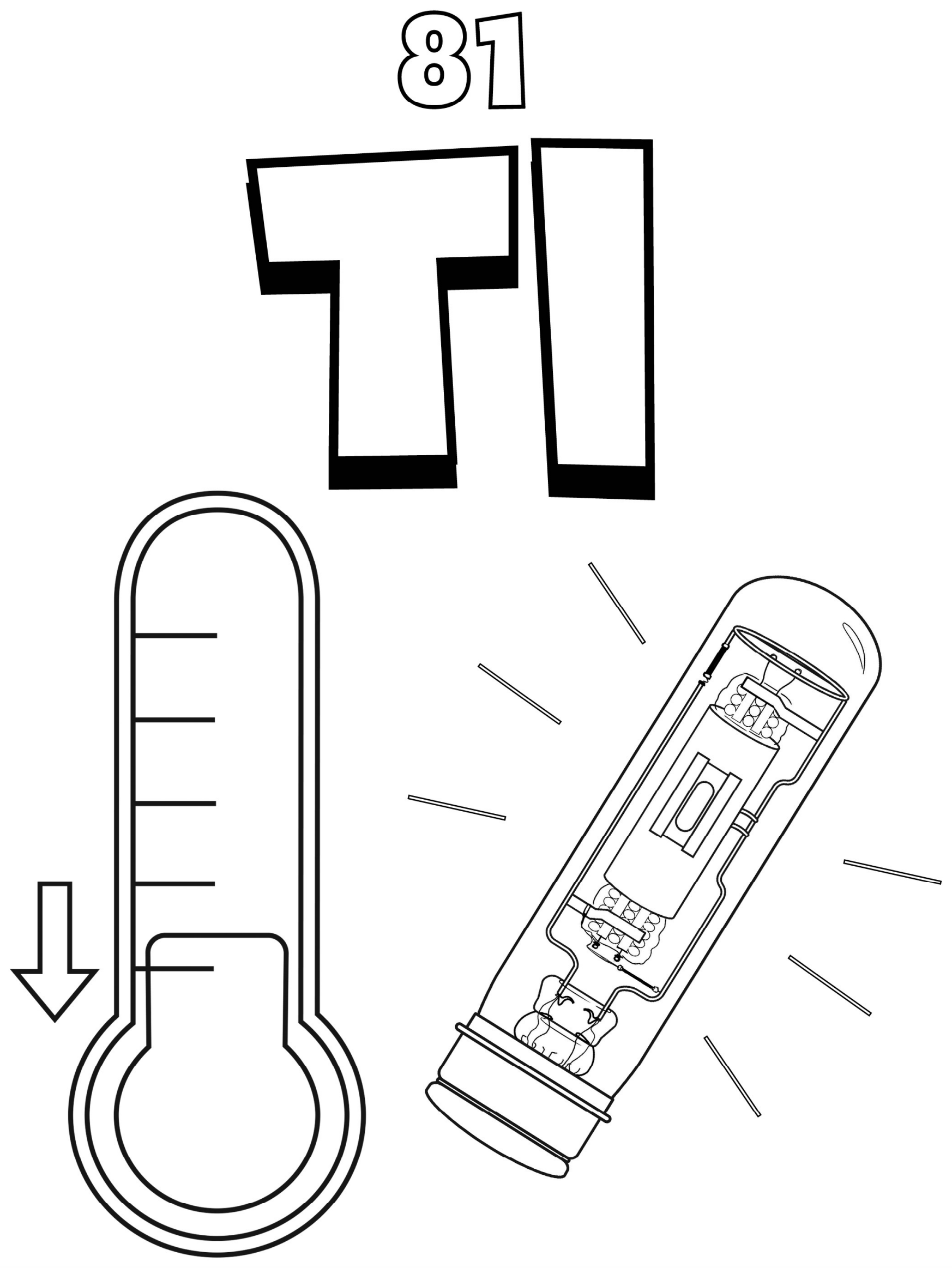


82
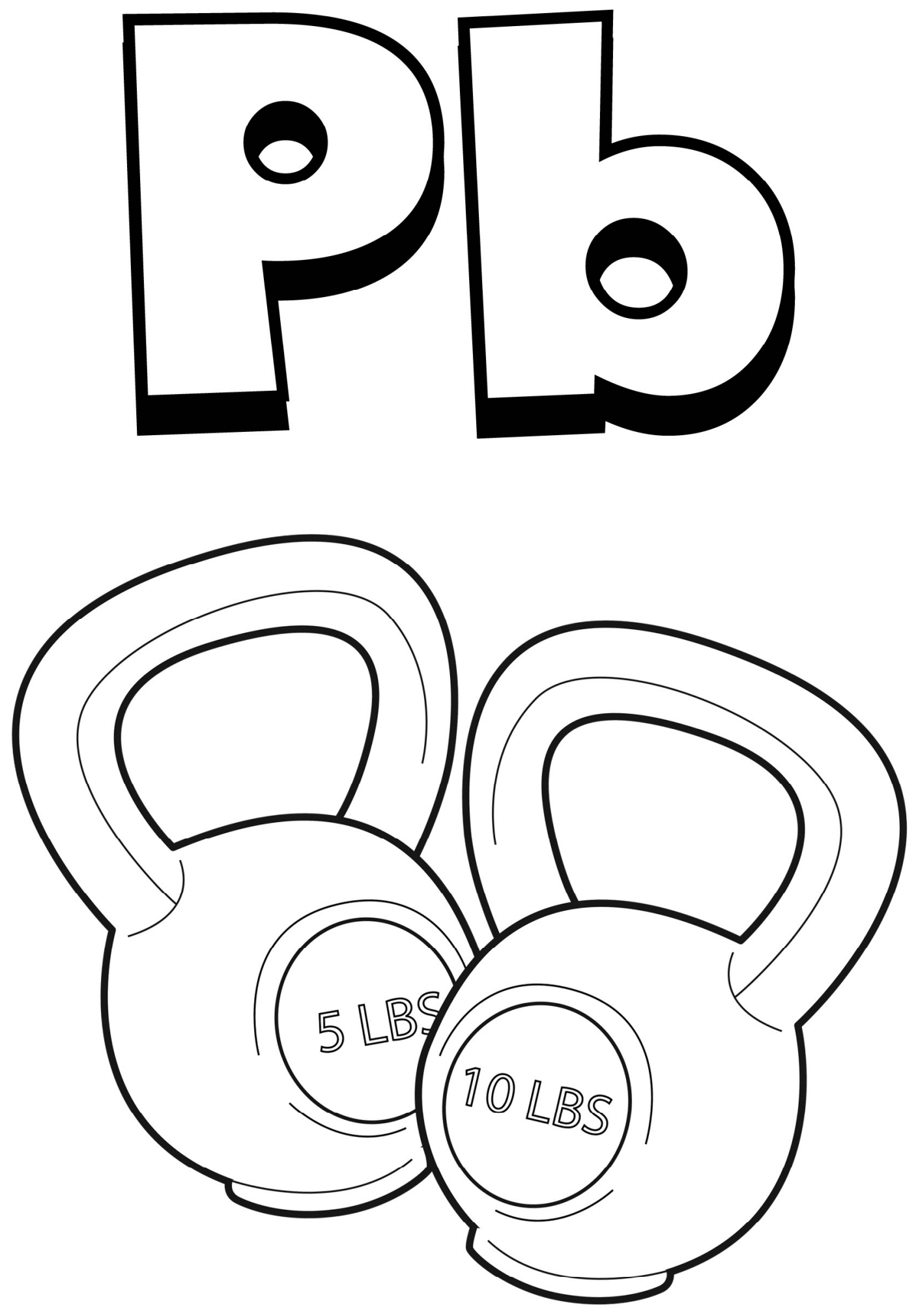


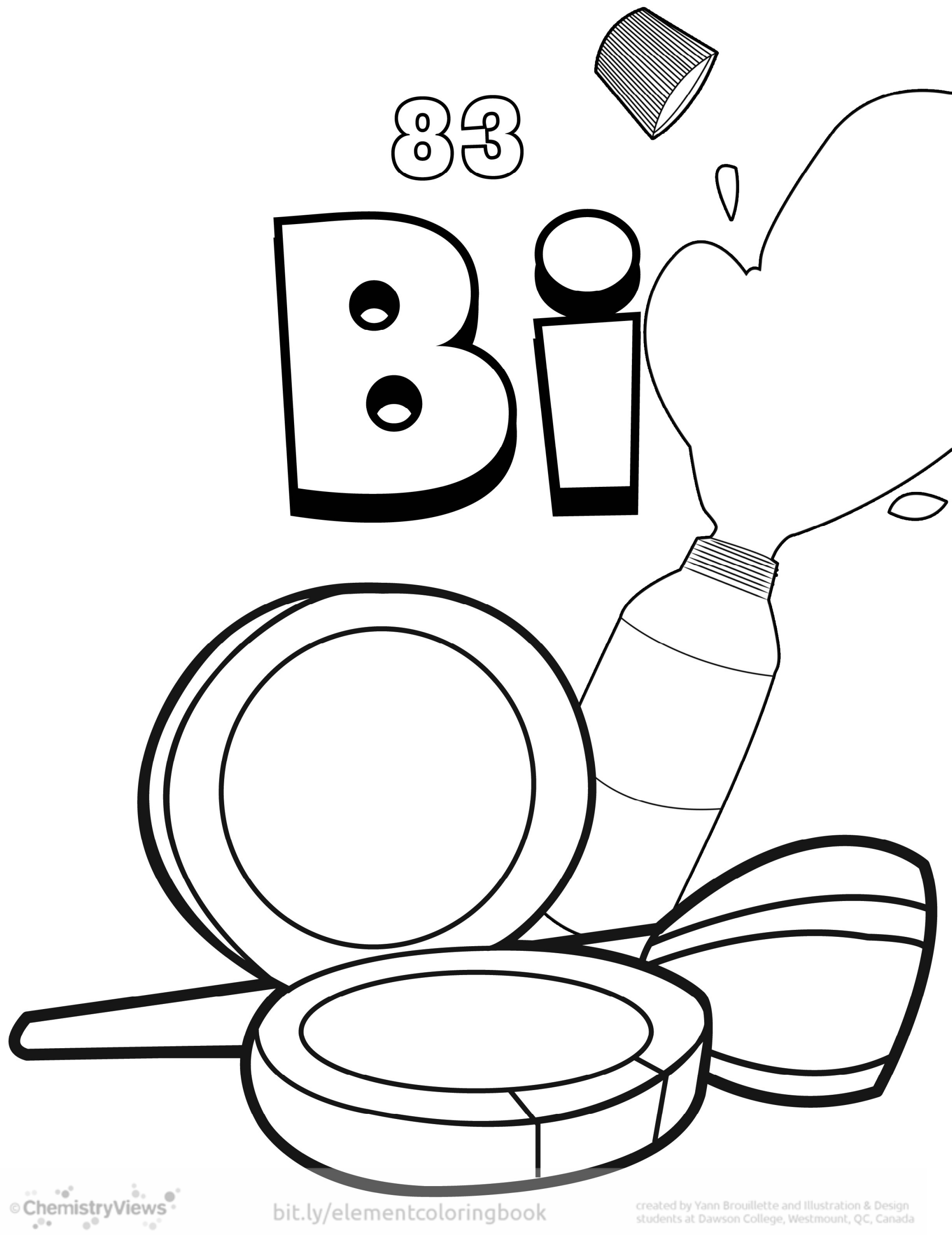




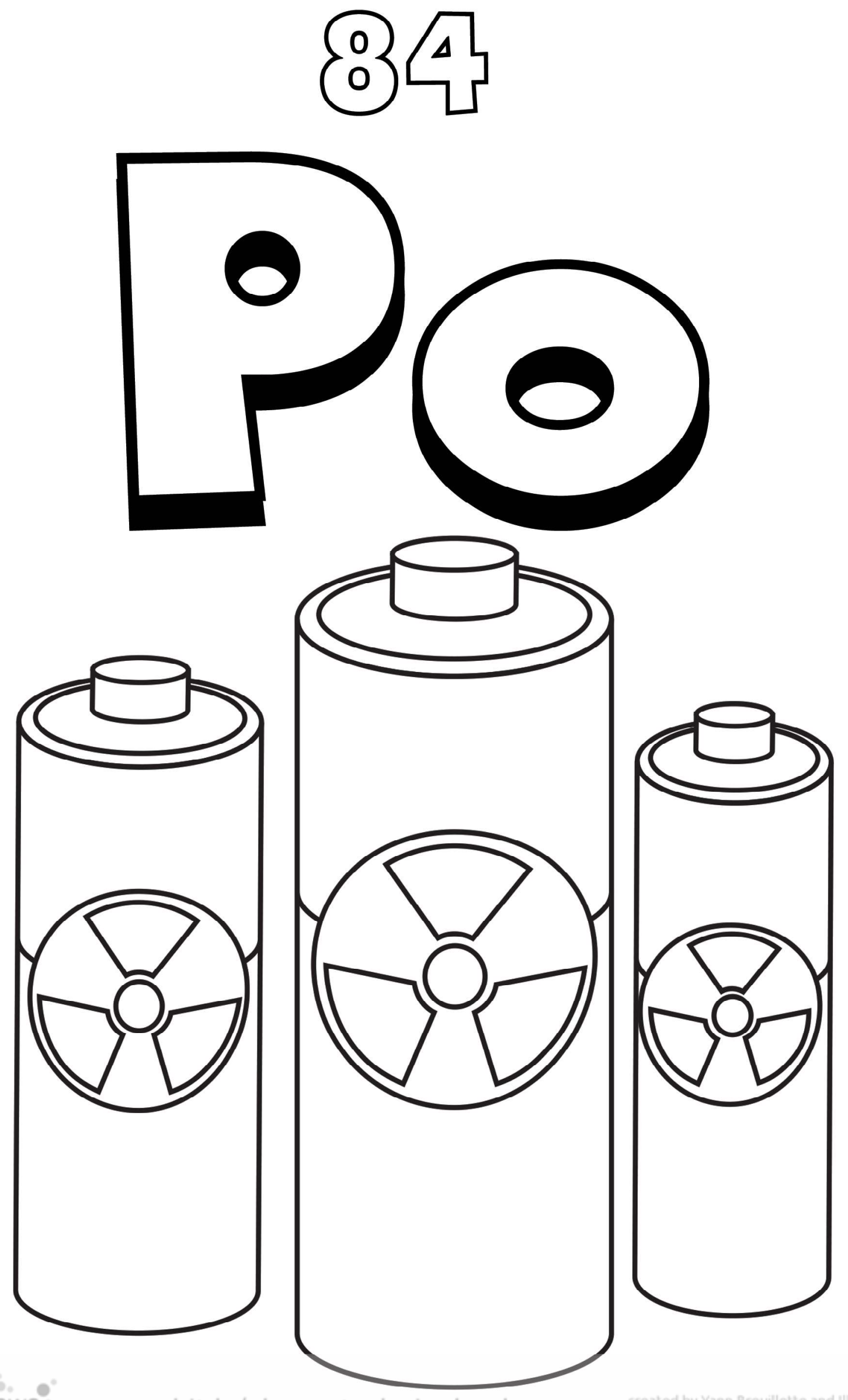




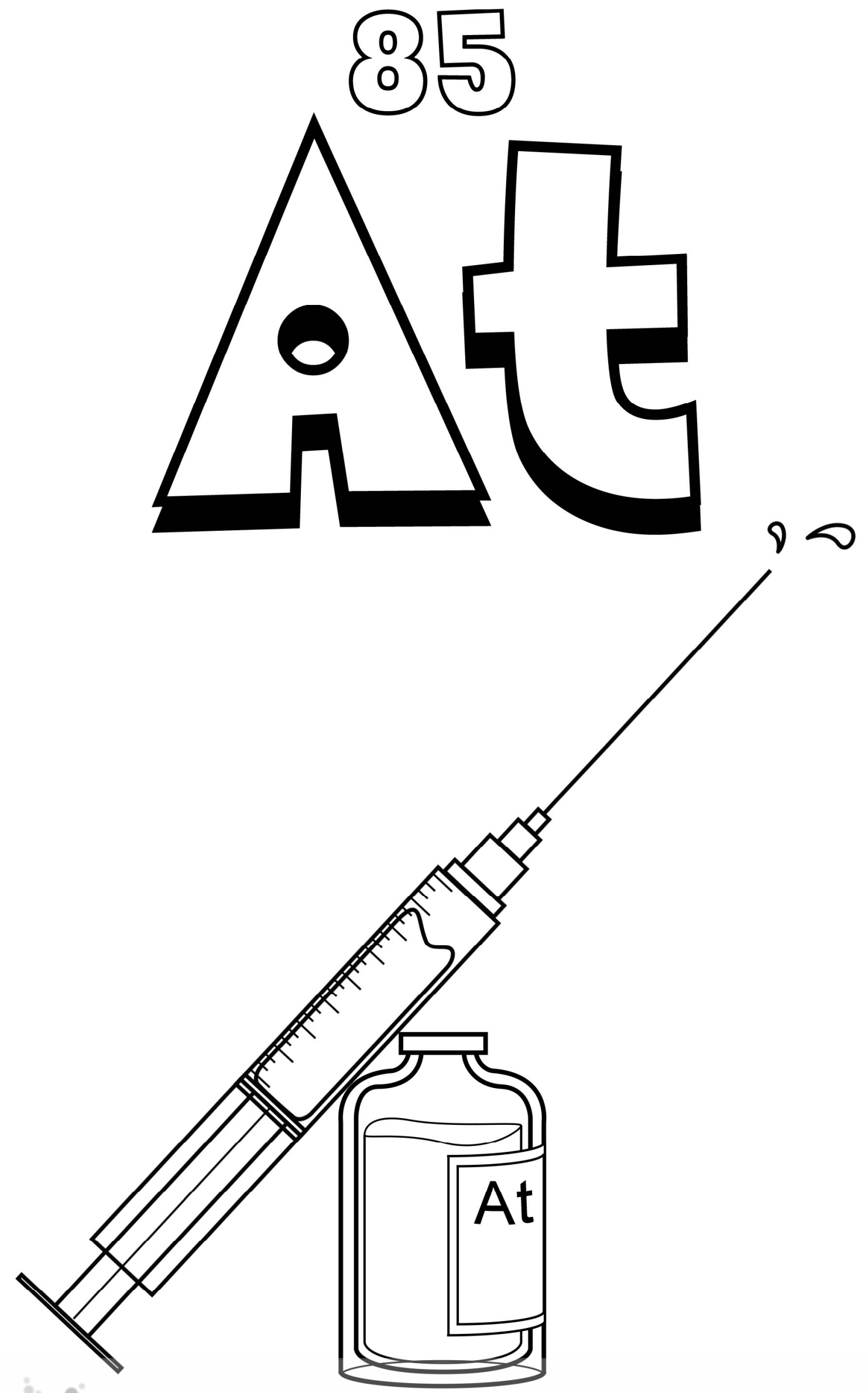




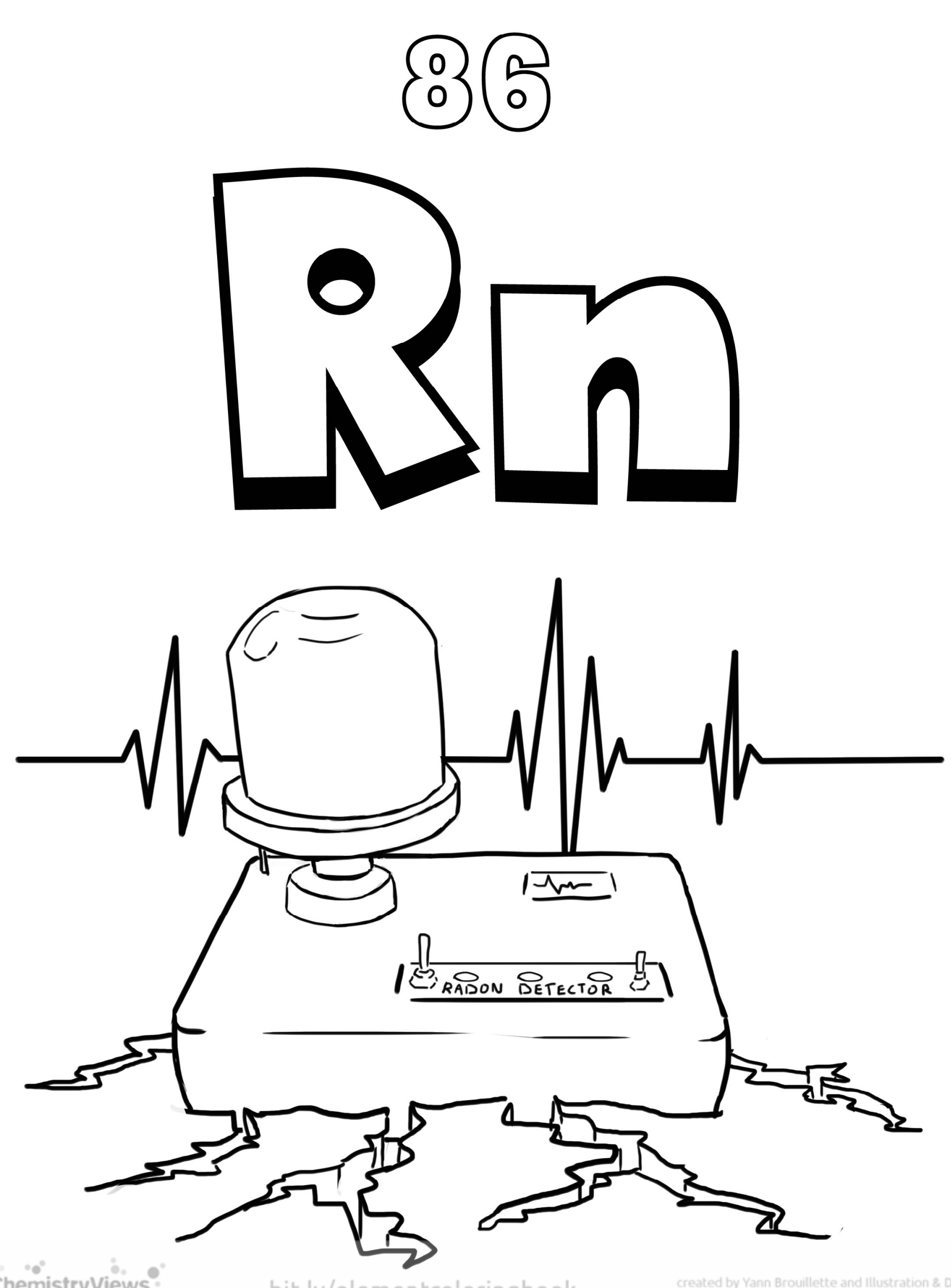




\section{9}
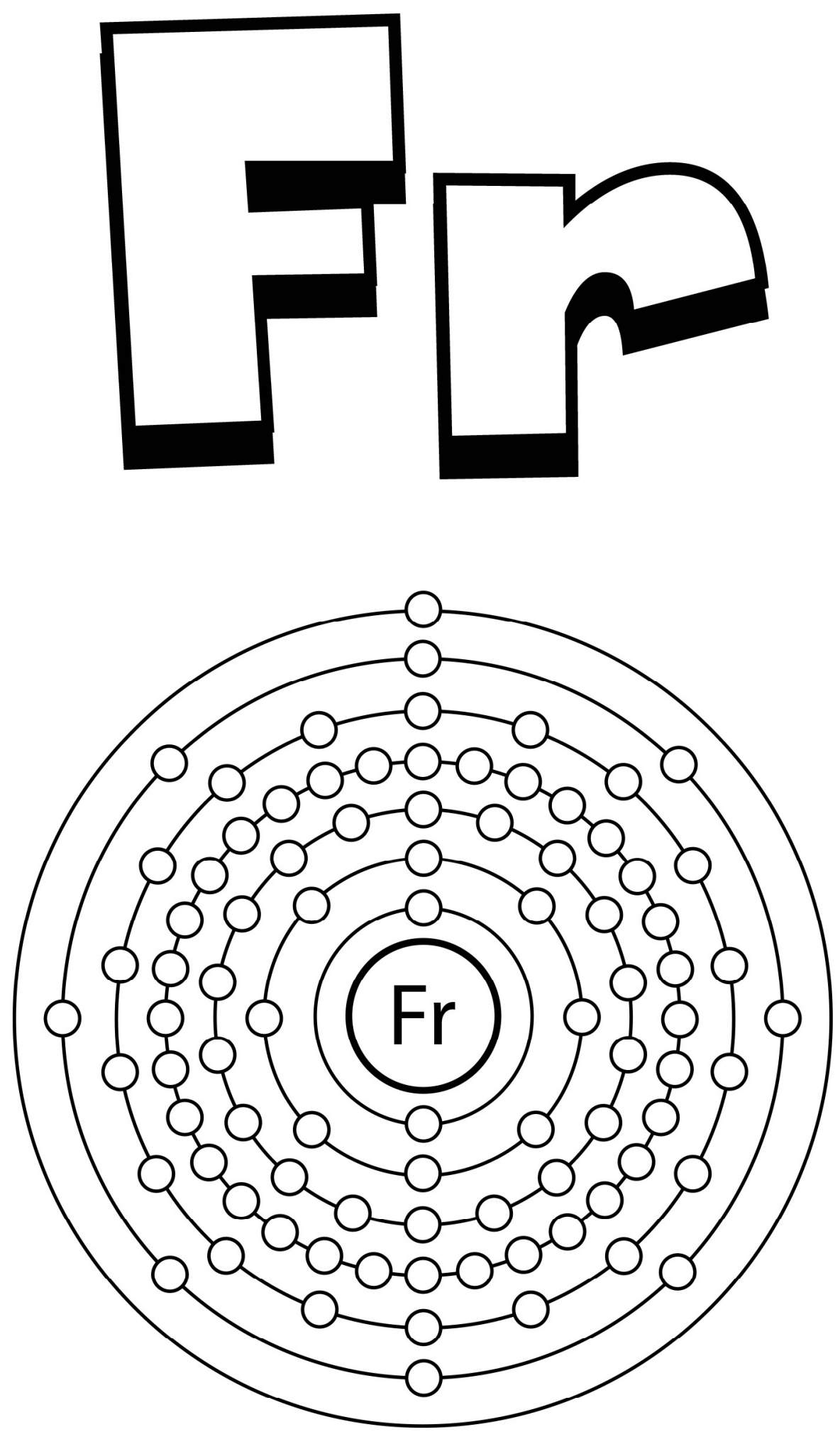
80
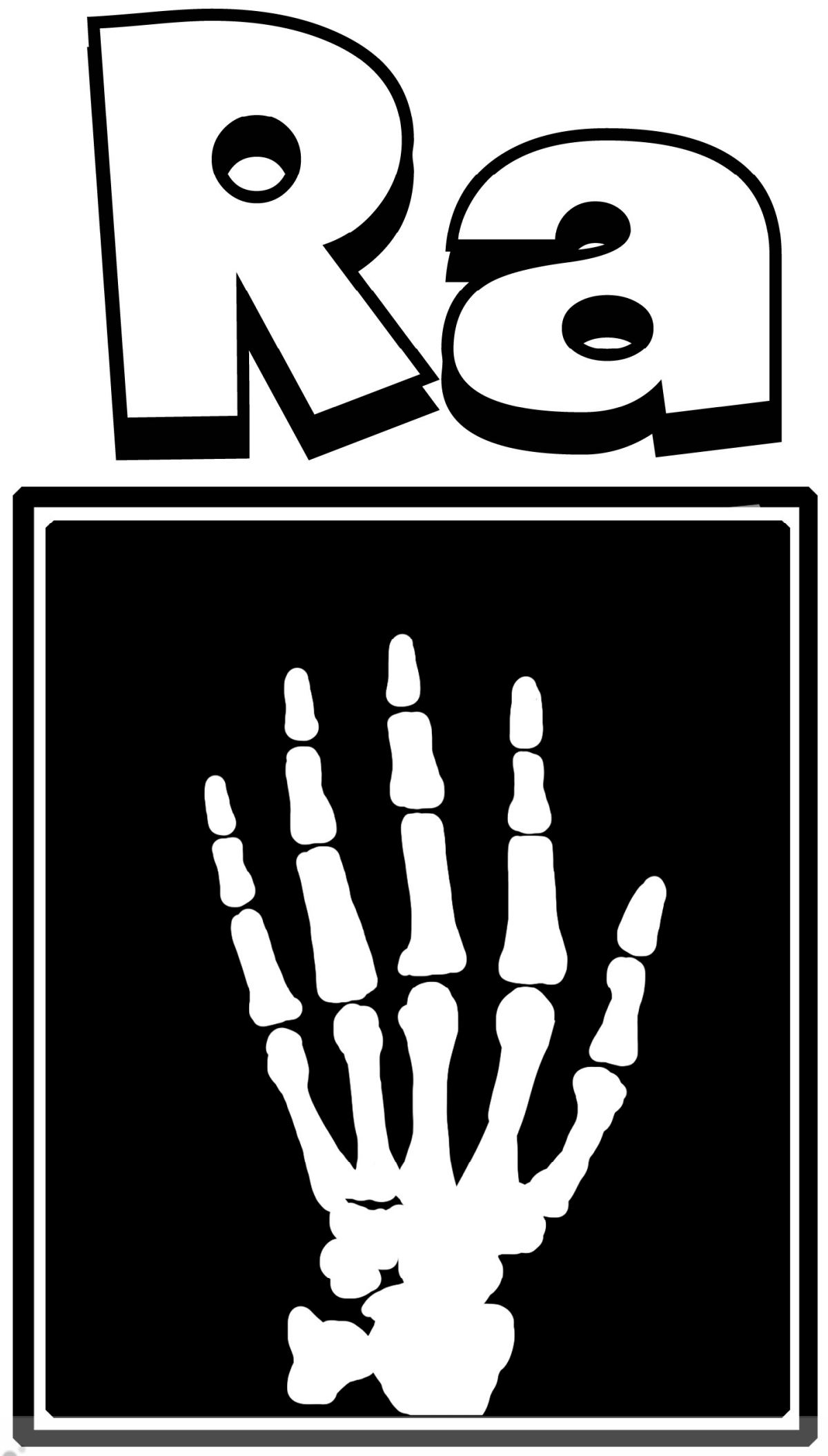

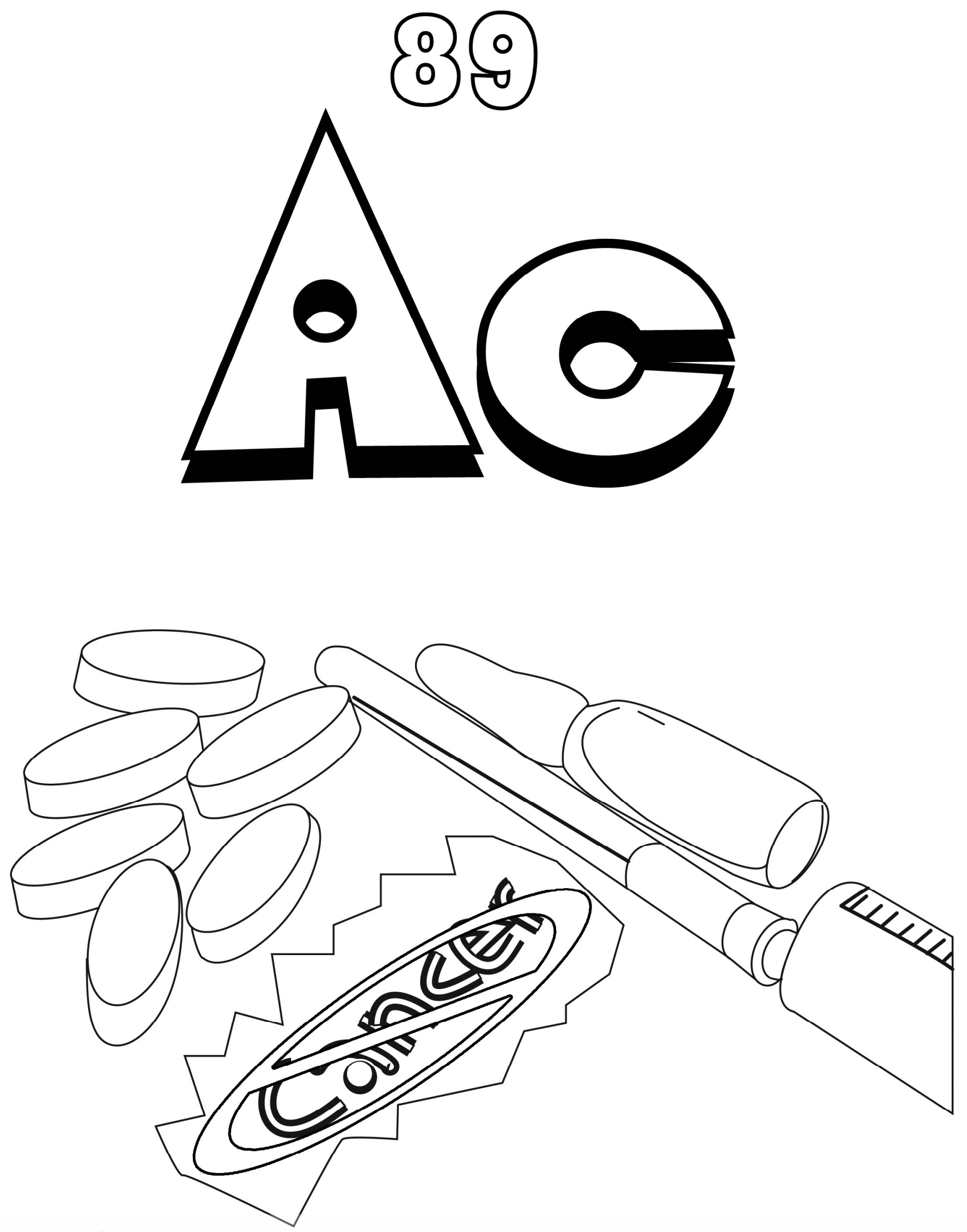

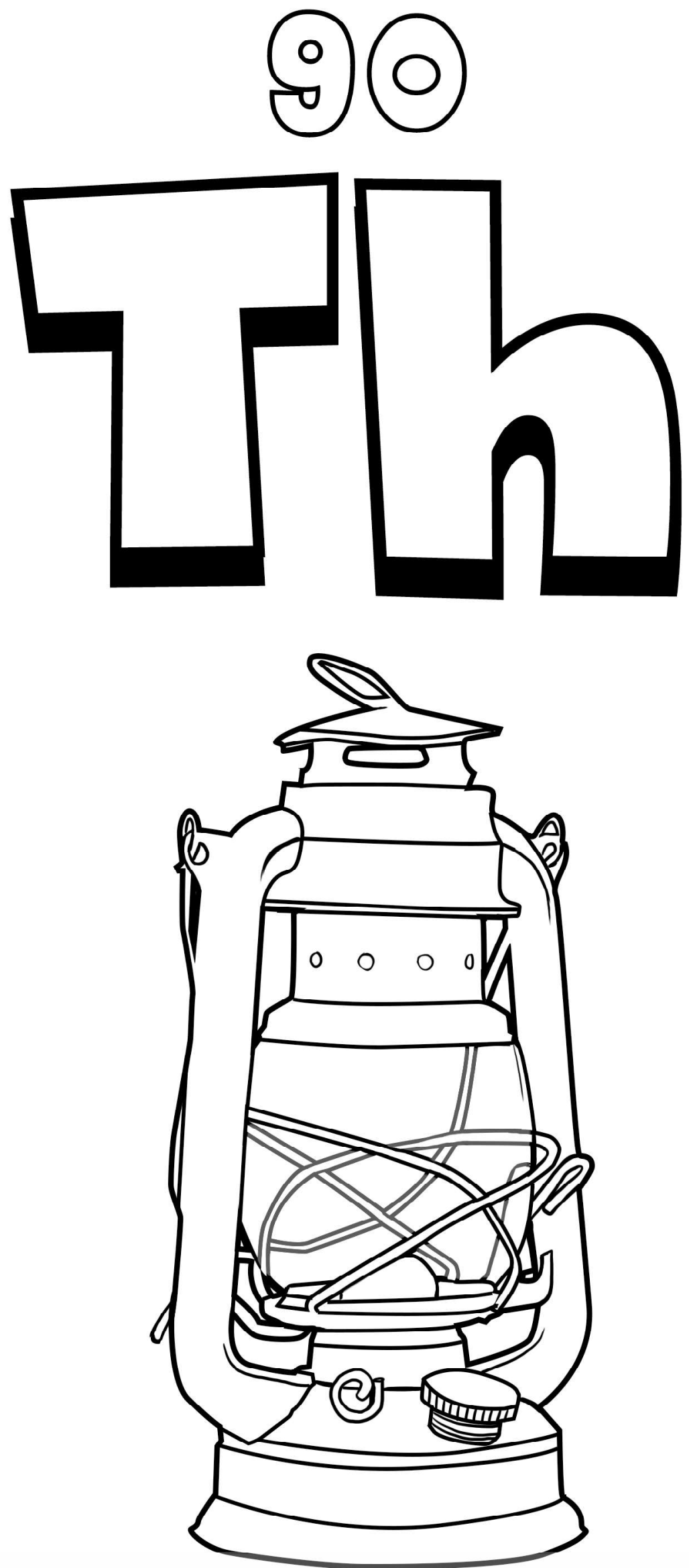


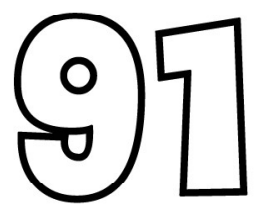
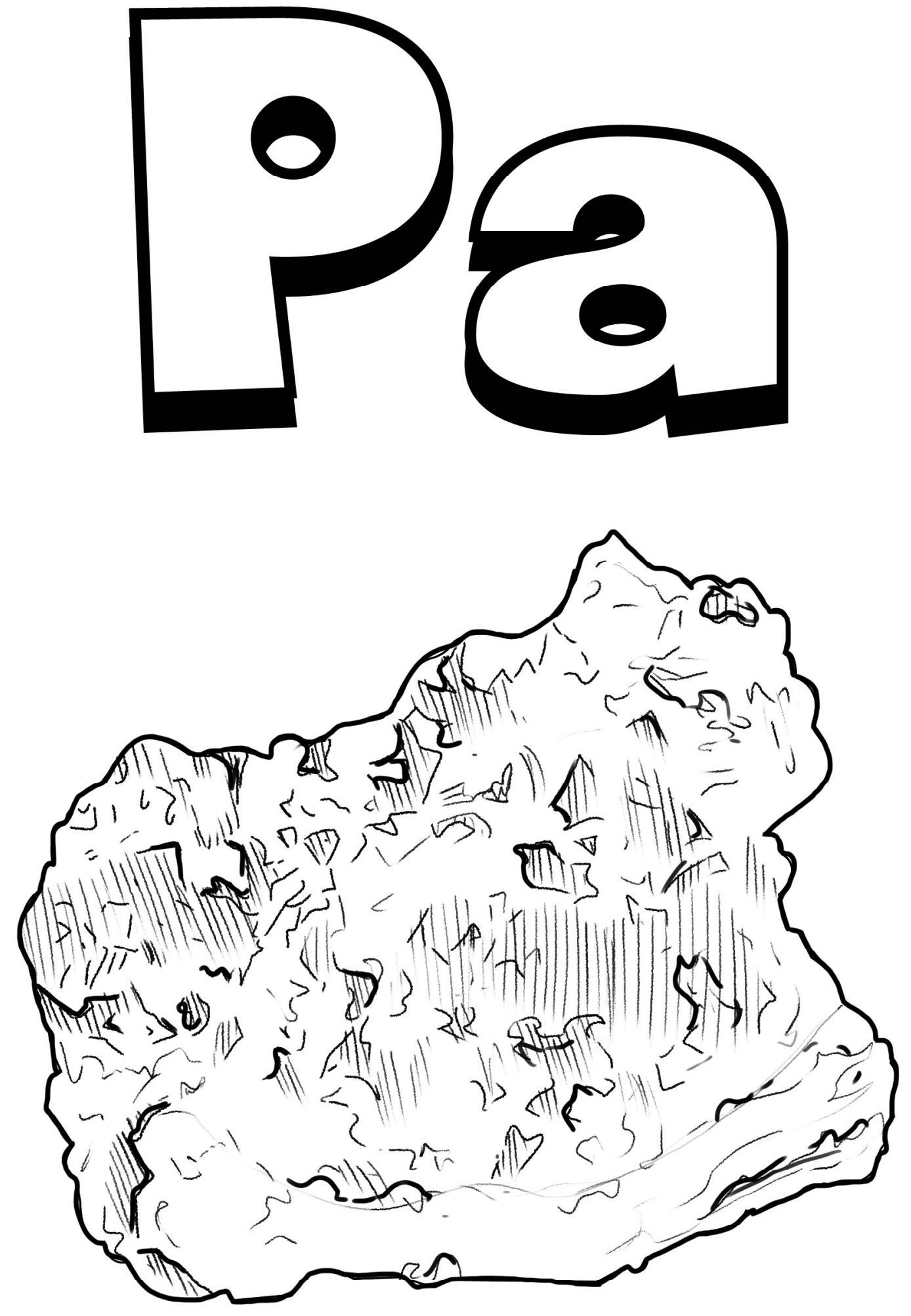


$$
02
$$
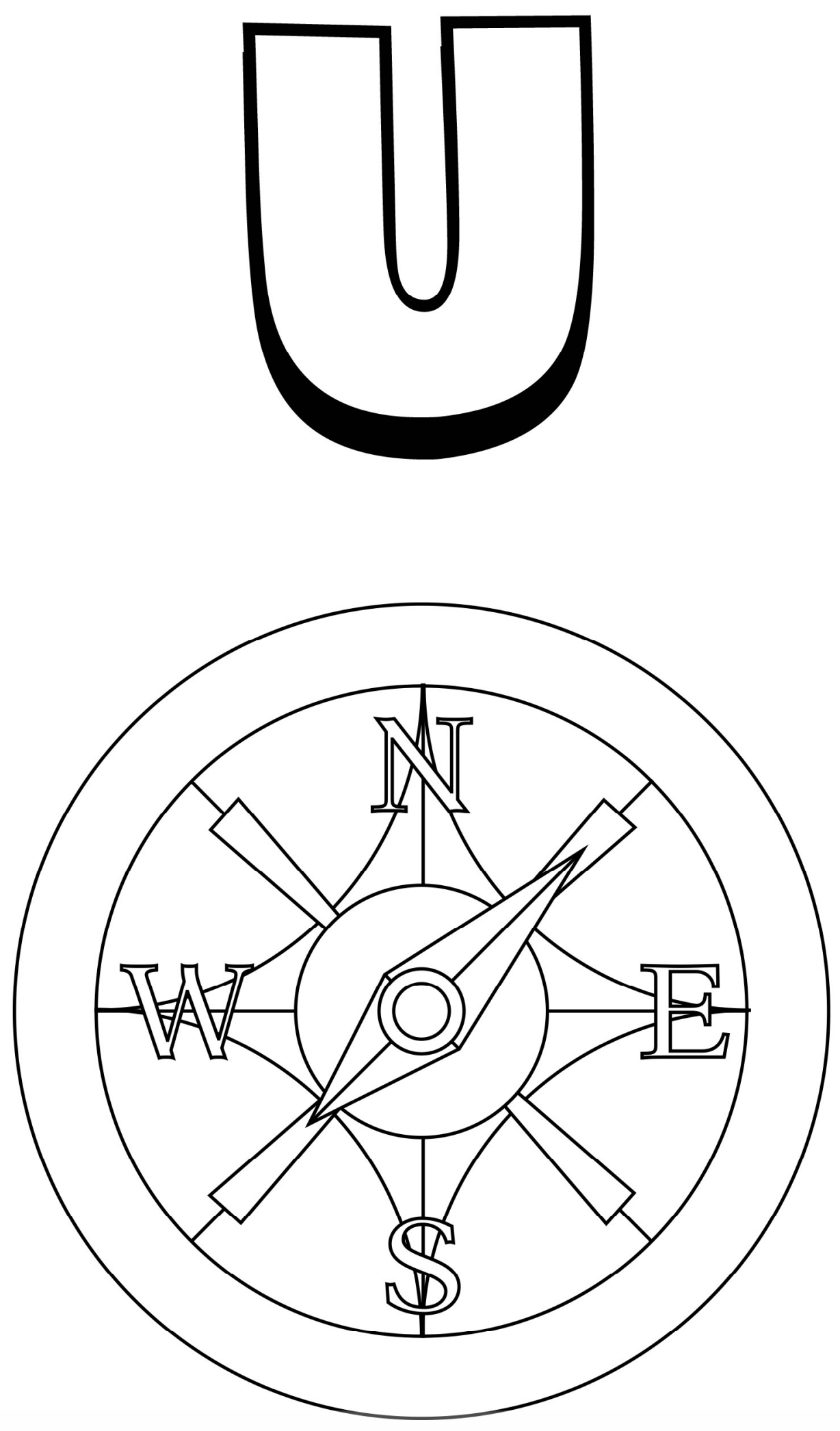
๑ீ)

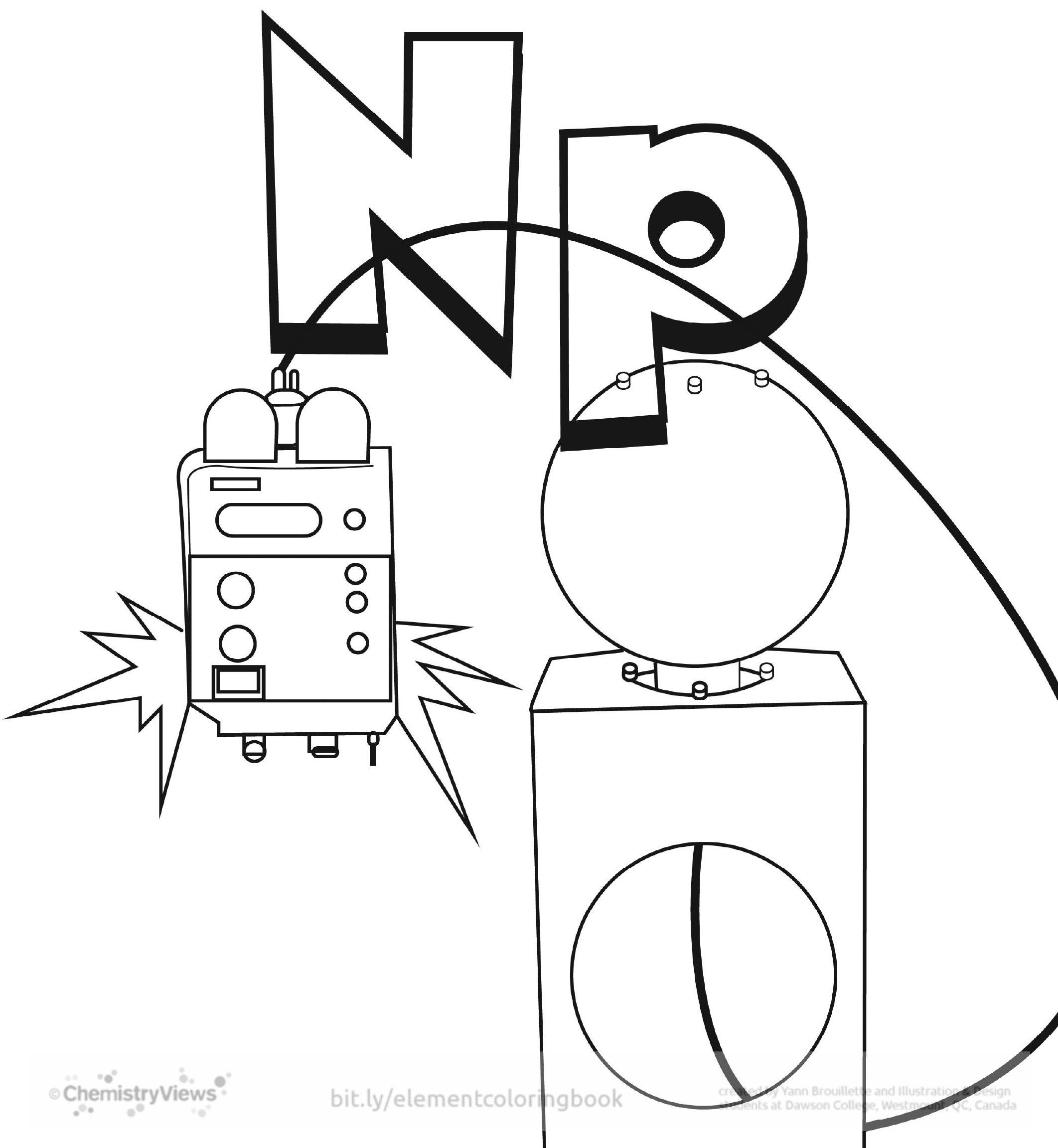




$$
84
$$

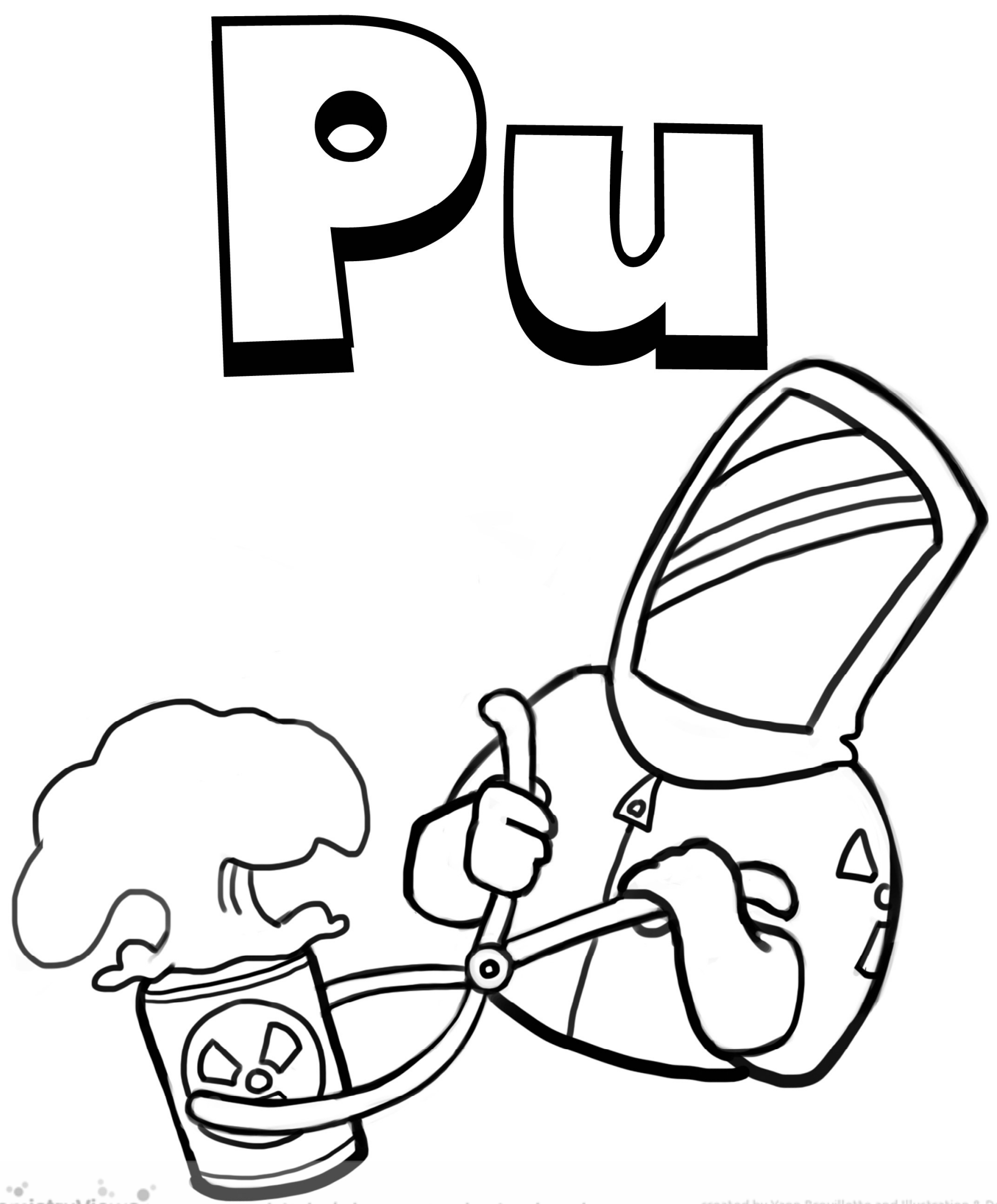



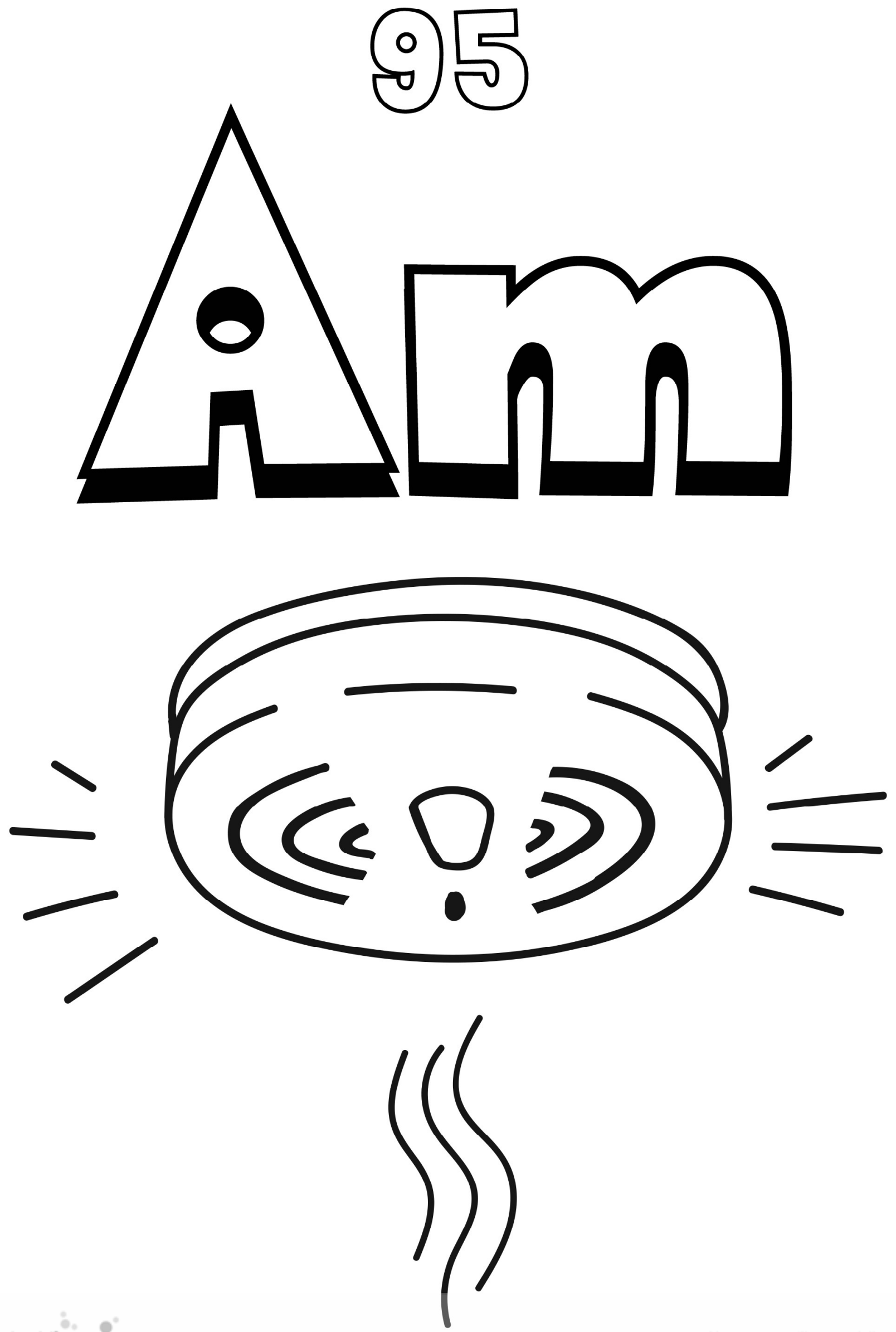


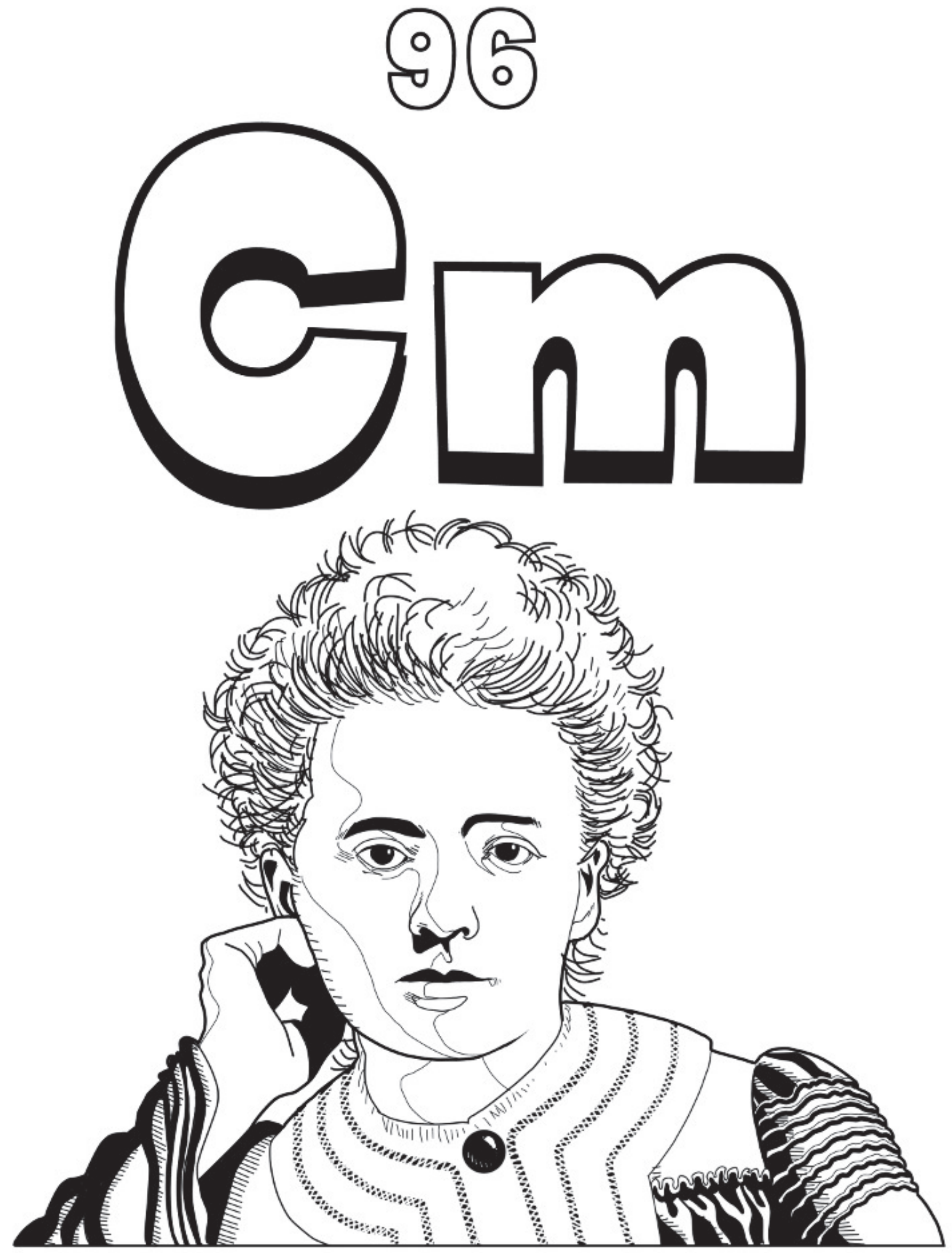




$$
87
$$
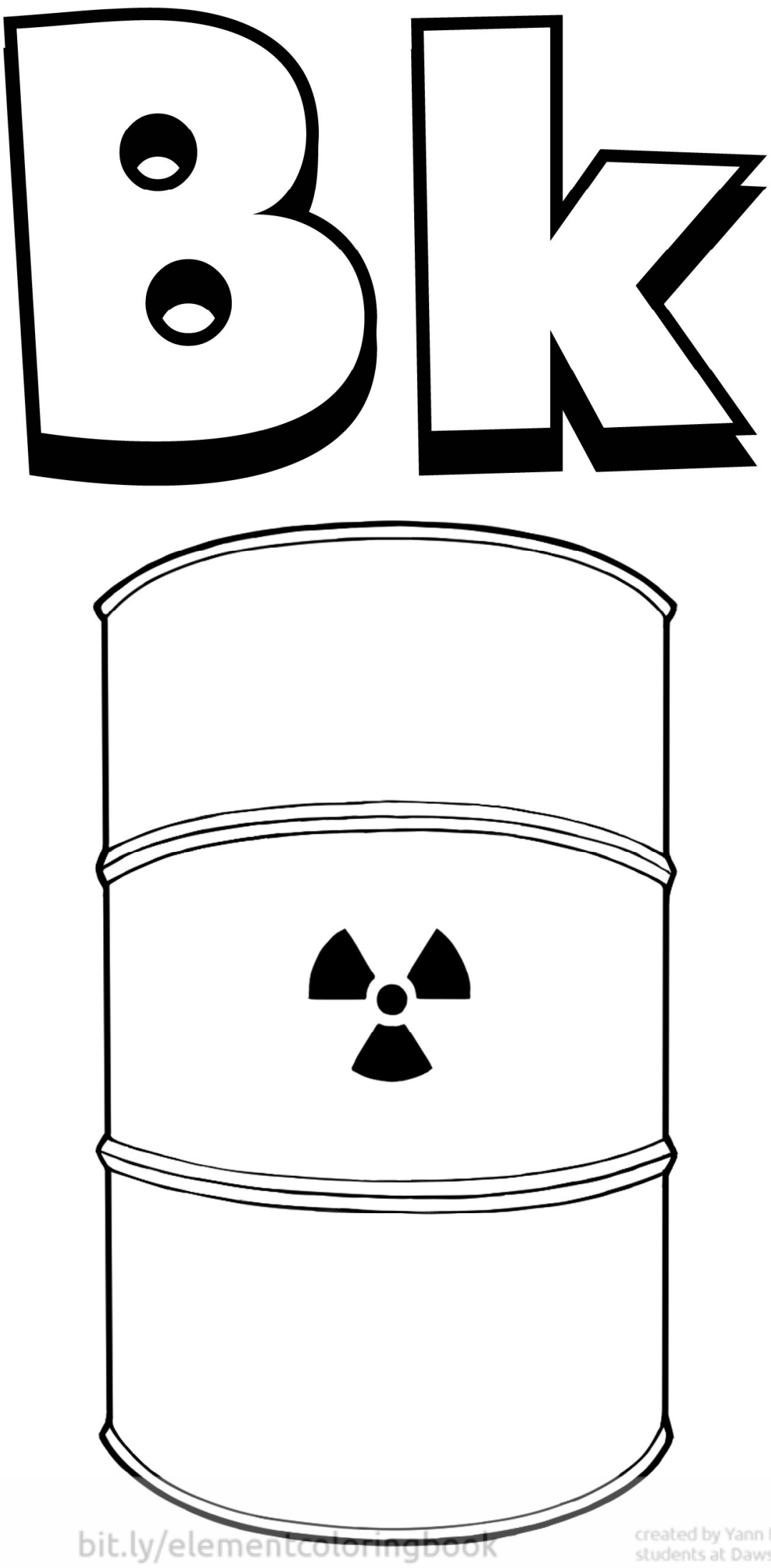

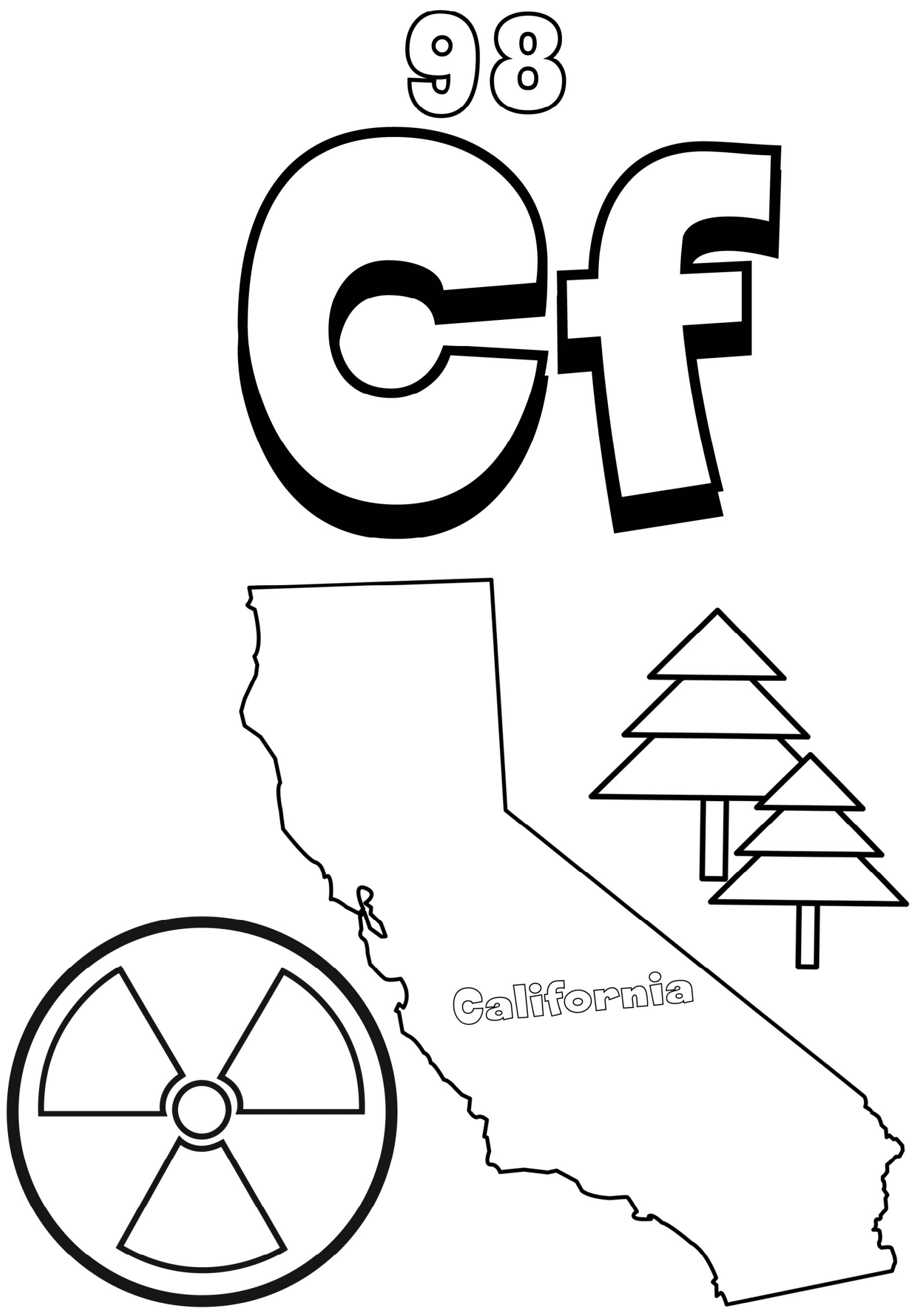
○)
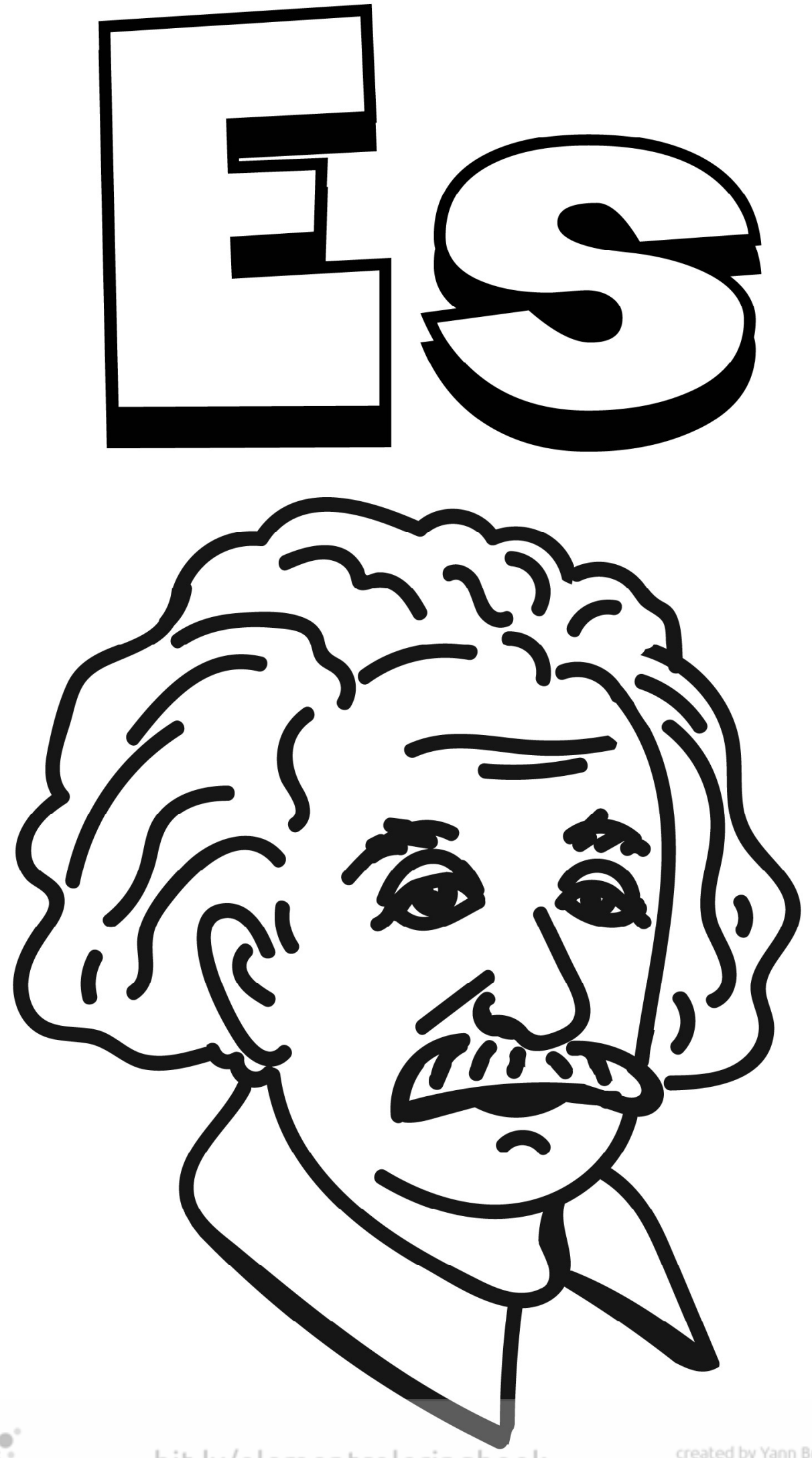

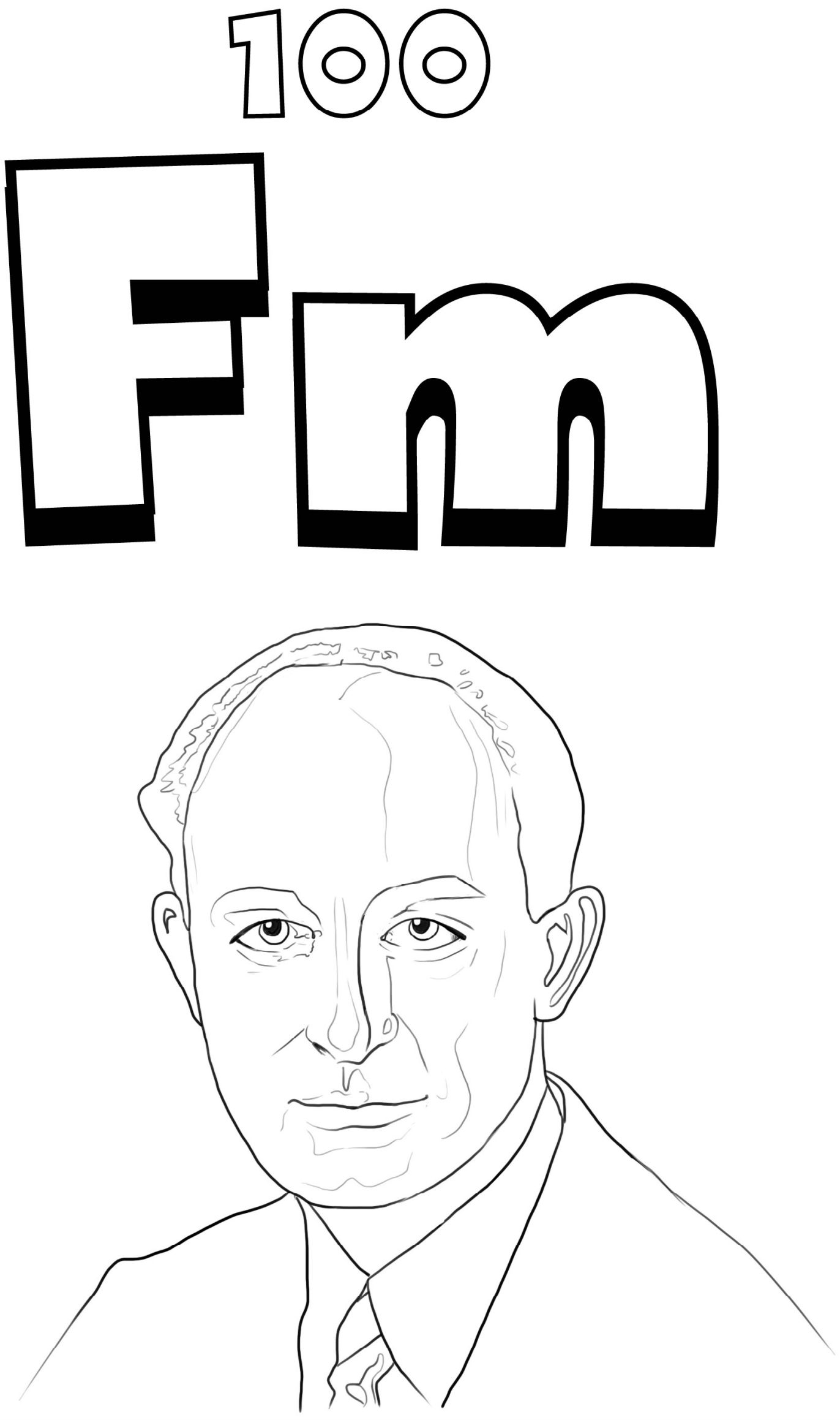


\section{\0)}
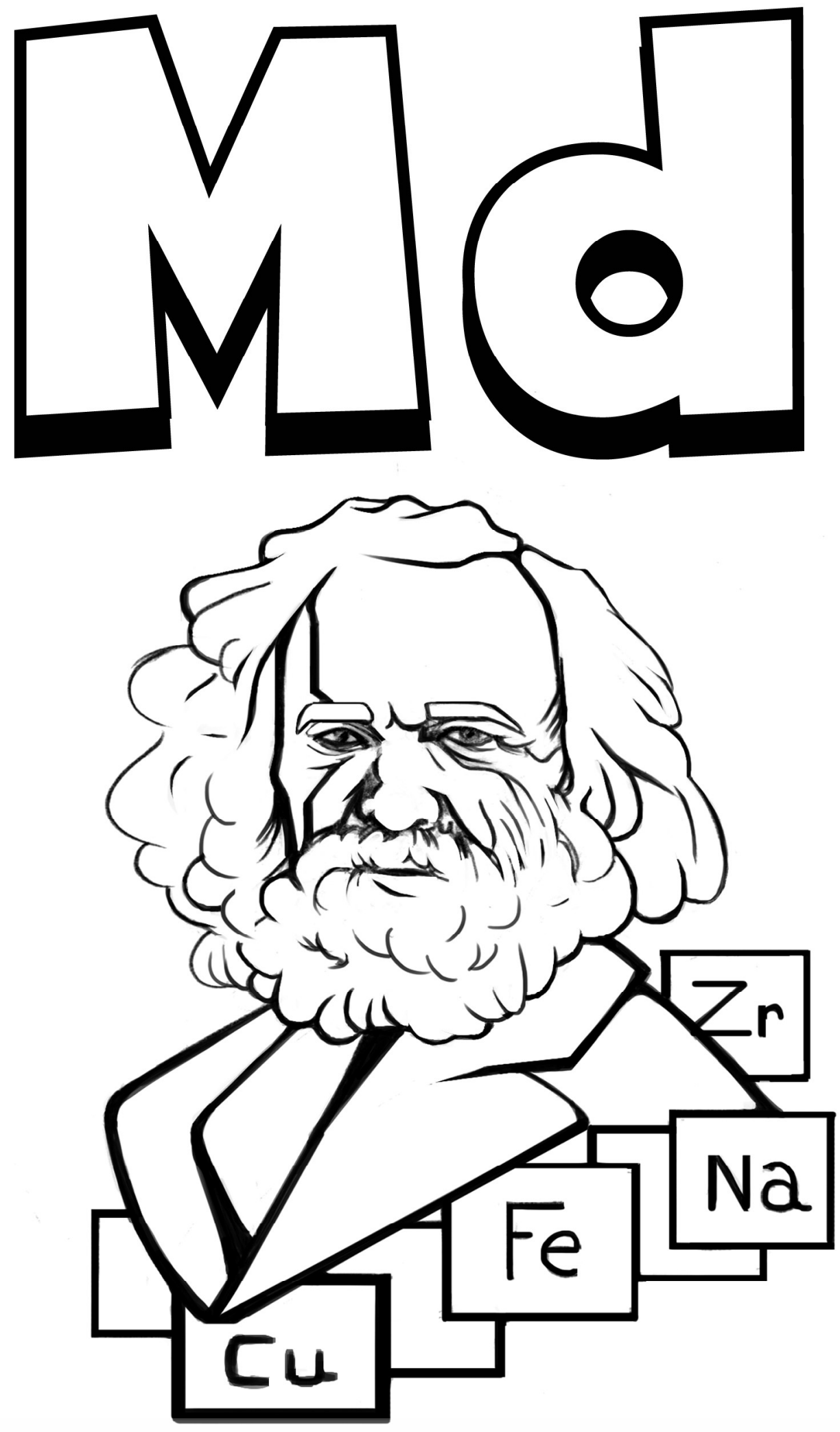


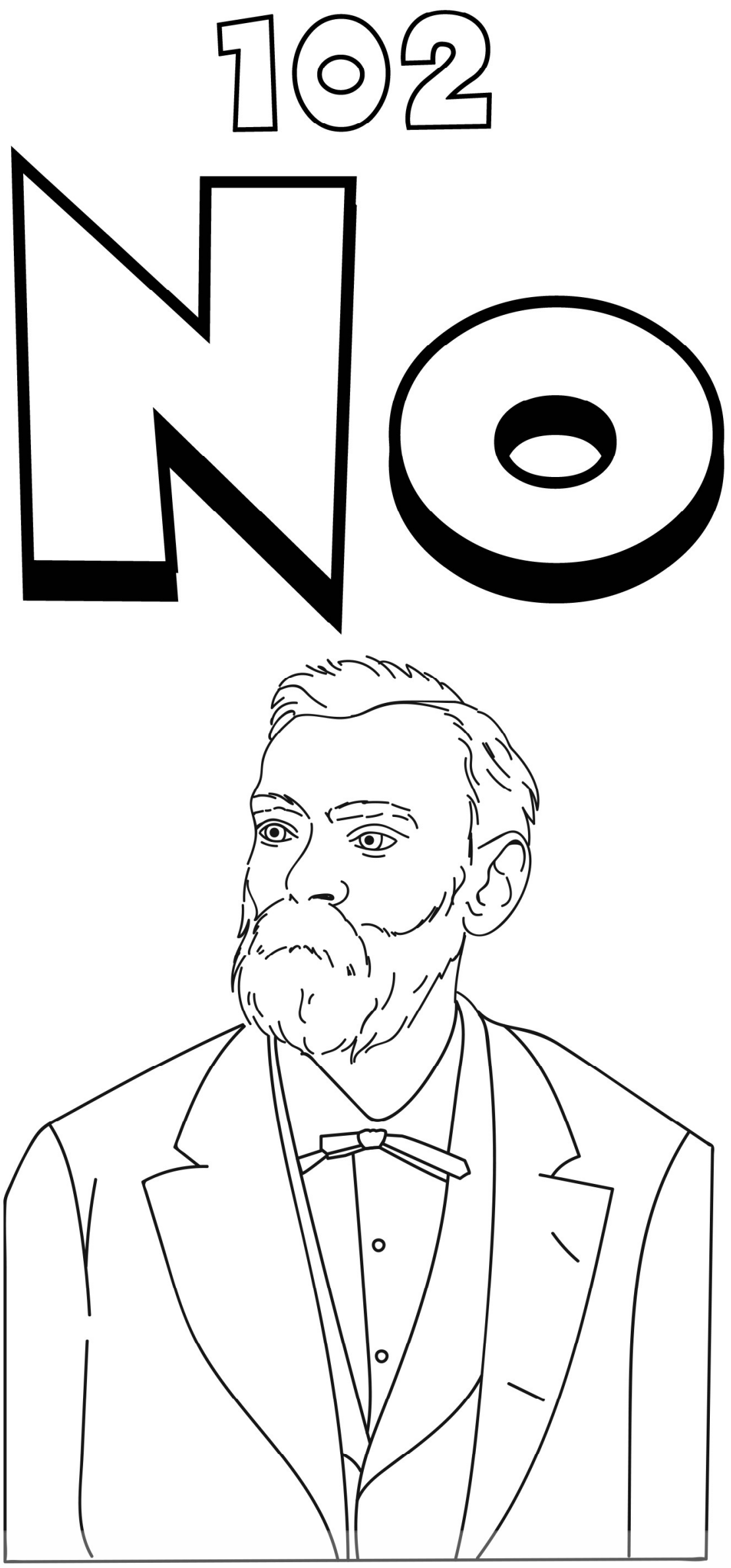


】๐)
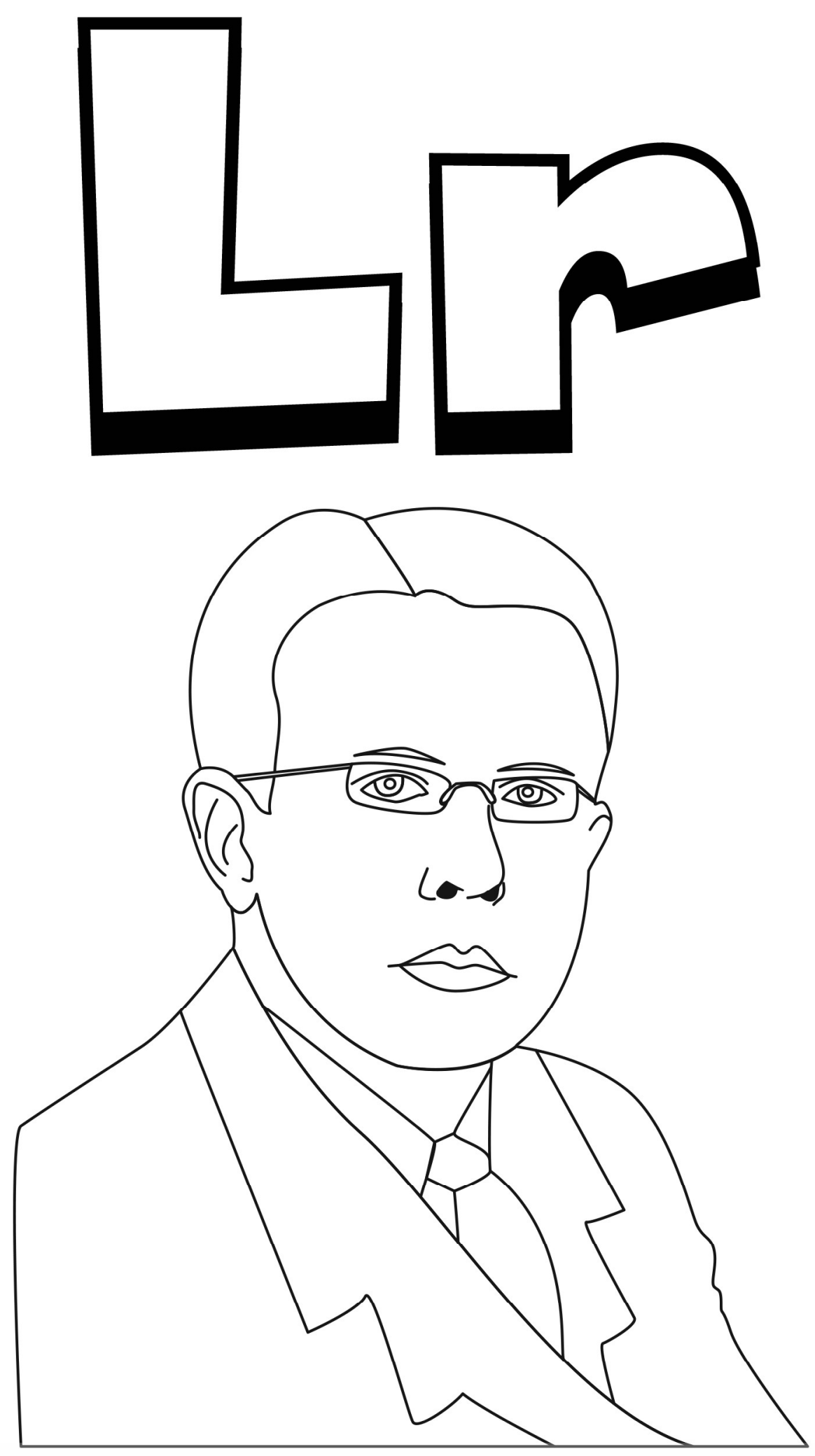


\section{0) 4}
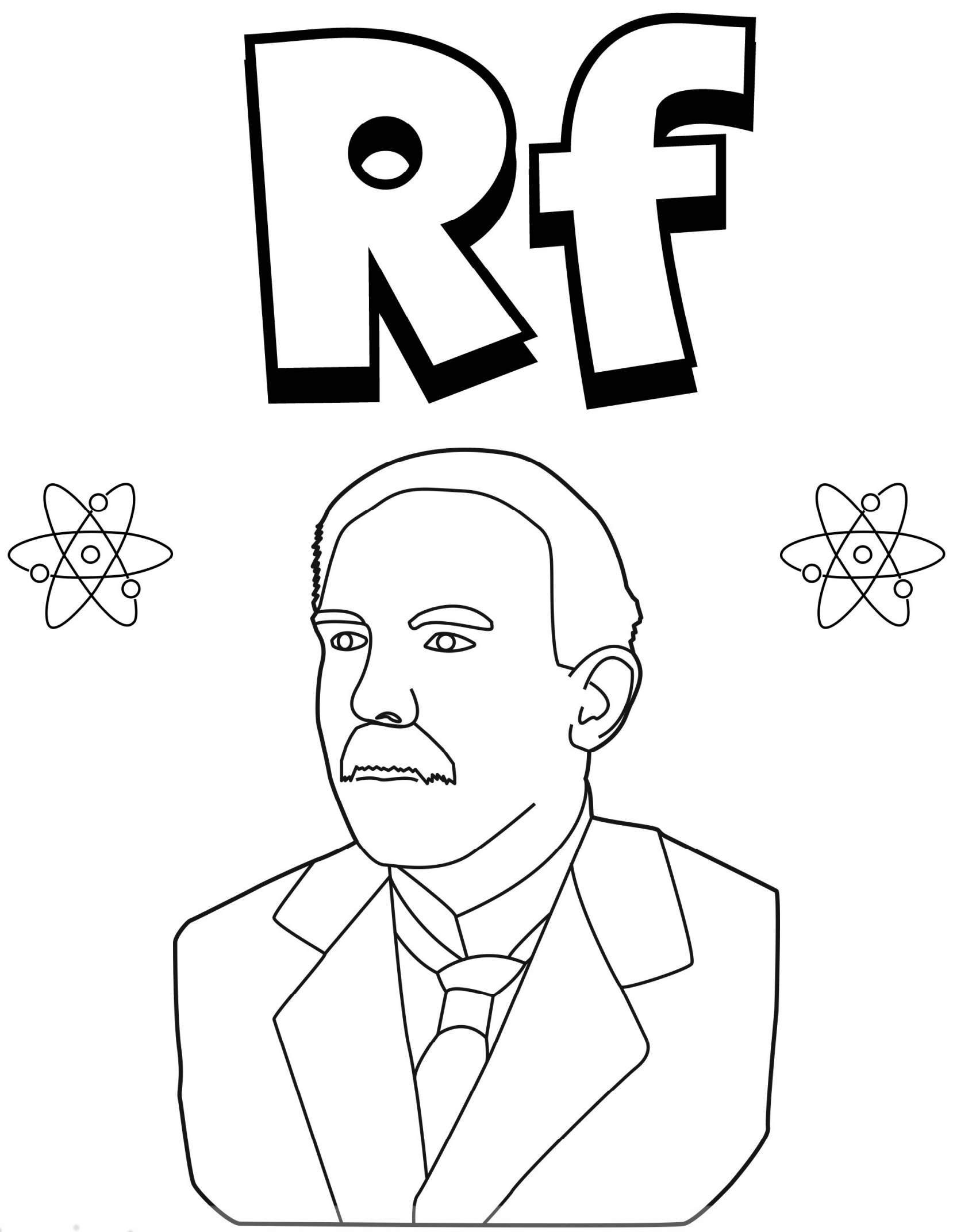

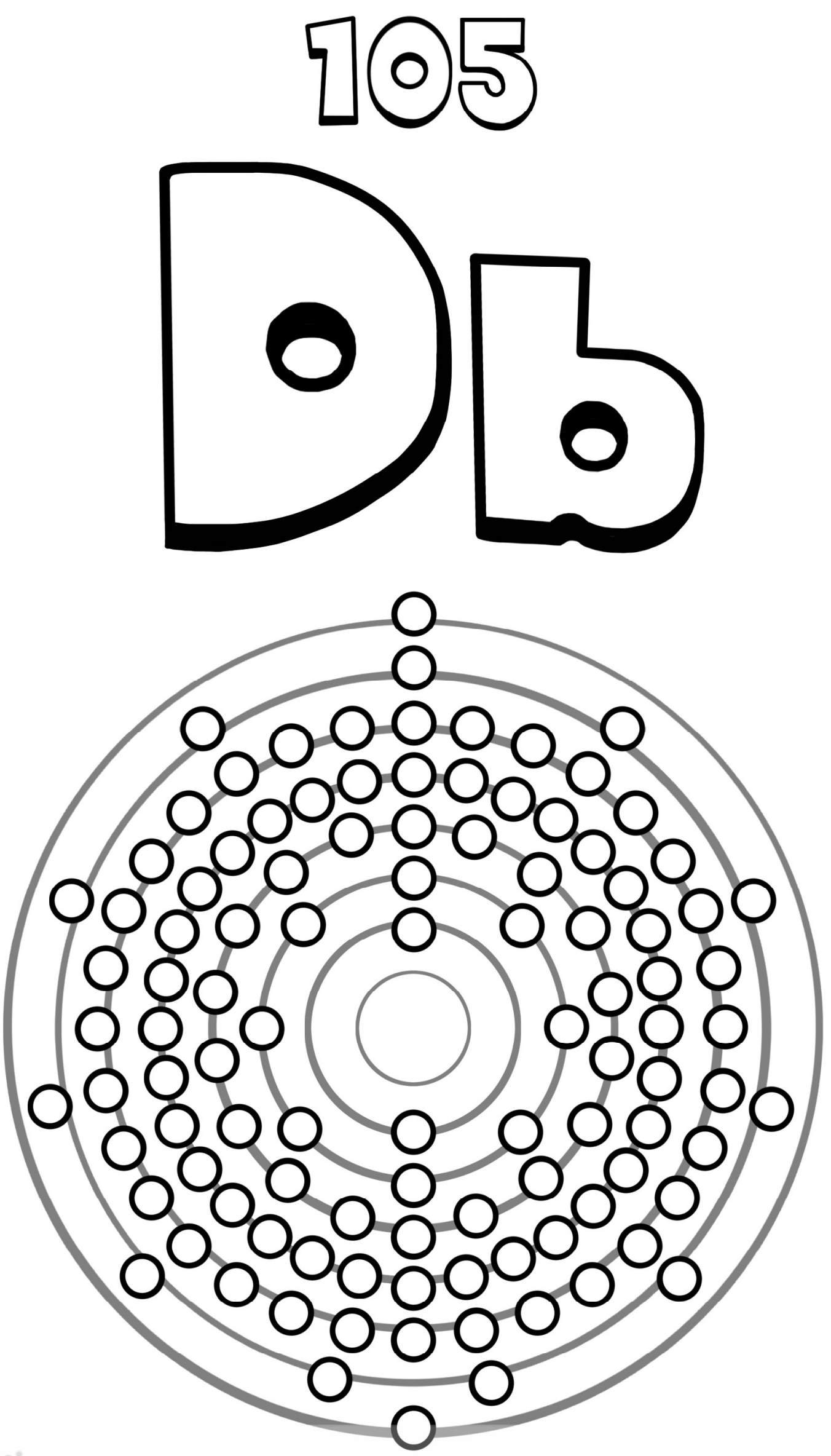


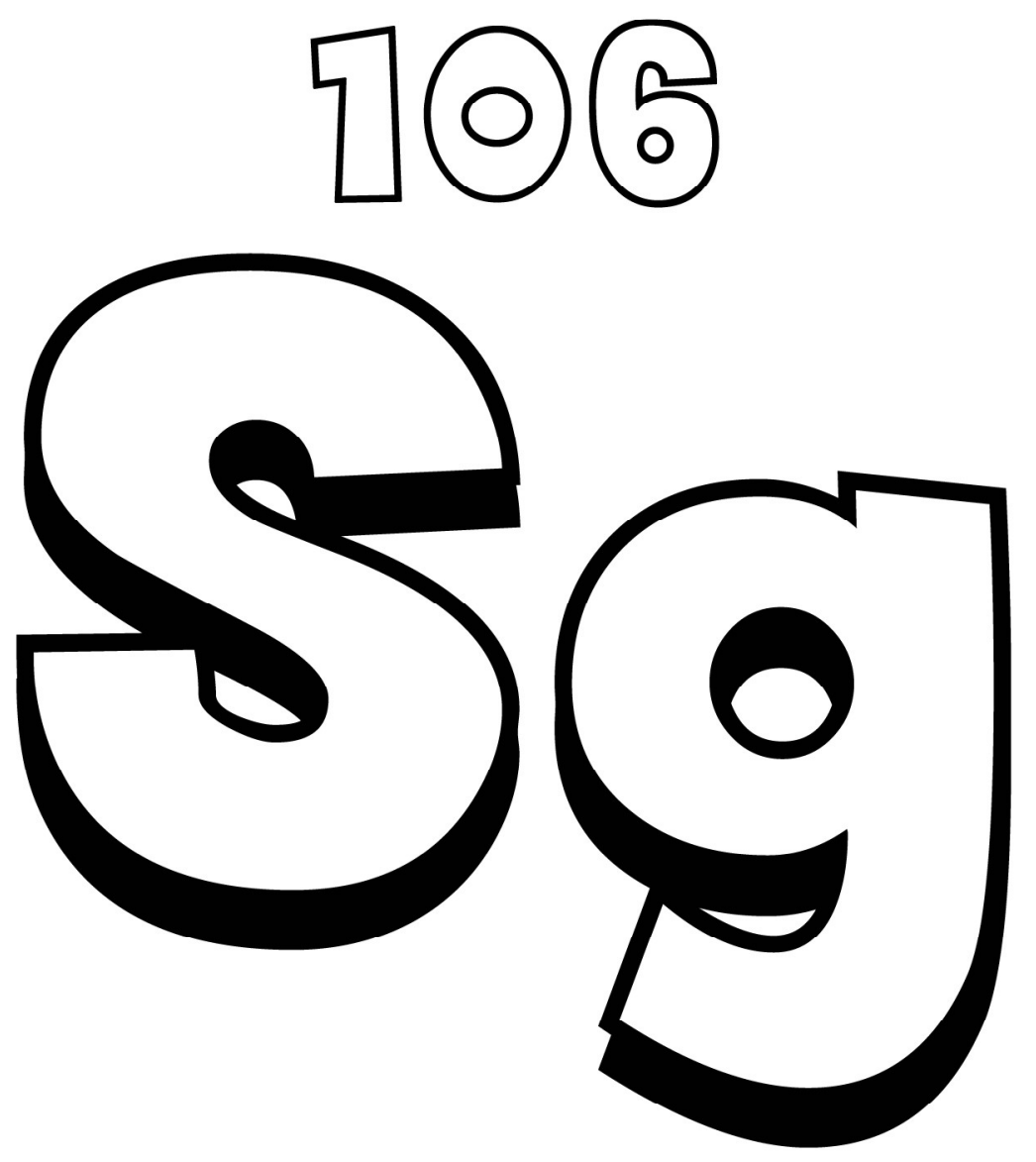



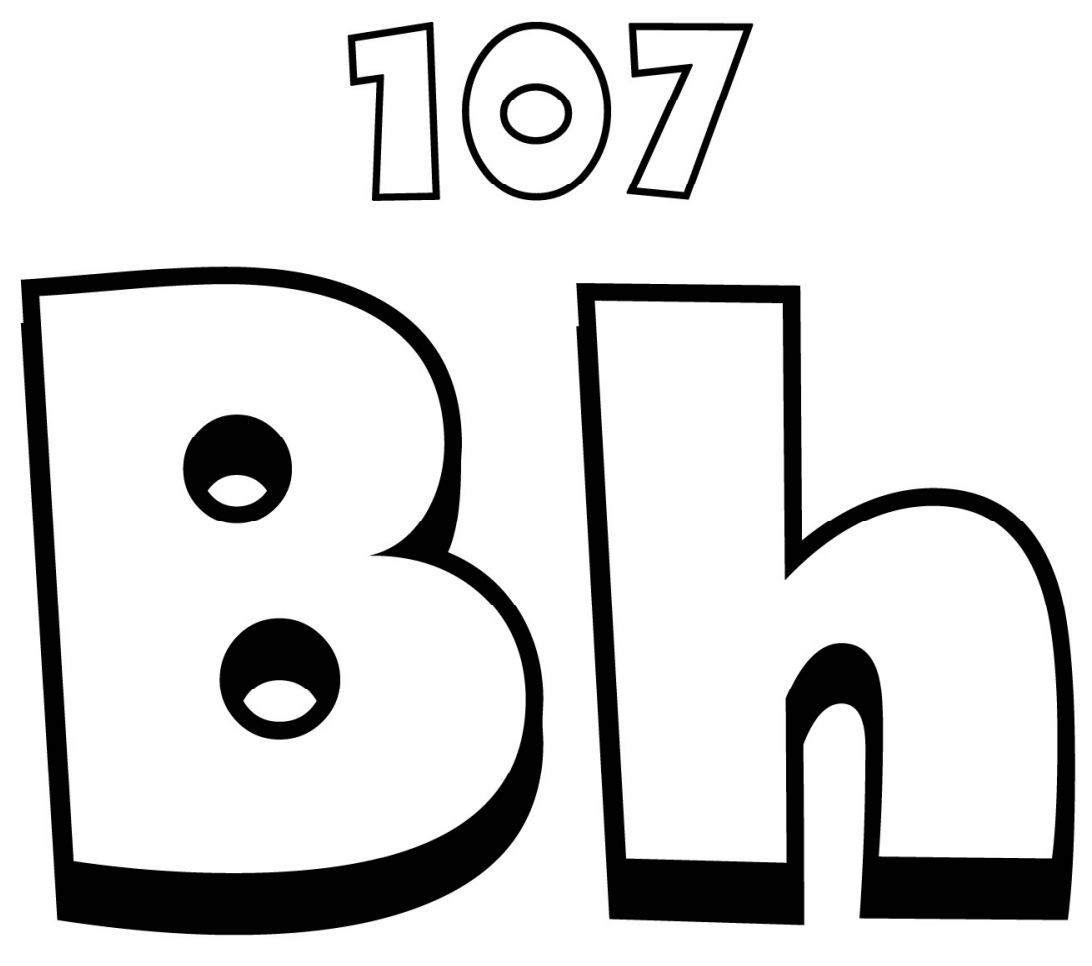
108
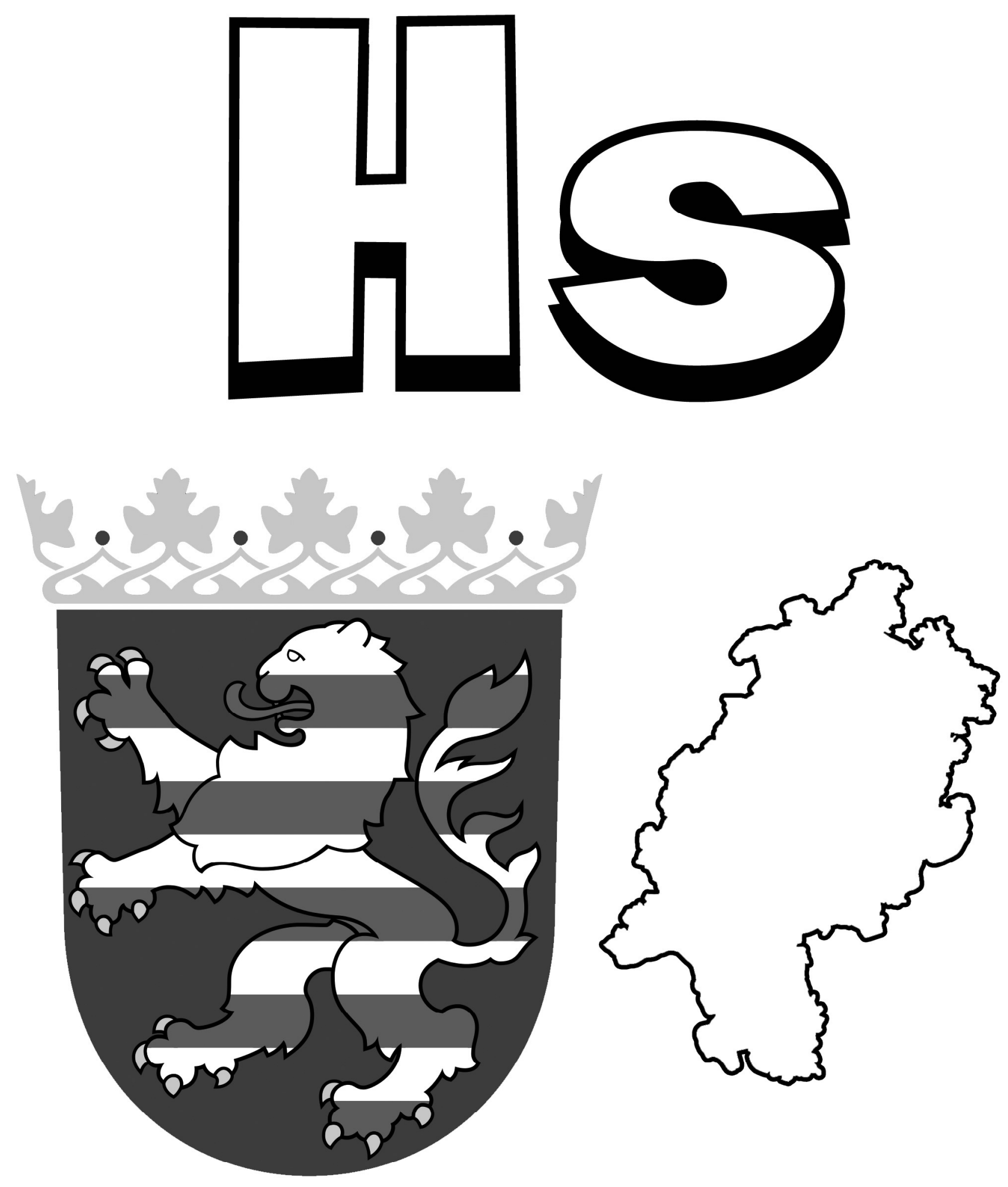

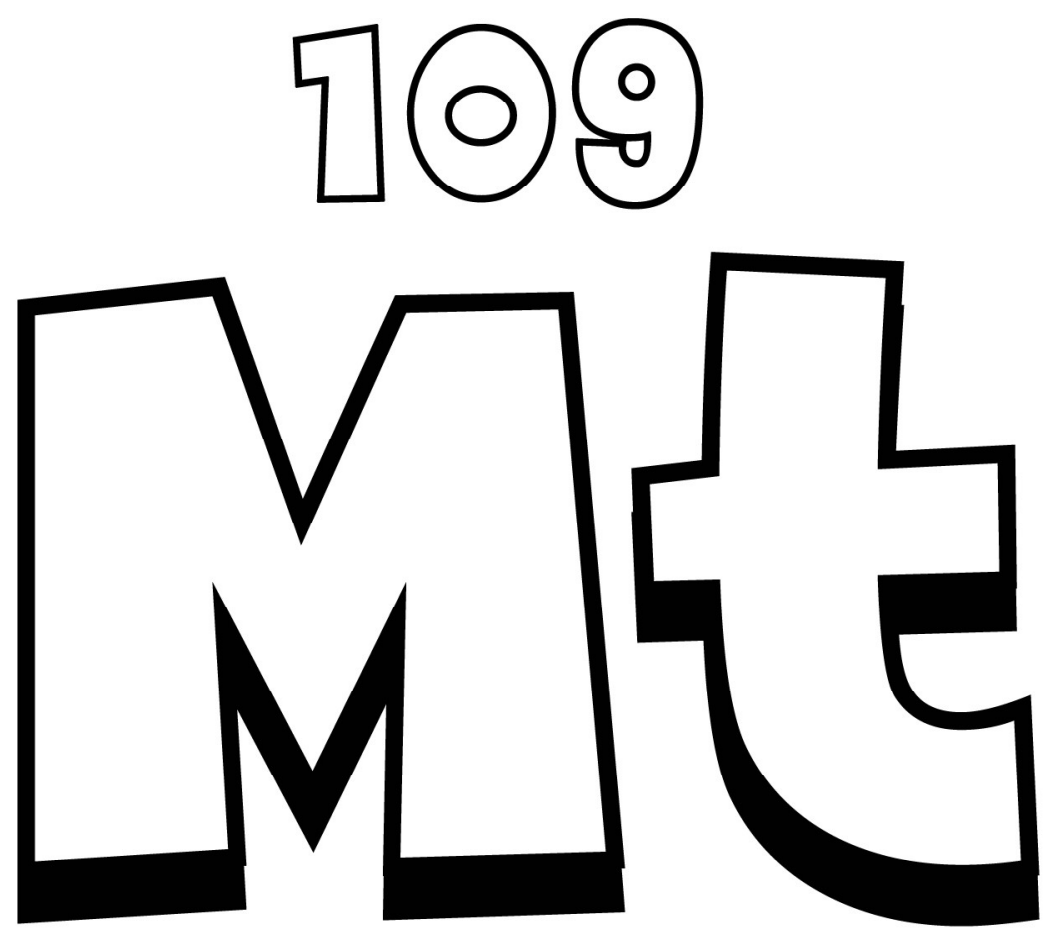

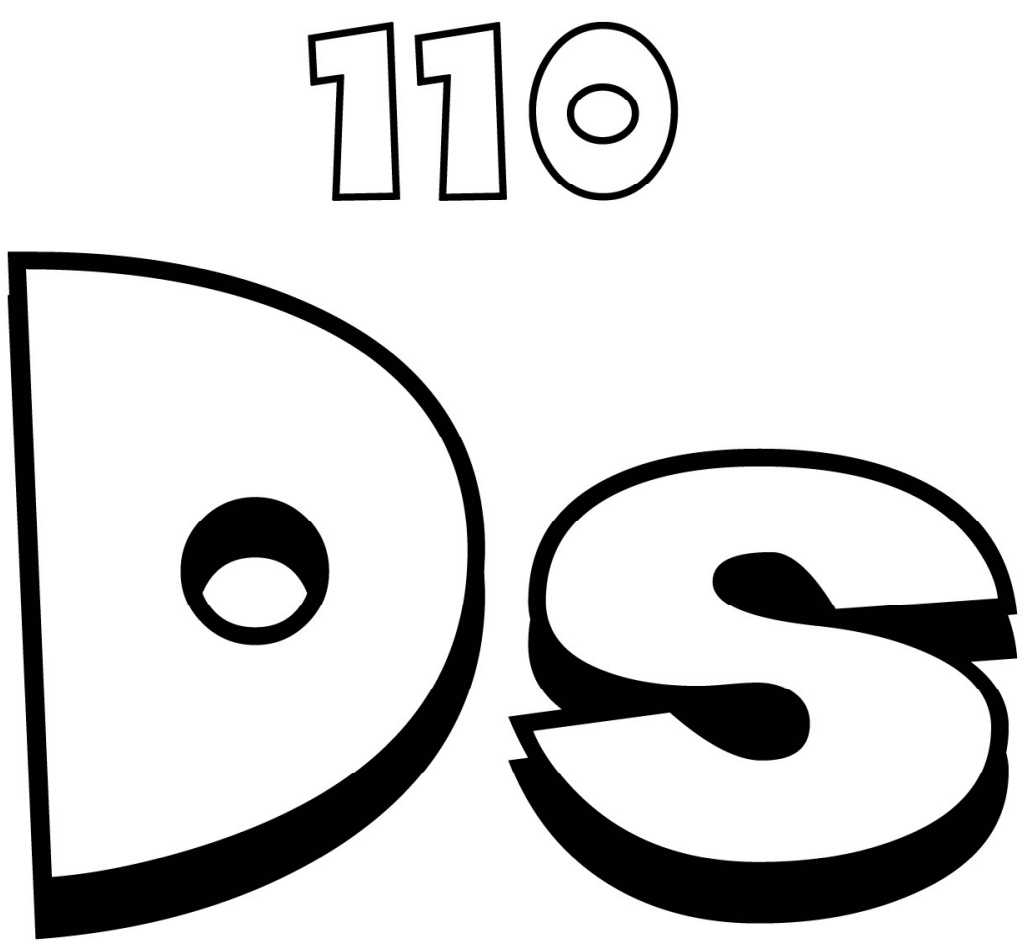

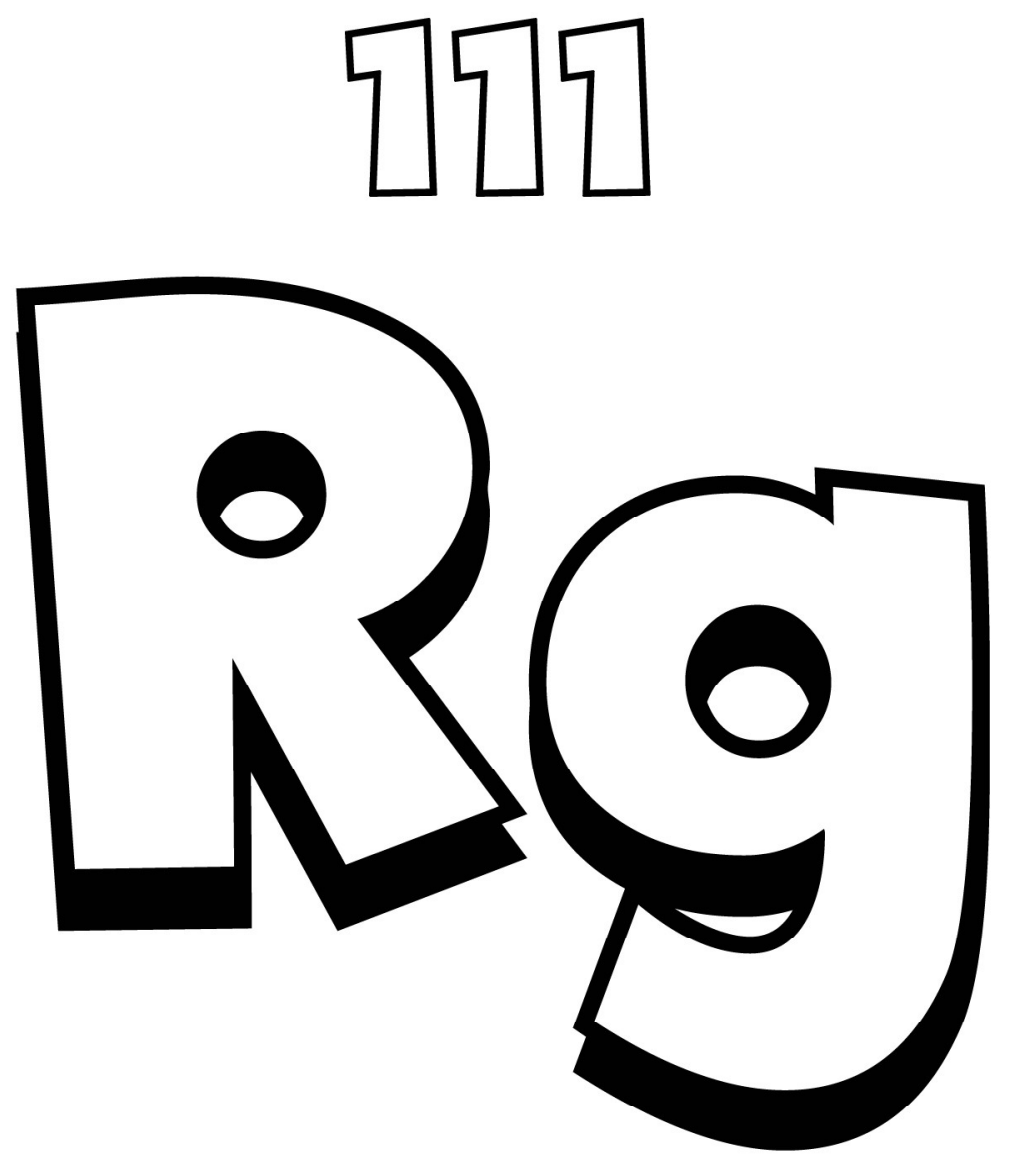


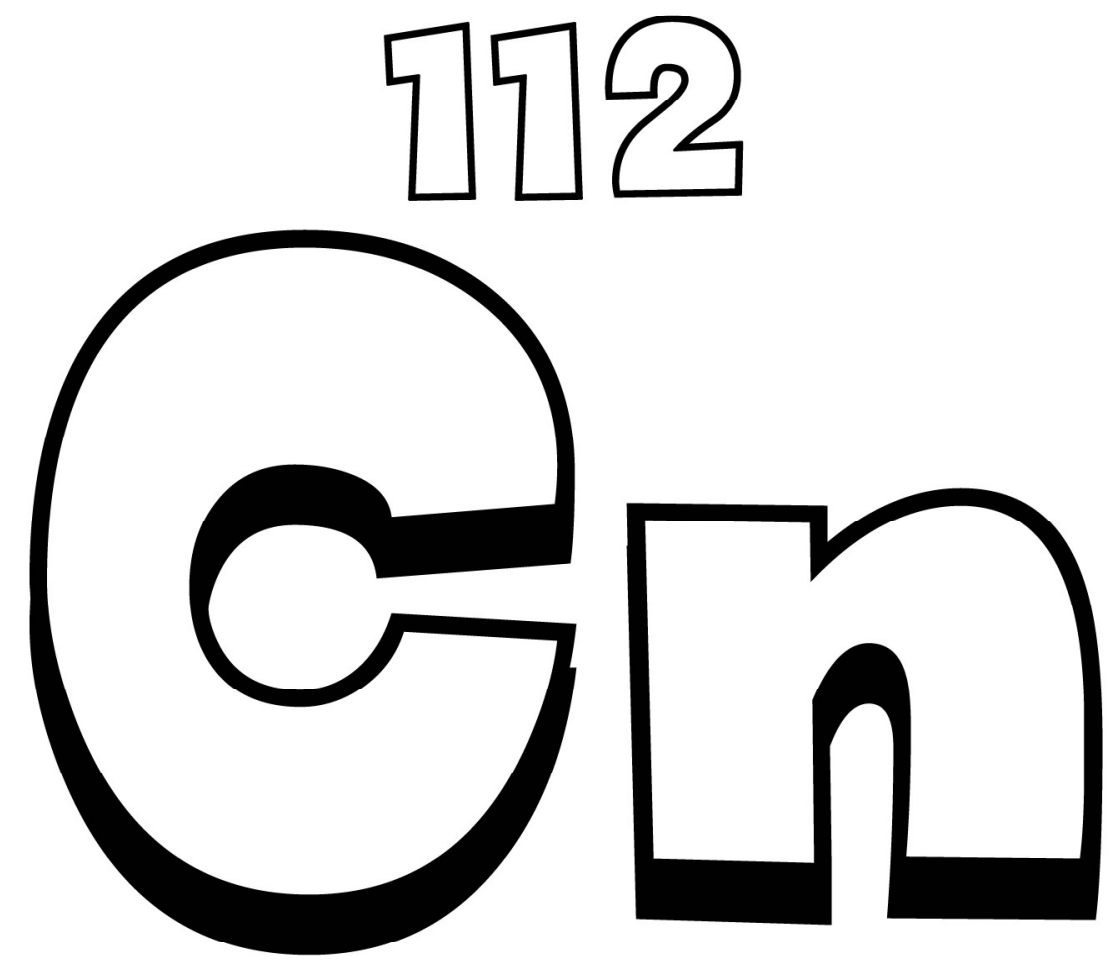


118
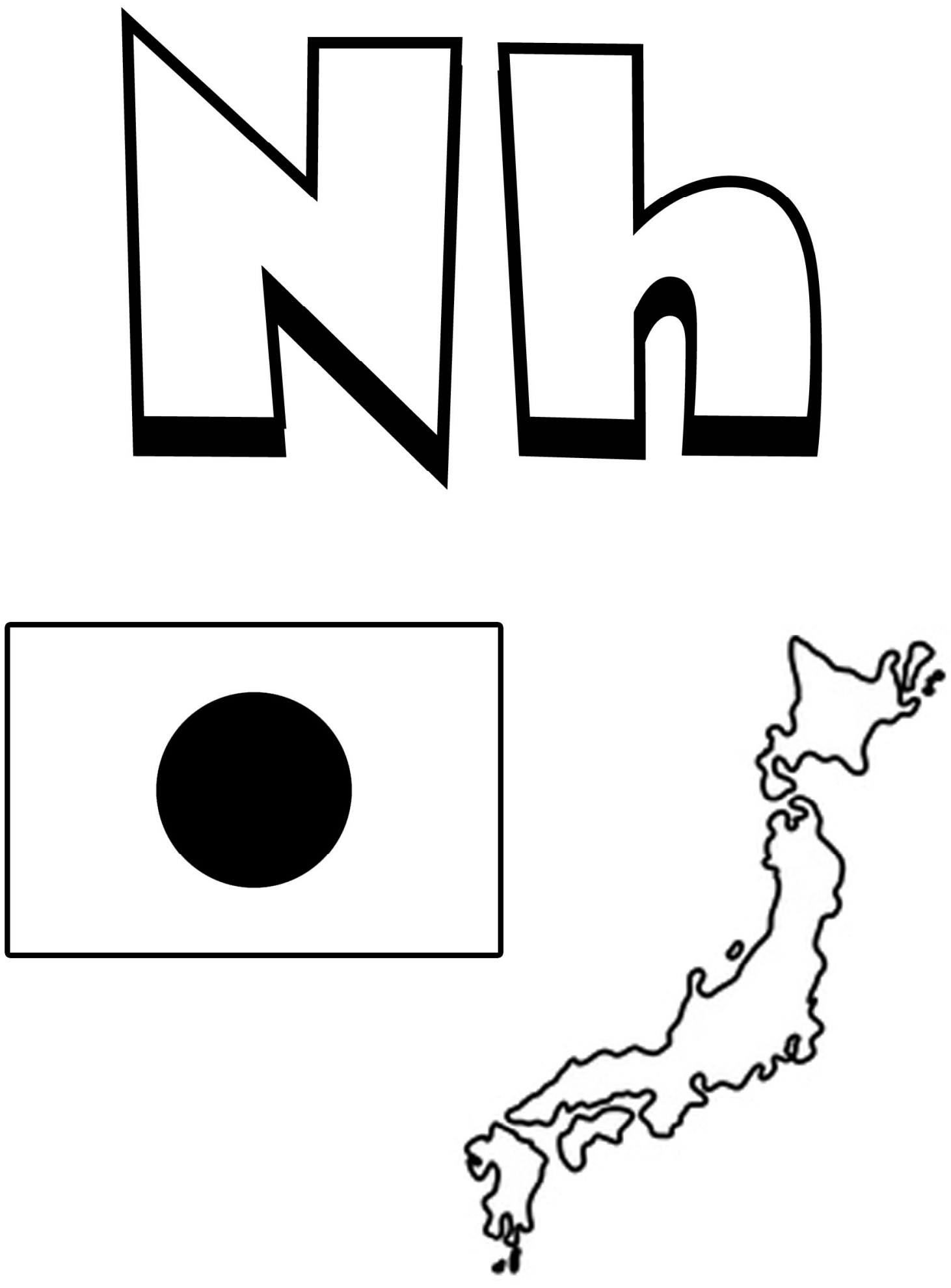

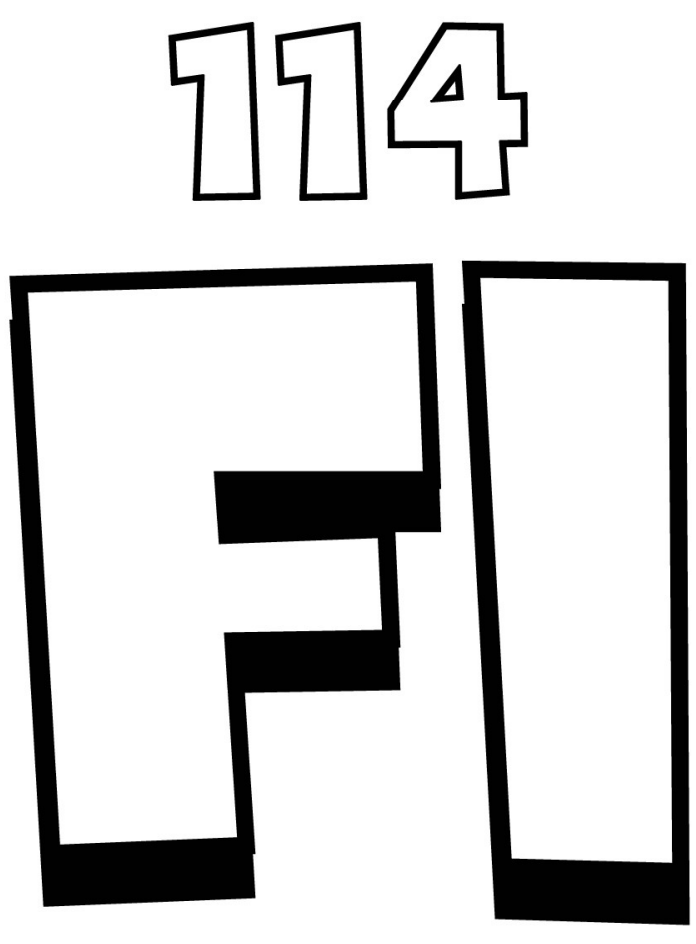

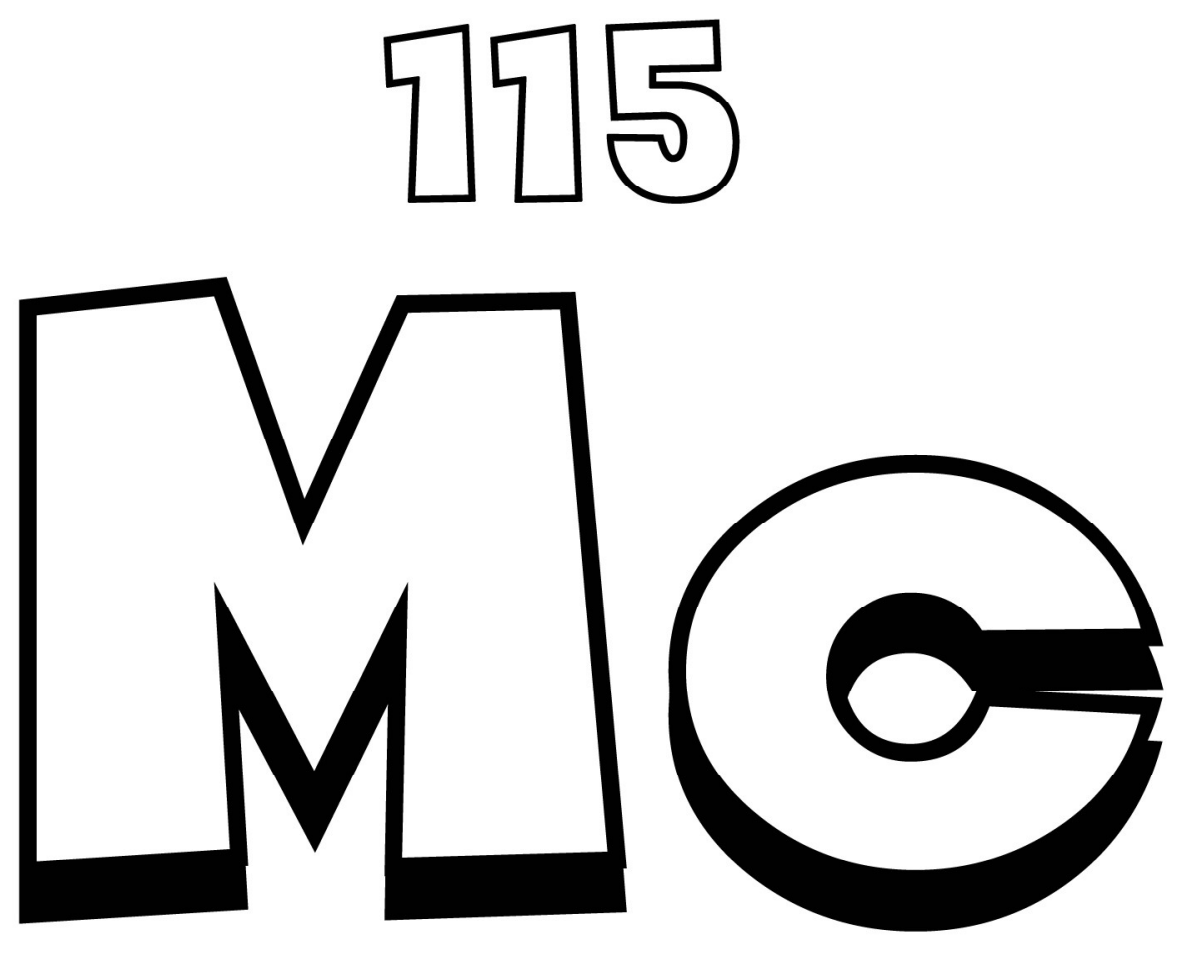

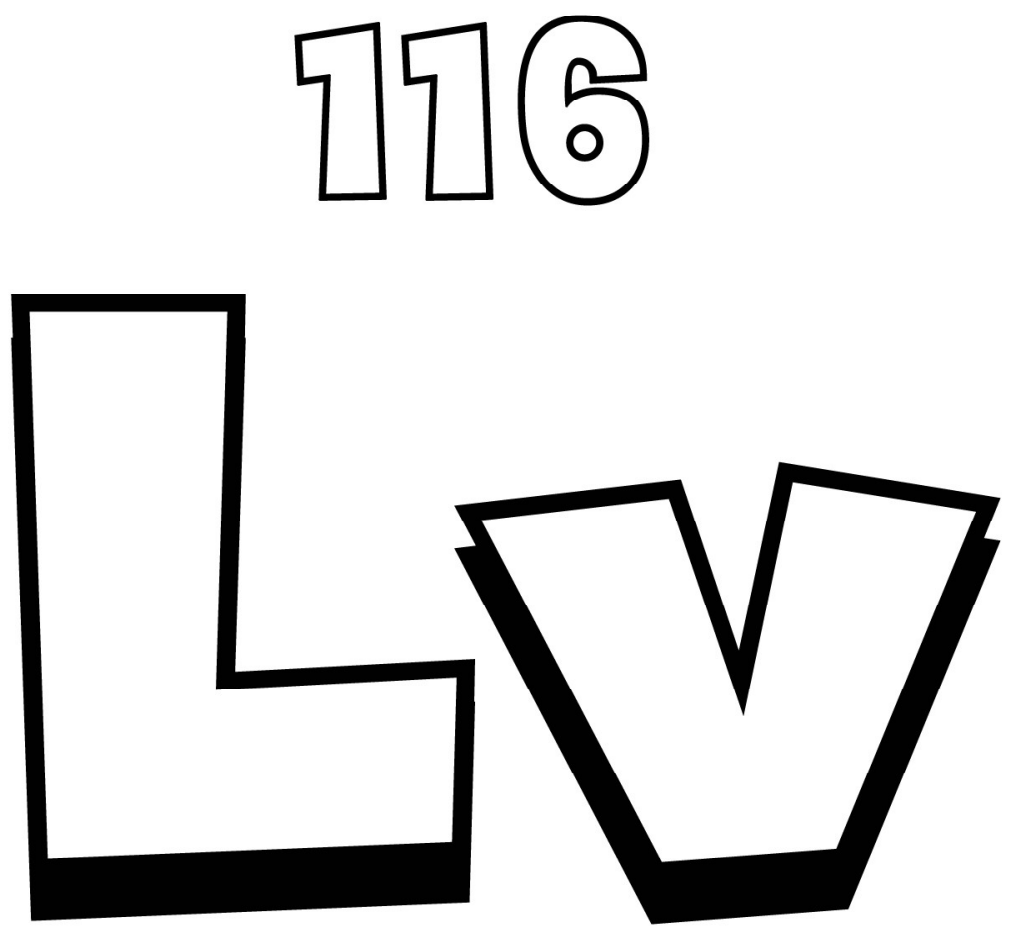

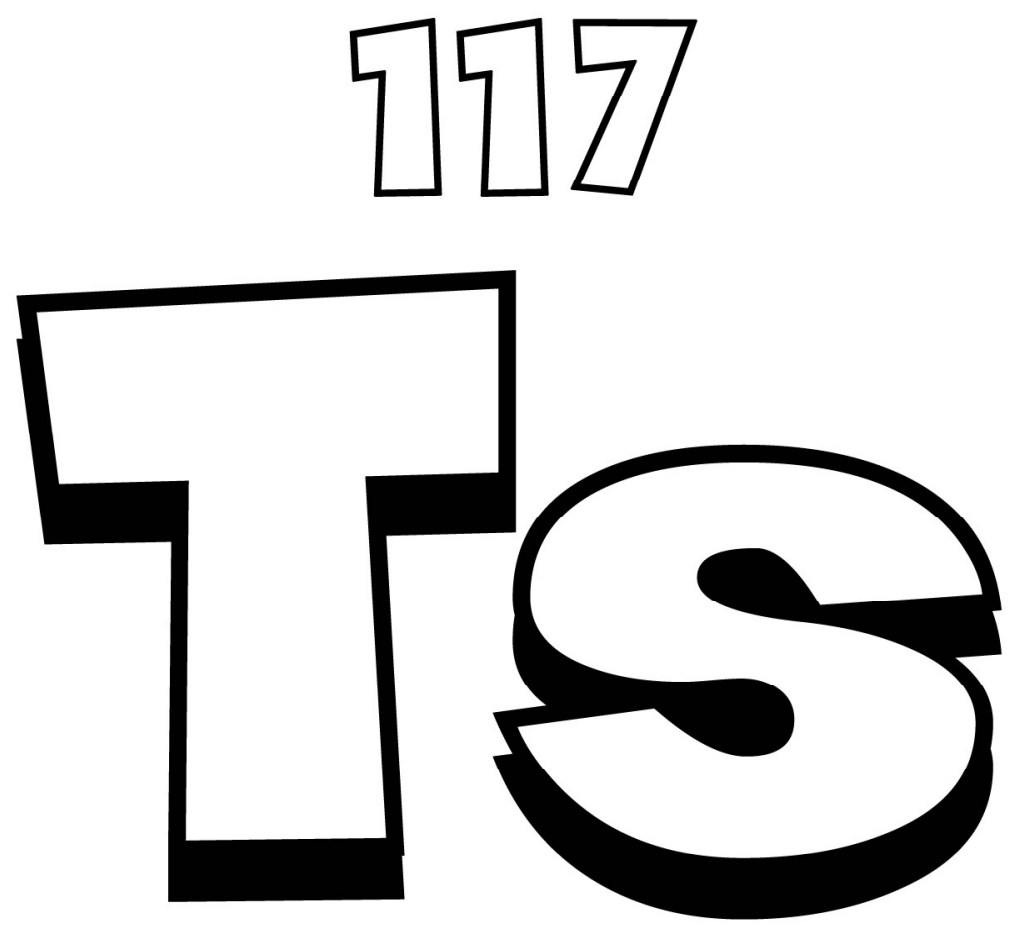

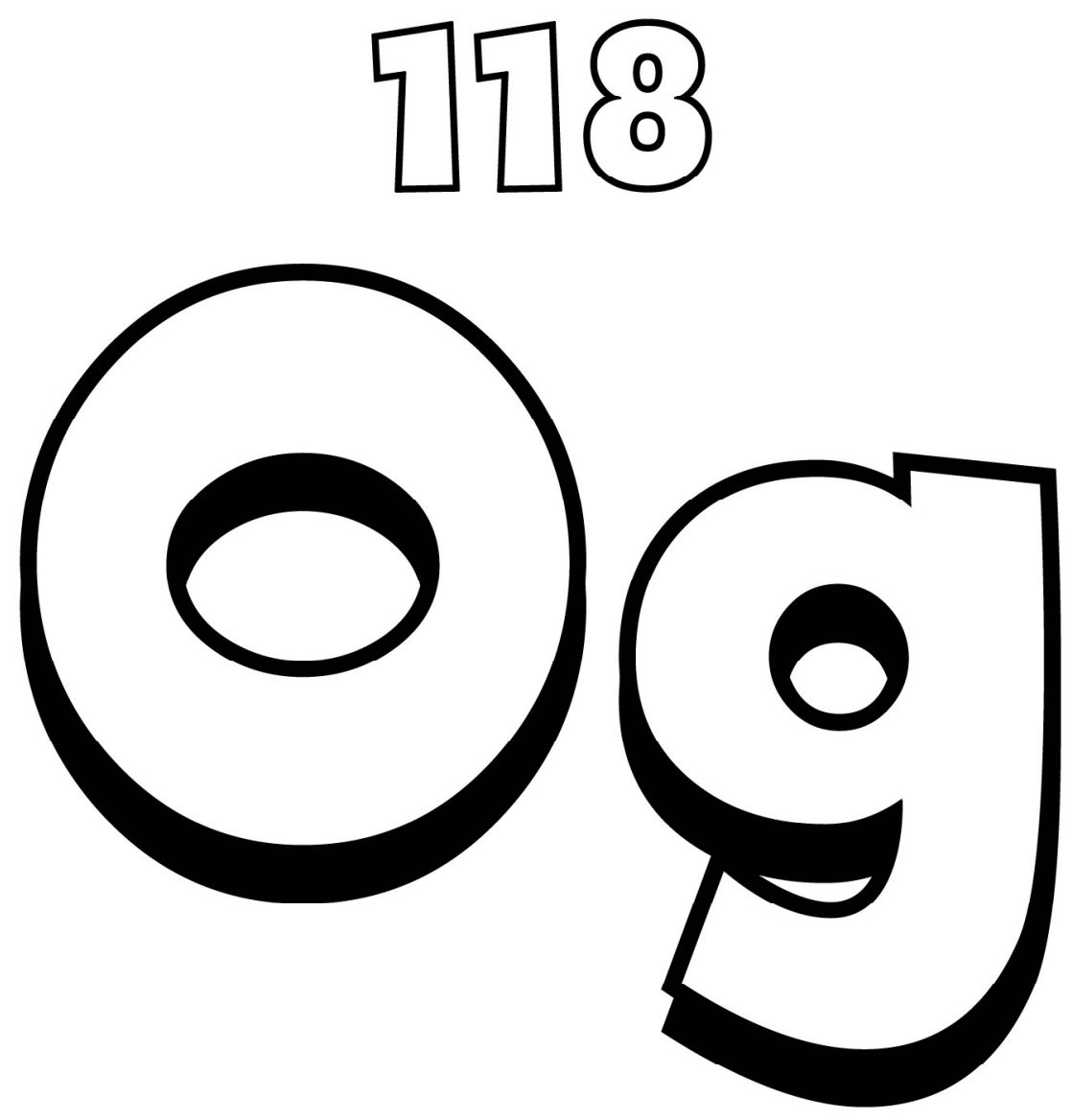


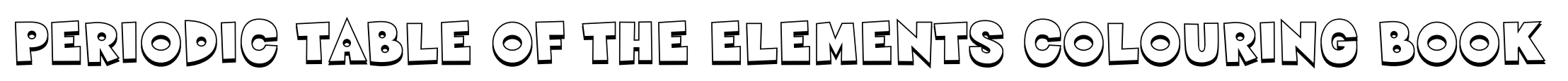

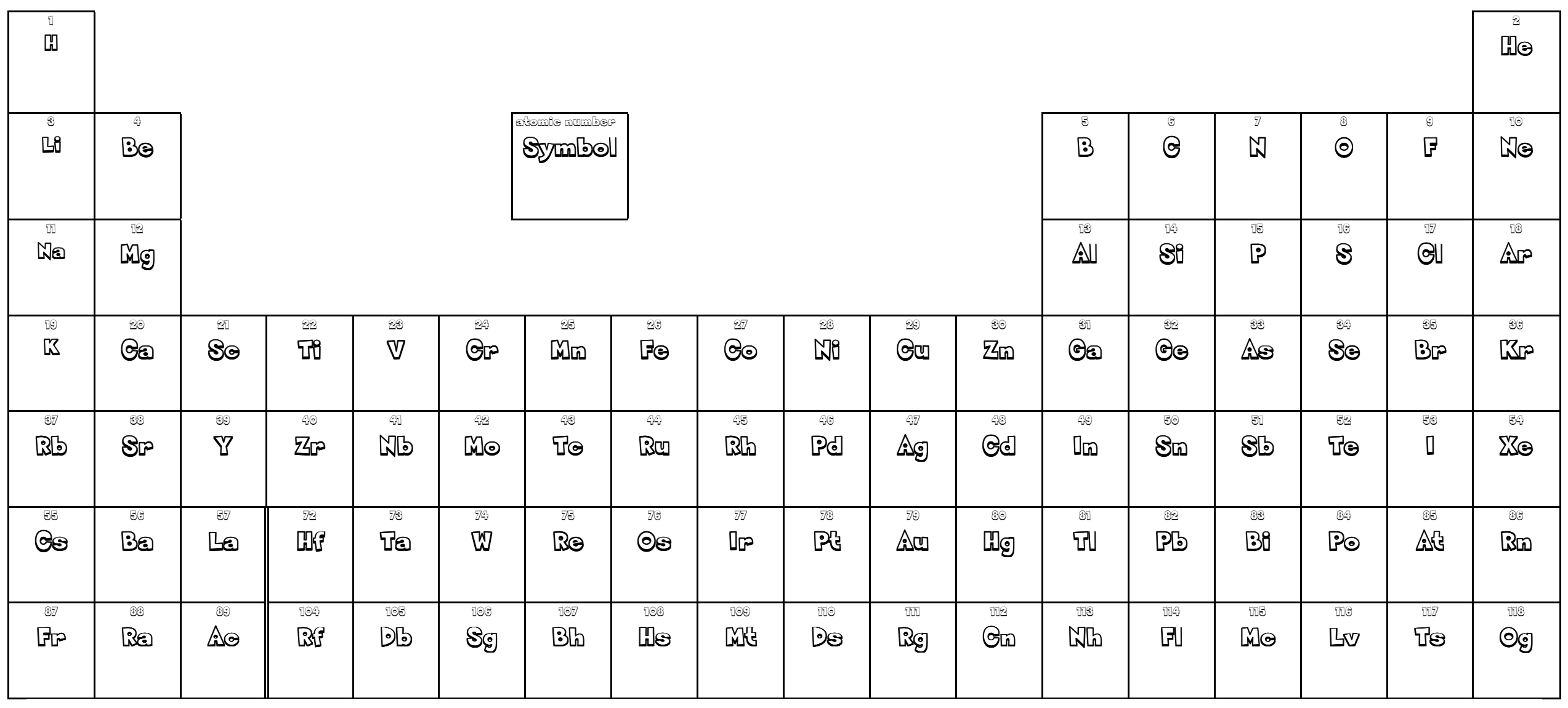

\begin{tabular}{|c|c|c|c|c|c|c|c|c|c|c|c|c|c|}
\hline $\mathrm{G}_{\Theta}$ & 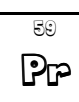 & N] & & $s^{\infty 2}$ & $\begin{array}{l}x_{0}^{\infty} \\
B_{凶}\end{array}$ & बகత & 悉 & 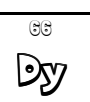 & DI & $F^{\infty}$ & ${ }^{\infty}$ & STh & 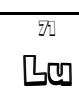 \\
\hline Wh & 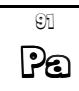 & $\begin{array}{ll}82 \\
028\end{array}$ & NDp & 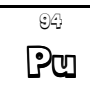 & 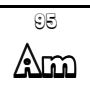 & فm & $B{ }_{3}$ & $Q P$ & $\begin{array}{l}\theta_{\theta} \\
F_{\theta}\end{array}$ & $\begin{array}{l}x^{100} \\
F^{600}\end{array}$ & 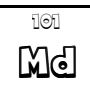 & $\begin{array}{l}102 \\
\text { No2 }\end{array}$ & $\begin{array}{l}1000 \\
\square P p\end{array}$ \\
\hline
\end{tabular}

